\title{
Regulation of skeletal muscle metabolism and contraction performance via teneurin-latrophilin action.
}

Andrea L. Reid ${ }^{1}$, David W. Hogg', Thomas L. Dodsworth' ${ }^{1}$, Yani Chen ${ }^{1}$, Ross M. Reid ${ }^{2}$, Mei

1. Department of Cell and Systems Biology, University of Toronto, Toronto, ON Canada, 2. Canada.

Number of Words: 13,243

Number of Figures: 11

Number of Tables: 3

Number of References: 72

Keywords: TCAP, GPCR, peptides, diabetes, calcium, CRISPR, siRNA, mitochondria 


\section{Abstract}

33 Skeletal muscle regulation is responsible for voluntary muscular movement in vertebrates. The

34 genes of two essential proteins, teneurins and latrophilins (LPHN), evolving in ancestors of

35 multicellular animals, form a ligand-receptor pair, and are now shown to be required for skeletal

36 muscle function. Teneurins possess a bioactive peptide, termed the teneurin C-terminal associated

37 peptide (TCAP) that interacts with the LPHNs to regulate skeletal muscle contractility strength

38 and fatigue by an insulin-independent glucose importation mechanism. CRISPR-based knockouts

39 and siRNA-associated knockdowns of LPHN-1 and-3 shows that TCAP stimulates an LPHN-

40 mediated cytosolic $\mathrm{Ca}^{2+}$ signal transduction cascade to increase energy metabolism and enhance

41 skeletal muscle function via increases in type-1 oxidative fiber formation and reduce the fatigue

42 response. Thus, the teneurin/TCAP-LPHN system is presented as a novel mechanism likely to

43 regulate the energy requirements and performance of skeletal muscle. 


\section{Introduction}

46 Skeletal muscle is critical for all voluntary behaviours and is derived from the earliest contractile

47 proteins present in the ancestral single-celled heterotrophs. Enhanced contractile strength and

48 efficient energy metabolism among these primitive skeletal muscle cells were critical for both

49 locomotion and feeding [1,2]. Because of these integrated requirements for the evolutionary

success of early metazoans, we have postulated that essential intercellular signaling systems

51 originating phylogenetically early, conferred a selective advantage upon these basal heterotrophs

52 by linking sensory and motor functions with cell metabolism [3]. Numerous studies have indicated

53 that the teneurins and their receptors, the latrophilins (LPHN) are part of an ancient regulatory

54 system that modulates cell adhesion and metabolism. The introduction of the teneurin and LPHN

55 genes into multicellular animals occurred via lateral gene transfer from prokaryotes into a single-

celled ancestor of metazoans [4-9]. Thus, the teneurins and LPHNs were evolutionarily poised to

57 play a seminal role in the development and coordination of cell-to-cell communication, adhesion

58 and metabolic activities.

59 Teneurins are essential for development and maintenance of the central nervous system (CNS)

60 [10-18]. Comprising a family of four paralogous proteins in vertebrates, the teneurins possess

61 several functional domains that confer specialized actions on their extracellular and intracellular

62 regions [19-21]. As type-II proteins, their carboxyl terminus is displaced extracellularly. The most

63 distal region contains a $\beta$-barrel structure unique to metazoans, but is similar to that found in

64 prokaryotic Tc-toxins [9,14,22-25]. Associated with this structure lies an extended amino-acid

65 chain termed the 'teneurin C-terminal associated peptide' (TCAP) [22-24]. The TCAPs possess

66 primary structure similarity to the Secretin superfamily of peptides that include, not only secretin

67 paralogues such as vasoactive intestinal peptide (VIP), growth hormone-releasing hormone 
68 (GHRH), glucagon and pituitary adenylate cyclase activating peptide (PACAP), but also the calcitonin and corticotropin-releasing factor (CRF) families. One of the distinguishing aspects of this peptide superfamily are their roles in the coordination of sensory, motor and energy 71 metabolism $[3,26,27]$.

72 The LPHNs are G-protein-coupled receptors (GPCR) belonging to the Adhesion GPCR family

73 (ADGRL) and are cognate receptors of the teneurins in vertebrates [28-30]. LPHNs have three distinct paralogous forms (LPHN1-3) and can bind to the C-terminal region of the teneurins, which

75 include the TCAP region. For example, Teneurin-2 and LPHN-1 binds with nanomolar affinity at the lectin-domain of LPHN-1[31]. A splice variant of C-terminal domain of teneurin-2, also termed

77 'LPHN1-associated synaptic surface organizer' (Lasso), binds to LPHN with, likewise, high 78 affinity in neurons. Moreover, transgenic over-expression of both TCAP-1 and the hormone79 binding domain (HBD) of LPHN-1 results in co-precipitation of both transgenic proteins indicating an interaction between TCAP-1 and LPHN-1 [32]. Recent structural studies of the teneurins indicate that the TCAP region may be auto-catalytically cleaved from the teneurins after

82 interaction with the LPHNs [14,22], or could be the result of a distinct teneurin splice variant resulting in the mRNA expression of the terminal exon that includes the TCAP sequence [33,34].

84 Regardless of the mechanism of TCAP release, the expected TCAP mature peptide, based on its genomic sequence, has distinct biological properties. Synthetic TCAP-1 regulates cytoskeletal 86 elements and energy metabolism in neurons critical for neuroplastic modulation in the central 87 nervous system (CNS). In rats, TCAP-1 modifies dendritic arborization and spine density in the 88 hippocampus [35,36], findings that were corroborated in primary cultures of rat embryonic hippocampal tissues that exhibited increased filopodia, neurite and axon development $[33,37,38]$. 
91 administration of TCAP-1 into rats increases brain glucose uptake as assessed by functional

92 positron emission tomography (fPET). These observations were corroborated by the expected

93 decreased serum glucose and insulin levels in rats, and in cell culture studies showing that TCAP-1

94 stimulates glucose uptake by increased glucose transporter transit to the membrane and

95 subsequently increases in ATP turnover providing increased energy for the neurons [39].

96 However, given the evolutionary history of the teneurins, it is plausible that the teneurins, LPHNs,

97 and TCAP could also play a role in the regulation of skeletal muscle. Skeletal muscle is one of the

98 most important sites of glucose metabolism and is responsible for $40 \%$ of glucose-associated

99 energy requirements [39] and 80\% of glucose uptake under insulin-stimulated conditions [40].

100 Muscle function and metabolism are intrinsically linked, as evidenced by metabolic syndromes

101 that result in poor muscle function and degradation. A key example of this is demonstrated in

102 patients with type-II diabetes where patients have reduced skeletal muscle function in the grip

103 force test compared to non-diabetic patients [41,42].

104 Based on these previous findings, we investigated the role of TCAP-1 on skeletal muscle function

105 for the first time. We demonstrate that skeletal muscle possesses the critical elements of teneurin-

106 LPHN interaction, and show that TCAP-1 regulates skeletal muscle contractile kinetics in vivo in

107 rats. These studies are supplemented by in vitro studies, using the mouse skeletal cell line, C2C12,

108 to show that TCAP regulates intracellular skeletal $\mathrm{Ca}^{2+}$ flux similar to that shown in neurons $[3,39]$.

109 Moreover, like neurons, the TCAP-mediated $\mathrm{Ca}^{+2}$ response leads to increased glucose metabolism

110 and mitochondrial activation, but results in skeletal muscle fiber regulation. We posit that the

111 teneurin-LPHN interaction is essential for skeletal muscle physiology and regulates skeletal

112 muscle performance. 


\section{$113 \quad$ Materials and Methods}

\section{Peptide Synthesis and Solubilization}

115 Both peptides; rat/mouse TCAP-1 and scrambled TCAP-1 (Fig. 1), were synthesized commercially 116 by AmbioPharm, Inc. and prepared as an acetylated salt at 95\% purity. Peptides were solubilized 117 in saline after alkalization as previously described [37] then diluted into the required media for in 118 vitro or in vivo studies (see below). The primary structure of all four rat and mouse TCAPs are 119 identical to each other (Fig.1A) and possess a 73-83\% sequence identity among the overall 120 sequences, although most of these changes reflect homologous and conservative substitutions. For 121 this reason, TCAP-1 was used in both rat and mouse preparations. Synthetic rat/mouse TCAP was 122 prepared with an initial N-terminal pyroglutamic acid to inhibit $\mathrm{N}$-terminal-directed peptidases, 123 and a C-terminal amidated-residue as expected based on the genomic sequence [24,37]. As a 124 control peptide, we have utilized a scrambled (sc) amino acid sequence version of rat/mouse 125 TCAP-1 where each residue, with the exception of the initial pyroglutamyl residue (pE), was 126 randomized in its placement within the peptide (Fig. 1B). This sc-TCAP-1 has been used in 127 previous studies to establish an additional level of controls to ensure that TCAP-1 is not affecting 128 non-specific (e.g. oligopeptide transporters; non-target receptors) actions. The vehicle included sc129 TCAP solubilized in $0.9 \%$ saline or cell culture medium, unless otherwise stated.

Figure 1. Primary structures of rat and mouse TCAP peptides. A. Comparison of the amino

132 acid sequences of mouse and rat TCAPs. B. Primary structure of the peptides used in this study.

133 Grey boxed regions indicates regions of identity relative to the rat/mouse TCAP isoforms. 


\section{Animals}

135

136

137

138

139

140

141

142

143

144 studies.

\section{In Vivo Studies}

148 The short-term application of TCAP-1 utilized 16 male adult SD rats $(250 \mathrm{~g})$ that were acclimated

149 for 1 week (w) on a 12:12 light-dark (LD) cycle. For 5 days (d) daily, the animals were treated

150 with either vehicle or TCAP-1 (10 nmoles $/ \mathrm{kg})$ by subcutaneous (SC) injection in the intrascapular

151 region. Animals were tested for muscle function by electrical muscle stimulation (see below) $3 \mathrm{~d}$

152 after the last treatment. Animals were immediately euthanized afterward. For the long-term study,

15320 adult male SD rats $(350 \mathrm{~g})$, acclimated for $1 \mathrm{w}$ on a 12:12 LD cycle and were treated with either

154 vehicle or intrascapular TCAP-1 (SC; 25 nmoles/kg) for 3 months (1 injection/week). Muscle 
155 function by electrical muscle stimulation was tested $2 \mathrm{w}$ after the last treatment. Animals were

156 immediately euthanized after electrical muscle stimulation studies (see below).

\section{PCR Expression of teneurin and LPHN}

159 RNA was extracted from tibialis anterior (TA) muscles using TRIzol (Thermo Scientific,

160 Waltham, MA, USA) following the manufacturer's instructions. The PCR reaction mix included

$1615 \mu \mathrm{L}$ cDNA, $2 \mu \mathrm{L}$ forward primer and $2 \mu \mathrm{L}$ reverse primer (Invitrogen; Table 1), $14.2 \mu \mathrm{L}$ water

162 (Sigma, Oakville, ON), $3 \mu \mathrm{L}$ 10x Taq Buffer with $\mathrm{KCl}$ (Thermo Scientific), $1.8 \mu \mathrm{L} \mathrm{MgCl}_{2}$ (Thermo

163 Scientific), $1 \mu \mathrm{L}$ deoxynucleotide Solution Mix and 0.5 $\mu \mathrm{L}$ Taq DNA Polymerase (New England

164 Biolabs). The reactions were incubated in an Eppendorf Mastercycler Gradient Thermal Cycler

165 for $7 \mathrm{~m}$ at $95^{\circ} \mathrm{C}$; followed by 35 cycles of $60 \mathrm{~s}$ at $95^{\circ} \mathrm{C}, 90 \mathrm{~s}$ at $67^{\circ} \mathrm{C}$, and $35 \mathrm{~s}$ at $72^{\circ} \mathrm{C}$; and then held

166 at $4^{\circ} \mathrm{C}$. cDNA samples were resolved on a $3 \%$ agarose gel at $100 \mathrm{~V}$ for $1.5 \mathrm{~h}$ and visualized using

167 a Bio-Rad ChemiDoc MP System with 0.5s exposure.

168

169

170

171

172

173

174

175

176

177 
Table 1. Primers used for in vitro and in vitro RT-PCR analyses. Forward and reverse primer pairs for the four teneurins, TCAPs, three ADGRLs, and $\beta$-actin control are indicated.

Gene

Forward Primer ( $\left.5^{\prime}-3^{\prime}\right)$

Reverse Primer $\left(5^{\prime}-3^{\prime}\right)$

Expected

band size

Teneurin-1

CACAGTCAGCGGCGTTACATCTTTGAG

GAATCCGTCATGCATCAGGTGTATTGT

$342 \mathrm{bp}$

Teneurin-2

ATCCTGAACTCGCCGTCCTCCTTA

CTCCAGGTTCTGAGTGGACACGGC

$405 \mathrm{bp}$

Teneurin-3

GTGAGTACCGTTGATGTCAAAGATG

Teneurin-4

ATCGACCAATTCCTGCTGAGCAAG

AGTGGAATACCCGGTGGGGAAGCAC

427 bp

TCAP-1

ACGTCAGTGTTGAATGGGAGGACTA

CCAGAGAGGCATCCCGGTAGAGTC

$567 \mathrm{bp}$

TCAP-2

GACAAGATGCACTACAGCATCGAG

TCAP-3

CAACAACGCCTTCTACCTGGAGAAC

CCTCCTGCCTATTTCACTCTGTCTCAT

$351 \mathrm{bp}$

CCATCTCATTCTGTCTTAAGAACTGG

$496 \mathrm{bp}$

TCAP-4

TTTGCCTCCAGTGGTTCCATCTT

CGATCTCACTTTGTCGCAAGAACT

$506 \mathrm{bp}$

ADGRL1

AGCCAGAGGACTTGACTCA

TGGATATTGTTGGCGCTGTCTGAC

$602 \mathrm{bp}$

ADGRL2 TGGAGCAAAAAGTC

TTCTAGGCCTCAGAGCTACAT

$249 \mathrm{bp}$

ADGRL3

TGAGCAACTGTGTGCAAATT

TTCAAAACAGC

$203 \mathrm{bp}$

TAACCACCAGCCACACCAT

$327 \mathrm{bp}$

$\beta$-actin

CAGCCATGTACGTAGCCATCCA

ATGTCACGCACGATTTCCCTCT

$247 \mathrm{bp}$

\section{Histological Studies}

TA muscle was excised then flash-frozen in liquid nitrogen cooled-isopentane. The tissue was cryo-sectioned at $10 \mu \mathrm{m}$ at $-20^{\circ} \mathrm{C}$ and transferred to coverslides and fixed using ice-cold methanol. Following blocking for $1 \mathrm{~h}$ with $10 \%$ normal goat serum (NGS: Cell Signaling, Inc.), the primary antibody (Table 2), diluted in $1 \%$ NGS, was added and incubated overnight $(\mathrm{ON})$ at $4^{\circ} \mathrm{C}$. Subsequently, after 3 phosphate-buffered saline (PBS) washes, the secondary antibody was added and incubated for $1 \mathrm{~h}$ at room temperature (RT) in the dark. Coverslips were attached, and the tissue imaged using confocal microscopy (Leica TCS-SP8) at 400x magnification. For fluorescence analyzes of protein expression, Image $\mathrm{J}$ software was used to measure arbitrary fluorescent units (AFU), where changes of AFU are proportional to protein expression changes. A total of 5 slides 
212 were quantified with 8 regions of interest (ROI) investigated. ROI was defined as regions with

213 multiple cell interactions free of artifacts.

214

215 Table 2. Primary and secondary antibodies used in western blot analyzes.

216

217

Name Primary Antibody

Secondary Antibody

Expected band size

218

219

220

LPHN-1

Goat polyclonal IgG

Donkey anti-goat HRP-linked

$130 \mathrm{kDa}$

221

LPHN-2

Goat polyclonal IgG

Donkey anti-goat HRP-linked

$163 \mathrm{kDa}$

222 LPHN-3

Rabbit polyclonal IgG

Donkey anti-rabbit HRP-linked

$162 \mathrm{kDa}$

223 SDH-A

Mouse monoclonal IgG

Rabbit anti-mouse HRP linked

$70 \mathrm{kDa}$

$224 \beta$-actin

Mouse monoclonal IgG

Rabbit anti-mouse HRP linked

$42 \mathrm{kDa}$

\section{Functional Positron Emission Tomography (fPET)}

229 Male Wistar rats were treated with either vehicle or TCAP-1 (10 nmoles $/ \mathrm{kg}$ ) by intrascapular SC 230 injection. 3d after treatment, $1 \mathrm{mCi}$ of $\left[{ }^{18} \mathrm{~F}\right]-2$-deoxyglucose $\left({ }^{18} \mathrm{~F}-\mathrm{DG}\right)$ radiotracer (IBA Molecular) 231 was administered intravenously (IV) under anesthesia. fPET scans were performed using a 232 Siemens Inveon microPET small animal PET scanner using the protocol as previously described 233 [39]. Briefly, body temperature was maintained with a thermostat-regulated recirculating water-

234 heated pad. Static emission data was acquired for $20 \mathrm{~m}$. The PET list mode data was converted to 235 2-dimensional (2D) sinograms, corrected for random coincidences, and normalized for scanner 236 uniformity. The PET image analysis was performed using the Amira 5.5.0 analysis software 237 package. For whole body ROIs (regions of high ${ }^{18} \mathrm{~F}-\mathrm{DG}$ uptake), a low threshold was set to 
delineate specific signals in the whole body while eliminating background. The total PET counts were calculated from all voxels within the segmented volumes of interest. These images were then compiled into 3-dimensional (3D) projections, thus allowing for accurate analyzes of muscle tissue. Fluorescence of the mean pixel was calibrated to volume of muscle being analyzed (mean pixel fluorescence $/ \mathrm{mm}^{3}$ ).

\section{NADH staining and analysis}

TA muscles from the treated SD rats were cryo-sectioned at $10 \mu \mathrm{m}$ thickness as described above. Cryo-sections were washed $2 \mathrm{x}$ with PBS, then $0.2 \%$ NBT solution in PBS (containing $0.1 \%$ NADH; Sigma, Oakville, ON) was added and incubated for $30 \mathrm{~m}$ at $37^{\circ} \mathrm{C}$. Slides were washed $2 \mathrm{x}$ in PBS before mounted, imaged at 100x magnification and analyzed on Image $\mathrm{J}$ software for pixel density, where darker pixels represent higher levels of NADH. Expression of NADH was analyzed based on a minimum of 100 fibres per tissue, with a minimum of 3-4 tissues analyzed for each group.

\section{Muscle function and integrity testing by electrical muscle stimulation}

The electrical muscle stimulation protocol was followed as described by Holwerda and Locke [43] with minor modifications. Briefly, animals were anesthetized with $5 \%$ isofluorane in $1 \mathrm{~L} / \mathrm{min}$ $\mathrm{O}_{2}$, and subsequently positioned into the testing apparatus. A $25 \mathrm{~g}$ needle was inserted through the soft tissue of the knee in order to ensure a stable position. The foot was placed on a lever attached to a servomotor and taped in position. Electrodes were placed below the skin but adjacent to the TA muscle. Dynamic Muscle Control (DMC; Version 5; Aurora Scientific) software was used for electrical stimulation and analyzes. The correct voltages for peak tetanic tension was established by increasing voltage by $1 \mathrm{~V}$ increments until optimal tetanus twitch was achieved. The test began 
261 with a single tetanus and single twitch protocol to establish the baseline followed by a 6-min

262 fatigue protocol $(8 \mathrm{~V}, 200 \mathrm{~Hz}, 300 \mathrm{~ms})$. After the termination of the protocol, tetanic and twitch

263 tensions were recorded at 0,1 , and 5 mins. Animals were immediately euthanized after recovery

264 measurements were recorded.

\section{Quantitative Reverse-Transcription Polymerase Chain Reaction (qRT-PCR):}

266 TA muscle mRNA and cDNA were prepared as previously described (see above). The cDNA

267 from all samples was used to prepare pools to establish standard curves of each gene. The cDNA

268 pool or cDNA samples were mixed with MasterMix containing SYBR select. The reactions were

269 loaded in a 384-well PCR plate and run in a BioRAD qRT thermal cycler for $2 \mathrm{~m}$ at $50^{\circ} \mathrm{C}, 7 \mathrm{~m}$ at $95^{\circ} \mathrm{C}$; followed by 39 cycles of $60 \mathrm{~s}$ at $95^{\circ} \mathrm{C}$, $90 \mathrm{~s}$ at $67^{\circ} \mathrm{C}$, and $35 \mathrm{~s}$ at $72^{\circ} \mathrm{C}$. Melting curves were

271 established by a step-wise gradient from $60-90^{\circ} \mathrm{C}$. The myosin heavy chain (MHC) isoforms,

272 MHCI, MHCIIa, MHCIIx and MHCIIb were analyzed by real-time PCR using the mRNA and 273 cDNA prepared above (see Table 3). 
281 Table 3. Rat MHC isoforms and $\beta$-actin control primers used for qRT-PCR. Forward and reverse 282 primer pairs are indicated for the four MHC isoforms.

283

284

285

Gene

Forward Primer $\left(5^{\prime}-3^{\prime}\right)$

Reverse Primer $\left(5^{\prime}-3^{\prime}\right)$

286

287

$\mathrm{MHCl}$

GAATGGCAAGACGGTGACTGT

GGAAGCGTACCTCTCCTTGAGA

288 MHClla

ATGACAACTCCTCTCGCTTTG

TTAAGCTGGAAAGTGACCCGG

289

MHCIIb

GAACACGAAGCGTGTCATCCA

AGGTTTCGATATCTGCGGAGG

290 MHCIIx

CCAATGAGACTAAGACGCCTGG

GCTATCGATGAATTGTCCCTCG

$291 \beta$-actin

AGCCATGTACGTAGCCA

CTCTCAGCTGTGGTGGTGAA

292

293

294

295

296

\section{In Vitro Studies}

297

\section{Culture and cDNA analyses of $\mathrm{C2C12}$ cell line}

299 The immortalized murine skeletal muscle cell line, C2C12, was used for all in vitro studies. Cells were maintained at 60-70\% confluency with Dulbecco's Modified Eagle Medium (DMEM)

301 supplemented with 20\% fetal bovine serum (FBS) and a penicillin/streptomycin antibiotic 302 combination (Invitrogen, Burlington, ON, Canada). To induce differentiation, the media was 303 changed to DMEM supplemented with $10 \%$ horse serum (HS) with the penicillin/streptomycin 304 antibiotic combination, and the cells were allowed to differentiate for $6 \mathrm{~d}$ (media replaced every 24 $305 \mathrm{hrs})$. For treatment, cells were serum-starved for $3 \mathrm{~h}$ and then treated with either vehicle or TCAP-1 $306(100 \mathrm{nM})$. The identification of teneurin, TCAP and LPHN cDNAs in C2C12 cells was performed 
with mRNA extracted from differentiated mouse C2C12 cells using the method described above using the primer sequences indicated in Table 1.

\section{Live-cell calcium imaging in $\mathrm{C2C12}$ myotubules}

311 The C2C12 skeletal cells were grown and differentiated on poly-D-lysine-coated $25 \mathrm{~mm}$ round

312 No. 1 glass coverslips (Warner Instruments, Hamden, CT, USA). Changes in intracellular $\mathrm{Ca}^{2+}$

313 were assessed using the membrane-permeable fluorescent indicator fluo-4, AM (Invitrogen,

314 Burlington, ON, Canada). Cells were loaded with fluo-4 by incubating coverslips in DMEM

315 containing $10 \mu \mathrm{M}$ fluo-4 for $30 \mathrm{~m}\left(37^{\circ} \mathrm{C}\right)$ followed by a $15 \mathrm{~m}$ wash in Locke's Buffer $(305-310$

$316 \mathrm{mOsmol}$ at $22^{\circ} \mathrm{C}$ ). In experiments assessing changes in intracellular $\mathrm{Ca}^{2+}$, coverslips were placed

317 in a flow-through bath chamber (RC-40HP, Warner Instruments, Hamden, CT, USA) of an

318 inverted microscope (Axio Observer Z1, Zeiss, Toronto, ON, Canada) equipped with a 40× oil

319 immersion objective. Cells were continuously bulk-perfused with Locke's buffer via a gravity drip

320 perfusion system at a rate of $2-3 \mathrm{ml} / \mathrm{min}$ at RT. Changes in fluo-4 fluorescence were imaged using

321 a green fluorescent protein (GFP) filter set (Semrock, Rochester, NY, USA) and a X-Cite 120

322 fluorescence illumination system (Excelitas Technologies, Mississauga, ON, Canada), controlled

323 by Volocity 4.0 imaging software (Quorum Technologies Inc., Guelph, ON, Canada).

324 Fluorescence emissions were detected with an Orca-ER Hamamatsu B/W CCD digital camera

325 (Hamamatsu, Middlesex, NJ, USA). Fluo-4 was excited with a wavelength of $480 \mathrm{~nm}$ for 100ms

326 every $3-5 \mathrm{~s}$ and fluorescence emission was measured at wavelength of $516 \mathrm{~nm}$. 


\section{Caffeine stimulation experiments}

331 Caffeine action on the cells was used to establish that the cells were viable. Caffeine (4 mM;

332 Sigma-Aldrich, Oakville, $\mathrm{ON}$ ) was applied to $\mathrm{C} 2 \mathrm{C} 12$ myotubes to stimulate $\mathrm{Ca}^{2+}$ release from the 333 sarcoplasmic reticulum (SR). Cells were either pre-treated with TCAP-1 (100 nM) or vehicle for 334 1h before stimulation with caffeine. Using Velocity 4.0 imaging software, ROIs were taken from 335 cytosolic regions within the myotubules ( $n=4$ coverslips, 4-5 ROIs per coverslip).

\section{GLUT4 Immunocytochemical studies}

338
C2C12 cells were differentiated, as described above. After $3 \mathrm{~h}$ of serum starvation, myotubules were treated either with vehicle, TCAP-1 $(100 \mathrm{nM})$ or insulin $(100 \mathrm{nM})$ for 15 or $30 \mathrm{~m}$. Cells were then fixed using 4\% paraformaldehyde and subsequently blocked with $10 \%$ NGS for $1 \mathrm{~h}$ at RT. The GLUT4 primary antibody, diluted in $1 \%$ NGS, was added to the cells and incubated at $4{ }^{\circ} \mathrm{C}$ overnight (OT). Following 4 PBS washes, the secondary antibody (diluted in 1\% NGS) was added and incubated $1 \mathrm{~h}$ at RT. The coverslips were mounted using DAPI-containing Vectashield. Slides were imaged on a confocal microscope with a 40x oil objective. The images were analyzed using Image J, where myotubules were selected as ROIs and were analyzed for red pixel intensity values, representing GLUT4 levels, and normalized to area size $(n=3-4$ coverslips per treatment, 7-8 myotubules per coverslip). For the IP3R inhibitor, 2-aminoethoxydiphenyl borate (2-APB; Sigma Aldrich, Oakville, ON) experiments, 2-APB $(100 \mu \mathrm{M})$ was applied for $4 \mathrm{~m}$ before the start of treatment with either sham (Locke's buffer) or TCAP-1 (100 nM), containing 2-APB for continuous blocking of IP3R. 


\section{Radioactive glucose uptake}

354 The ${ }^{3} \mathrm{H}-2$-deoxyglucose uptake protocol was followed as previously described with minor modifications $[44,45]$. At day-6 post-plating, C2C12 myotubules were washed 2x with Locke's without serum and glucose. The culture was incubated in the Locke's buffer for $1 \mathrm{~h}$ at $37^{\circ} \mathrm{C}$ followed by exposure to $100 \mathrm{nM}$ insulin, $100 \mathrm{nM}$ TCAP-1, $100 \mathrm{nM}$ SC-TCAP-1, or saline. ${ }^{3} \mathrm{H}-2$ deoxyglucose $(0.5 \mu \mathrm{Ci} / \mathrm{ml})$ was added to the culture $5 \mathrm{~m}$ before termination of treatment exposure. Uptake of ${ }^{3} \mathrm{H}-2$-deoxyglucose was stopped immediately after $5 \mathrm{~m}$ with $3 \mathrm{x}$ washes of ice-cold $0.9 \%$ saline solution. The cells were digested with $1 \mathrm{~mL}$ of $0.05 \mathrm{M} \mathrm{NaOH}$ at $0,30,45$, and 60 min after treatment. Radioactivity of the cell lysates were measured using a beta liquid scintillation counter (Beckman Coulter), and recorded in counts per minute (CPM).

\section{Intracellular ATP and NADH assays}

365 ATP assays were conducted using Promega ATP Assay kits (Wisconsin, USA) following the manufacturer's instructions. Briefly, C2C12 cells were seeded at 10,000 cells/well in 96-well plates. The following day, cells were treated with either vehicle or TCAP-1 (100 nM) and lysed at

371 decays over the course of the experiment, TCAP-1-treated cells were compared relatively to the

372 vehicle-treated cells for each time point $(n=8)$. For the resazurin NADH assay, the C2C12 cells 373 were seeded at 10,000 cells /well in 96-well plates. The resazurin assay was started the following 374 day by adding the resazurin solution (525 nM, Sigma) to all wells. Cells were treated with either 375 vehicle or TCAP-1 (100 nM). Fluorescent readings were measured every 5m over 1h, with 
excitation at $530 \mathrm{~nm}$ and emission read at $590 \mathrm{~nm}$. The measurements of blank wells not containing cells were subtracted from all readings.

\section{Western blot of succinate dehydrogenase in $\mathrm{C} 2 \mathrm{C} 12$ cells}

Following TCAP-1 treatments, proteins were extracted from $\mathrm{C} 2 \mathrm{C} 12$ cells and lysed with radioimmunoprecipitation assay (RIPA) buffer supplemented with the protease inhibitor, phenylmethylsulfonic fluoride (PMSF) (Cell Signaling Technology, MA USA) and measured using a bicinchonic acid (BCA) protein assay (Pierce BCA Protein Assay; Thermo-Fisher Scientific, Toronto, Canada). All protein extracts were re-suspended in sample buffer and sizefractioned by SDS-PAGE, electro-transferred to nitrocellulose membranes. Afterwards, membranes were incubated with the succinate dehydrogenase (SDH) primary antibody and subsequently treated with secondary antibody conjugated with chemiluminescent tags (Table 2). Following TCAP-1 treatments, C2C12 cells were lysed with $500 \mu \mathrm{L}$ of RIPA buffer supplemented with PMSF. Cells were harvested and centrifuged at $20,000 \mathrm{rcf}$ for $20 \mathrm{~m}$ at $4^{\circ} \mathrm{C}$. Protein concentrations (as described above) were measured to standardize the dilutions of respective supernatant samples. Samples $(15 \mu \mathrm{g})$ were re-suspended in sample buffer and size-fractioned by SDS-PAGE $(10 \%)$ at $100 \mathrm{~V}$ for $1 \mathrm{~h}$. The protein extract was electro-transferred to Hybond-ECL nitrocellulose membranes (Amersham) for $2 \mathrm{~h}$ at 100V. Membranes were washed $3 \mathrm{x}$ with PBS and blocked in 5\% milk-PBST (5\% w/v non-fat milk powder in PBS with $0.2 \%$ Tween20; PBST) at RT for $1 \mathrm{~h}$, then incubated with primary antibodies in $1 \%$ milk-PBST OT at $4^{\circ} \mathrm{C}$. The membranes were washed 3x in PBST at RT and incubated with a horseradish peroxidase (HRP)-conjugated secondary antibody (VWR, Amersham; diluted to $1: 7500$ in 1\% milk-PBST) for $1 \mathrm{~h}$ at RT then 
washed 3x in PBST at RT. The proteins were detected by adding chemiluminescence detection reagent (ECL Amersham) to the membranes and exposing onto ECL Hyperfilm (VWR) for 30m.

\section{Diacylglycerol (DAG) and inositol triphosphate (IP3) assays}

401 The protocols provided by commercial DAG and IP3 assays (MyBiosource, San Diego, 402 California, USA) were followed. To determine the downstream $\mathrm{Ca}^{2+}$ response, 6 replicates of 403 C2C12 cells were prepared using the TCAP-1 treatment protocol described above then treated with 404 either vehicle, the IP3R antagonist, 2-APB, or the phospholipase C inhibitor, U73122. Cell lysates 405 were added to a microELISA plate coated with purified mouse DAG or IP3 antibodies. 406 Subsequently, 3,3',5,5'-tetramethylbenzidine (TMB) solution was added to detect the HRP407 conjugates as colour changes. Finally, sulphuric acid $(0.01 \mathrm{~N})$ was added to terminate the reaction.

408 The absorbance change was measured at $450 \mathrm{~nm}$ by spectrophotometry (SpectraMax Plus, NH, 409 USA). For the IP3R inhibitor, 2-APB $(100 \mu \mathrm{M})$ was applied before the start of treatment with either sham (Locke's buffer with scTCAP-1) or TCAP-1 (100 nM). For live-cell fluorescence experiments, $\mathrm{C} 2 \mathrm{C} 12$ cells were differentiated and intracellular $\mathrm{Ca}^{2+}$ flux was assessed via fluo-4

412 via a flow-through bath chamber of an inverted microscope. Cells were quantified with a GFP 413 filter set at $480 \mathrm{~nm}$ with the fluorescence emission measured at $516 \mathrm{~nm}$.

417 Changes in mitochondrial $\mathrm{Ca}^{2+}$ levels were assessed using fluorescent indicator, Rhodamine-2-

418 AM (Rhod-2). C2C12 myotubules were loaded with Rhod-2 by incubating coverslips in DMEM 419 containing $4 \mu \mathrm{M}$ Rhod-2 (from a 1mM stock solution in DMSO with $20 \%$ pluronic; Invitrogen- 
421 Cells then acclimated for $15 \mathrm{~m}$ at $22^{\circ} \mathrm{C}$. To assess changes in mitochondrial $\mathrm{Ca}^{2+}$ levels, cells were

422 continuously perfused in a flow-through chamber as indicated previously. Changes in Rhod-2

423 fluorescence was imaged using a TRITC filter set (Semrock, Rochester, NY, USA) and an X-Cite

424120 fluorescence illumination system (Quorum Technologies, Inc. Guelph ON, Canada).

425 Emissions were detected using an Orca-ER Hamamatsu BW CCD digital camera as described 426 above. Rhod-2 was excited at 552nm every $100 \mathrm{~ms}$ and measured at $577 \mathrm{~nm}$. Multiple ROI were

427 taken from the nuclear regions of the myotubules $(n=5,5-7$ ROIs per coverslip). Changes in 428 mitochondrial membrane potential were assessed using R123-based fluorescence. C2C12 429 myotubules were prepared with by incubating a coverslips in DMEM containing $5 \mu \mathrm{M}$ R123 for $30 \mathrm{~m}\left(37^{\circ} \mathrm{C}\right)$ followed by a $15 \mathrm{~m}$ wash in Locke's Buffer. Changes in R123 fluorescence was imaged 431 using the green GFP filter set using the same experimental configuration as previously described. 432 R123 was excited with a wavelength of $480 \mathrm{~nm}$ for $100 \mathrm{~ms}$ every $5 \mathrm{~s}$ and fluorescence emission 433 was measured at $516 \mathrm{~nm}$.

\section{SiRNA knockdowns (KD) and CRISPR Knockouts (KO) of LPHN-1 and -3}

436 For the siRNA KD studies, transfection with siRNA oligonucleotides was performed after $4 \mathrm{~d}$ of 437 C2C12 differentiation using Dharmacon SmartPOOL (Horizon Inc. Canada) siRNA for LPHN1 438 (L-061299-00-0005), LPHN3 (L-040779-00-0005) and a non-targeting control (D-001810-10-05).

439 Dharmacon SmartPOOL siRNAs targeted against LPHN-1 and-3, glyceraldehyde-3-phosphate 440 (GAPD) and a non-targeting control were re-suspended in 1x siRNA buffer from $20 \mu \mathrm{M}$ stocks. 441 The stocks were diluted in serum-free and antibiotic-free DMEM to $250 \mathrm{nM}$. A 7.5 $\mu \mathrm{L}$ aliquot of 442 Mirus TranslT-X2 (Mirus Bio LLC) transfection reagent was diluted in $200 \mu \mathrm{L}$ serum- and antibiotic-free DMEM and incubated at RT for $30 \mathrm{~m}$. The mixture was added to $\mathrm{C} 2 \mathrm{C} 12$ cells (see 
444 above) with a final siRNA concentration of $25 \mathrm{nM}$. The cells were differentiated in siRNA445 containing media for $2 \mathrm{~d}$ for a total of $6 \mathrm{~d}$ of differentiation before use in the experiments. For 446 CRISPR studies, single-guided RNA (sgRNA) constructs were designed to target the mouse 447 LPHN-1 and -3 gene at 3 locations (see Fig. 2). C2C12 cells were transfected with sgRNA constructs (Fig. 2C) and a Cas9 plasmid, generating heterogenous pools of transfected cells. The

449 CRISPR/Cas-transfected C2C12 cells (either hetergenous pools or clones) were trypsinized and 450 pelleted for DNA extraction. Genomic DNA was extracted using Lucigen QuickExtract DNA 451 extraction solution (Biosearch Technologies, Inc) according to the manufacturer's direction. The 452 LPHN-1 and -3 genes were amplified by PCR and digested by T7 endonuclease using the EnGen Mutation Detection Kit (New England Biolabs) according to directions in combination with the 454 custom primers that flank the appropriate CRISPR-targeting regions (Fig. 2C). The fragments were identified as previously described above. Clones that showed low or no WT PCR amplicon were screened for LPHN1 expression by qRT-PCR. Selected clones showing significantly reduced LPHN1 mRNA expression by qRT-PCR and western were termed 'LPHN1 E5U KO’ and 'LPHN1 E5D KO' based on the exon position of mutated site and were used for further study (Fig. 2). The activity of the clones were determined by TCAP-1-induced cytosolic $\mathrm{Ca}^{2+}$ flux in the manner described above. Peroxisome proliferator-activated receptor $\gamma$ coactivator $1 \alpha$ (PGC-1 $\alpha$ ) expression in $\mathrm{C} 2 \mathrm{C} 12$ cells was determined using the qRT-PCR methods described above.

Figure 2. CRISPR-based targets for the mouse LPHN-1 and -3 genomic sequences. A.

464 Schematics of LPHN-1 and -3 genomic organization. The oligonucleotides targeting these regions

465 are indicated as arrows. B. Sequence of the oligonucleotides used in the CRISPR knockdowns as 466 indicated in ' $A$ ' above. 
468 Statistical Analyses

469 All data on graphs are represented as mean \pm SEM. All data were analyzed by Student's t-test or 470 one or two-way ANOVA, as described within each figure caption. Tukey's post-hoc test and 471 Sidak's post-hoc test were used to determine significance in one-way and two-way ANOVA 472 analyzes, respectively. An a priori hypothesis of $\mathrm{p}<0.05$ was used as a threshold for statistical 473 significance. GraphPad Prism 7-8 was used to analyze each statistical test.

474

$475 \quad$ Results

476

477 The primary structure of rat and mouse TCAP-1 possesses a high degree of homology among the

478 other three paralogues (Fig 1A). Because the primary structure of rat and mouse TCAP-1 is 479 identical, it was used for all studies, as well as a proxy for the other TCAP isoforms. The first 480 studies completed established that the teneurins, TCAP and LPHNs could be expressed in rat 481 skeletal muscle. Secondarily, the physiological role of TCAP-1 in rat skeletal muscle was 482 examined.

\section{$483 \quad$ In Vivo Rat Studies}

484 In rat TA muscle mRNA extracts, all 4 teneurin mRNAs were identified based on the PCR primers 485 indicated in Table 1. Teneurins-3 and-4 showed the strongest response, although both teneurins-1 486 and -2 were present, albiet weakly expressed. In contrast, TCAP-1 and -2 showed a strong signal 487 relative to that indicated by teneurins- 1 and -2 whereas TCAP-4 showed a signal consistent with 488 teneurin-4. Although these studies were not quantitative, they do establish that both teneurins and 
TCAP paralogues are present in rat skeletal muscle. However, importantly, both LPHN-1 and -3 cDNA bands were also strongly expressed, although there was no evidence of LPHN-2 in this preparation (Fig 3A).

Figure 3. Expression of the teneurin/TCAP-LPHN immunoreactivity (ir) in rat skeletal muscle: A. PCR expression of teneurins, TCAP and LPHNs in rat TA muscle. B. Immunological expression of $\beta$-dystroglycan, teneurin and LPHN in rat skeletal muscle. Arrows indicate nodes of aggregation (Scale bar: $100 \mu \mathrm{M}$ ). C. Enhanced examination of ir-LPHN regions in TA muscle cells. Left panel scale bar indicates $100 \mu \mathrm{M}$, whereas the right panel scale bar indicates $50 \mu \mathrm{M}$. Black arrows indicate cells with high LPHN-1 labelling, whereas white arrows indicate cells of low LPHN-1 labelling. D. Quantification of ir-LPHN-1 as a function of muscle cell diameter (size) as shown in 'C' (Student's t-Test $\mathrm{p}<0.0001 ; * * * *)$. E. Changes in fiber type in short-term TCAP-1 administration (t-test indicated for each pair). F. Changes in fiber-type over long term TCAP-1 administration (t-test indicated for each pair).

To corroborate these cDNA studies, immunohistochemical (IHC) studies were performed in rat TA muscle tissue. Initially, $\beta$-dystroglycan (DG) labelling was used to establish the sarcolemmic boundary of the cells, as previous studies indicated a relationship between DG and TCAP signaling [33]. Further, IHC co-localization labeling of Teneurin-1,-3 -and LPHN-1 was utilized to establish the cellular anatomical relationship between the teneurins and LPHNs. Immunoreactive (ir) teneurin-1 did not show a strong signal (data not shown), consistent with the RT-PCR data indicated above, however the ir-teneurin-3 showed a clear response indicating specific nodes of aggregation in the sarcolemma (Fig. 3B). Importantly, ir-LPHN-1 labelling of these tissues showed co-localization with the ir-DG along with ir-teneurin and ir-TCAP labelling consistent with the 
513 PCR studies indicated in Fig. 3A. The variation among the PCR and ir-teneurin -1 and -3 expression was expected due to affinity differences among the antibodies and primers (see discussion). Moreover, these studies establish a clear relationship between TCAP, teneurins and

516 LPHNs in rat skeletal muscle (Fig. 3B). Morphological differences, with respect to cross-section

517 diameter between the vehicle- and TCAP-1-treated animals could be established. Thus, TCAP-1

518 administration induced a $25 \%$ increase $(p<0.001)$ between the number of small and intermediate

519 cells relative to the untreated vehicle rats (Fig. 3C, D). Because small and intermediate fibers are

520 typically oxidative muscle fibres, these observations suggested that TCAP could stimulate glucose

521 uptake in skeletal muscle. To corroborate these findings, the expression of myosin heavy chain

522 (MHC) was evaluated in the TA muscle of both short-term and long term TCAP-treated animals.

523 In both cases, there was a significant $(\mathrm{p}<0.01) 3$ - to 3.5-fold increase in the expression of the MHCI

524 fibres in the TCAP-1-treated animals compared to the non-treated vehicle, although significant

$525(\mathrm{p}<0.05)$ differences were also observed among MHCIIa, MHCIIx and MHCIIb expression among

526 the treated and untreated animals (Fig. 3E,F).

527 Taken together, these studies indicated that TCAP-1 may increase glucose transport into skeletal 528 muscle. Therefore, TCAP-1-induced glucose uptake into the hind-limb was measured directly by 529 fPET. Thus, using ${ }^{18}$ F-deoxyglucose (FDG), a single dose of SC TCAP-1-treatment-induced FDG 530 uptake in the hind-limb muscle by 2 -fold $(\mathrm{p}<0.05)$ (Fig. 4.A,B) after $3 \mathrm{~d}$ of treatment relative to 531 vehicle treatment. These data corroborated our supposition that TCAP-1 acted, in part, to increase 532 glucose importation into skeletal muscle. If this was the case, then this increase in glucose 533 importation should increase skeletal muscle NADH production as a result of 2-glyceraldehyde-3534 phosphate conversion to 2-1,3 diphosphoglycerate and secondarily through elements of the tri535 carboxycyclic (TCA) acid cycle in the conversion to pyruvate. TCAP-1-treated muscle significant 
$536(\mathrm{p}<0.05)$ increased NADH-staining compared to vehicle (Fig. 4C, D) supporting increased TCAP-

537 1-mediated glucose transport.

Figure 4. Glucose uptake and metabolism in rat hind-limb and TA muscle. A. Function positronic emission tomography (fPET) of rat hind limb showing increase of ${ }^{18} \mathrm{~F}$-deoxyglucose

541 ( $\left.{ }^{18} \mathrm{~F}-\mathrm{DG}\right)$ uptake after 3 days from TCAP-1 administration. B. Quantification of the ${ }^{18} \mathrm{~F}-\mathrm{DG}$ uptake 542 in hindlimb after 3 days. $(n=5$; student's t-test; $\mathrm{p}<0.05)$. C. Stimulation of NADH in TA muscle 543 after administration of TCAP-1. Above panel, (hematoxylin and eosin stain), bottom panel, NADH 544 activity (shown as black regions). Scale bar indicates $100 \mu \mathrm{M}$. D. Quantification of the NADH545 labelled cells shown in ' $\mathrm{C}$ '. ${ }^{*} \mathrm{p}<0.05 ;{ }^{*} \mathrm{p}<0.01 ; * * * \mathrm{p}<0.001 ; * * * * \mathrm{p}<0.0001$. Mean \pm SEM 546 indicated $n=4$.

Muscle performance is related to the amount of energetic substrates available, therefore, we examined the role of TCAP-1 on muscle activity in vivo in rats by determining the efficacy of TCAP-1-mediated contractility using electrical stimulation of the TA muscle. After a 5-d daily assessed. TCAP-1-treated animals showed improved muscle dynamics. TCAP-1-treated animals exhibited enhanced baseline contraction kinetics with respect to increased peak twitch force $(\mathrm{p}<0.05)$ (Fig. 5 A,B), slower contraction velocity $(\mathrm{p}<0.05)$ (Fig 5C), and potentially higher faster 555 relaxation rates (Fig. 5D) compared to vehicle-treated animals. Following baseline measurements, 556 a 6-m fatigue protocol was induced in the muscle where contractile kinetics were recorded at 0,1 , 557 and $5 \mathrm{~m}$ after the fatigue protocol. TCAP-1 enhanced recovery from the twitch stimulation (Fig. 558 5E-G). Although TCAP-1 did not influence peak twitch force (Fig. 5E), it significantly $(\mathrm{p}<0.05)$ 559 maintained twitch max dx/dt (Fig. 5F) and 1/2RT (Fig. 5G) over the course of the fatigue protocol 
560

561

562

563

564

565

566

567

568

569

570

571

572

573

574

575

576

577

\section{$578 \quad$ In Vitro Mouse Cell Studies}

579 The initial PCR screen of $\mathrm{C} 2 \mathrm{C} 12$ cells indicated that, although only teneurin-3 was highly

which was diminished in vehicle-treated animals. All data was normalized to muscle mass. The treatment did not affect muscle mass (Fig. 5H), tetanic force (Fig. 5I) or the fatigue force curve (Fig. 5J). Thus, TCAP-1 enhanced the efficiency of the existing muscle morphology, rather than increasing muscle mass, and maintained contraction cycling efficiency during fatigue. To assess the effects of a long-term (LT) treatment, rats were administered either vehicle or TCAP-1, for 3 months (1 injection/week). Two weeks post-treatment, the TCAP-1-treated animals elicited a comparable peak twitch force to vehicle-treated animals (Fig. 5K-J), however had significantly $(\mathrm{p}<0.05)$ slower contraction velocity and faster $(\mathrm{p}<0.05)$ relaxation rate $($ Fig. $5 \mathrm{~L}, \mathrm{M})$.

Figure 5. In vivo actions of TCAP-1 on rat TA muscle kinetics. A-J. Muscle twitch kinetics after animals treated with TCAP-1 once a day for 5 days before testing A. Representative twitch traces (black, vehicle; gray, TCAP-1). B. Baseline contraction kinetics (t-test). C. Contraction velocity (t-test). D. Relaxation rate (t-test). E. Peak twitch force (2-way ANOVA). F. Twitch max dx/dt (2-way ANOVA). G. 1/2RT analysis (2-way ANOVA). TCAP-1 treatment did not affect muscle weight (t-test) $(\mathbf{H})$, tetanic force (t-test) $(\mathbf{I})$ or fatigue force over time (J) (n=7-8). K-M. Long term treatment of TCAP-1 on rat hind-limb twitch kinetics. K. contraction max dx/dt. L. 1/2RT rate. M. Relaxation rate.

expressed (Fig.6A), all 4 TCAP transcripts could be discerned (Fig. 6B). In both undifferentiated C2C12 myoblasts, and 6-d myotubules, the transcripts for LPHN-1 and -3 were present (Fig. 6C). IHC expression of TCAP-1 showed a similar punctate expression in the cytosol of the C2C12 
myoblasts (Fig. 6D) as we have previously shown for neurons [38] where FITC-labelled TCAP-1 was present at several sarcolemmic regions consistent with the expected expression of the receptor $[32,33,38]$. Moreover, because TCAP-1 regulates actin organization and polymerization in neurons [38], the C2C12 cells were treated with TCAP-1 and examined using the phalloidin stain to highlight actin fibers (Fig. 6E). This resulted in a major increase in actin polymerization in the TCAP-1-treated cells at both $30 \mathrm{~m}(\mathrm{p}<0.01)$ and $2 \mathrm{~d}(\mathrm{p}<0.001)$.

Figure 6. Expression of teneurin, TCAP and LPHN in C2C12 myoblasts. A. PCR-based teneurin expression; B. PCR-based TCAP expression; C. PCR-based LPHN expression. D. C2C12 cells labelled with TCAP-1 antisera showing the difference between the endogenous ir-TCAP and the presence of FITC-TCAP-1 localization. ir-TCAP-1 is indicated in red, whereas the DNAassociated DAPI labelling is indicated in blue. FITC-labeled TCAP-1 is shown in green. Arrows indicate regions of FITC-TCAP-1 uptake. Scale bars indicate $50 \mu \mathrm{M}$ E. Actions of TCAP-1 on the proliferation of the $\mathrm{C} 2 \mathrm{C} 12$ myoblasts when treated with TCAP-1 at 30 minutes and 2 days. Actin is indicated in red, whereas the nuclei are indicated in the DAPI-based blue. Scale bars indicate $100 \mu \mathrm{M}$.

Having established that TCAP-1 behaved in a similar manner as previously shown in neurons, the viability of the $\mathrm{Ca}^{2+}$ response in the differentiated myotubules was evaluated to determine their efficacy before proceeding to further studies. Initially, caffeine was used to determine the limits of the $\mathrm{Ca}^{2+}$ response in the differentiated myotubules relative to the TCAP-1 response (Fig. 7AD). These studies indicated that the myotubules were active and viable, and with respect to the $\mathrm{Ca}^{2+}$ response, did not show an appreciable decrease in cytosolic $\mathrm{Ca}^{2+}$ concentrations (Fig. 7B), although it did attenuate the rate of cytosolic $\mathrm{Ca}^{2+}$ concentrations $(\mathrm{p}<0.01)$. Taken together, these 
607

608

609

610

611

612

613

614

615

616

617

618

619

620

621

622

623

624

625

626

627

628

629

630

studies indicated that the myotubules were viable with respect to our preparation, and that the attenuating TCAP-1 response indicated that additional regulating factors were likely present. Thus, given these observations, the direct action of TCAP-1 on $\mathrm{Ca}^{2+}$ flux in myotubules was examined (Fig. 7E-H). TCAP-1 increased $\mathrm{Ca}^{2+}$ concentrations by almost 4 -fold relative to the control-treated cells $(\mathrm{p}<0.001)$.

Figure 7. Caffeine- and TCAP-1- mediated $\mathrm{Ca}^{2+}$ response in differentiated $\mathrm{C2C12}$ myocytes. A. Heat-map images showing the $\mathrm{Ca}^{2+}$ response induced by caffeine, TCAP-1 or vehicle. Mean and SEM is indicated. B. Dynamic concentration changes over the period of analysis shown in 'A'. Mean \pm SEM is indicated. C. Total concentration changes of the manipulations of the study period indicated in 'A'. D. Rate of $\mathrm{Ca}^{2+}$ release between caffeine and TCAP-1. E. TCAP-1 mediated $\mathrm{Ca}^{2+}$ actions show normal morphology in cells. F. Rate of increase in $\mathrm{Ca}^{2+}$-associated fluorescence after administration of TCAP-1. G. Quantification of the change in TCAP-1 mediated intracellular $\mathrm{Ca}^{2+}$ concentrations indicated in ' $\mathrm{F}$ '. Significance was determined by a Students ttest. $(* \mathrm{p}<0.05 ; * * \mathrm{p}<0.01 ; * * * \mathrm{p}<0.001 ; * * * * \mathrm{p}<0.0001$. Mean \pm SEM indicated $\mathrm{n}=4)$.

In skeletal muscle, the predominant glucose transporter protein (GLUT) isoform is the insulinsensitive GLUT4 protein. Using insulin as a control, a significant $(\mathrm{p}<0.001)$ increase in the expression of the ir-GLUT4 transporters was observed for both TCAP-1 and insulin treatments over 30m (Fig. 8 A,B) in C2C12 cells. To determine whether this GLUT4 response was dependent on the TCAP-1-mediated $\mathrm{Ca}^{2+}$ release, the IP3R antagonist, 2-APB, that abolishes the TCAP-1 $\mathrm{Ca}^{2+}$ response, was investigated. In the presence of the inhibitor, both TCAP-1 $(\mathrm{p}<0.01)$ and insulin $(\mathrm{p}<0.001)$ inhibited the ir-GLUT4 expression (Fig. 8A,C). This importation of glucose by TCAP-1 was further corroborated in $\mathrm{C} 2 \mathrm{C} 12$ cells showing that TCAP-1 significantly $(\mathrm{p}<0.0001)$ induced 
631

632

633

634

635

636

637

638

639

640

641

642

643

644

645

646

647

648

649

650

651

652

653

654

655

${ }^{3} \mathrm{H}$-2-deoxyglucose increase into the cytosol over $30 \mathrm{~m}$, similar to that of insulin (Fig. 8D). However, both peptides show distinct glucose-uptake profiles, where insulin induces a significant increase at $30 \mathrm{~m}(\mathrm{p}<0.001), 45 \mathrm{~m}(\mathrm{p}<0.001)$ and $60 \mathrm{~m}(\mathrm{p}<0.01)$, whereas TCAP-1 induces an increase at $30 \mathrm{~m}(\mathrm{p}<0.001)$ but was attenuated by $45 \mathrm{~m}(\mathrm{p}<0.01)$ and returns to baseline at $60 \mathrm{~m}$. The sc-TCAP-1 treatment, used separately as a negative peptide control in this study, showed no significant change from the saline vehicle.

Figure 8: TCAP-mediated glucose metabolism in C2C12 cells. A. Regulation of ir-GLUT4 by TCAP-1 and insulin myotubules. Red indicates ir-GLUT4 whereas blue shows DAPI staining of the nuclei. Arrows indicated regions of high immunoreactivity. Scale bar=100 $\mu \mathrm{M}$. B. Quantification of ir-GLUT4 expression over 30 minutes. C. Effect of the IP3R inhibitor, 2-APB on TCAP-1- and insulin-mediated ir-GLUT4 labelling. D. Uptake of ${ }^{3} \mathrm{H}$-2-deoxyglucose in C2C12 myoblasts by TCAP-1 and insulin. E. Changes in static ATP concentrations following treatment by TCAP-1. F. NADH production increase as determined by a resesourin assay following TCAP-1 treatment relative to the vehicle. G. Increased ir-succinate dehydrogenase expression after 1 hour following TCAP-1 treatment as determined by western blot. H. Quantification of the data indicated in 'G'. Significance was determined by a t-test as indicated in C, F and $\mathrm{H}$ or one-way ANOVA shown in B D and E. $(* \mathrm{p}<0.05 ; * * \mathrm{p}<0.01 ; * * * \mathrm{p}<0.001 ; * * * * \mathrm{p}<0.0001$. Mean \pm SEM indicated $\mathrm{n}=6)$.

Increased glucose importation increases ATP and NADH turnover in cells due to glycolytic and tricylic acid (TCA) cycle activity. Therefore, this was examined with respect to TCAP-1 treatment. As a result, both ATP $(\mathrm{p}<0.001)$ (Fig. 8E) and NADH $(\mathrm{p}<0.001)$ (Fig. 8F) turnover were significantly increased after 30m of TCAP-1 treatment, although NADH levels remained about $60 \%$ higher $(\mathrm{p}<0.001)$ than vehicle levels after $60 \mathrm{~m}$. Moreover, succinate dehydrogenase (SDH; a 
rate-limiting step of the TCA cycle) protein expression was increased by over 2-fold after TCAP1 treatment corroborating the previous experiments of increased ATP and NADH production $(\mathrm{p}<0.05$; Fig. $8 \mathrm{G}, \mathrm{H})$.

As we have previously established that the IP3-DAG pathway is important for TCAP-1-mediated intracellular $\mathrm{Ca}^{2+}$ flux in neurons, this pathway was examined in $\mathrm{C} 2 \mathrm{C} 12$ cells. Relative to the vehicle, TCAP-1 induced a significant increase at 5 and $15 \min (\mathrm{p}<0.001$; Fig. 9A) in intracellular DAG concentrations and a major increase between 1 and $15 \min (p<0.0001$; Fig. 9B $)$ in IP3 concentrations. To confirm this action, TCAP-1-treated $\mathrm{C} 2 \mathrm{C} 12$ cells were blocked with either the IP3R antagonist, 2-APB, or the phospholase C inhibitor, U73122. The 2-APB and U73122 treatment reduced TCAP-1-mediated Fluo-4 concentrations to about $30 \%(\mathrm{p}<0.01)$ of their original values indicating that the IP3-DAG pathway plays an active role in increase of TCAP-1-mediated intracellular $\mathrm{Ca}^{2+}$ flux (Fig. 8C,D). Because this TCAP-1-mediated rise in intracellular $\mathrm{Ca}^{2+}$ concentrations can target the mitochondria [39], the mitochondrial $\mathrm{Ca}^{2+}$ dye, rhodamine 1-AM (Rhod-2) was utilized to determine the concentration of $\mathrm{Ca}^{2+}$ sequestration in mitochondria. There was a 5-fold increase $(\mathrm{p}<0.001)$ in Rhod-2-associated $\mathrm{Ca}^{2+}$ labelling over 200s (Fig. 9E,F). Related to this, Rhod-123, was used to determine the level of mitochondrial polarization. TCAP-1 treatment significantly decreased Rhod-123 fluorescence $(\mathrm{p}<0.001)$ relative to vehicle indicating depolarization of the mitochondria membrane (Fig. 9G, H).

Figure 9. TCAP-1 mediated calcium regulation in C2C12 cells. A. TCAP-1 mediated increase in intracellular DAG concentrations (mean and SEM shown; $n=6$ ). B. TCAP-1 mediated increase in intracellular IP3 concentrations (mean and SEM shown; $n=6$ ). C. Increase in intracellular TCAP-1 mediated $\mathrm{Ca}^{2+}$ concentrations and inhibition by the IP3 receptor (2-APB) and 
679 phospholipase C (U73122) antagonists; D. Quantification of data shown in C (n=6). E. Uptake in

$680 \mathrm{Ca}^{2+}$-mediated Rhod-2 into mitochondrial membranes. F. Quantification of data shown in E based 681 on the change at 200 seconds. G. Decrease in Rhod-123 immunofluorescence in mitochondrial 682 membranes as a result of TCAP-1 administration. This decrease in Rhod-123 indicates a decrease 683 in mitochondrial membrane depolarization. H. Quantification of the data indicated in G based on 684 the changes at 225 seconds. $(* \mathrm{p}<0.05 ; * * \mathrm{p}<0.01 ; * * * \mathrm{p}<0.001 ; * * * * \mathrm{p}<0.0001$.) in neurons, this is the first study to examine teneurin/TCAP and LPHN activity in skeletal muscle using the siRNA oligonucleotides. The LPHN-1 receptor mRNA was reduced about an $80 \%$ $(p<0.01)$ relative to the WT cells. Transfection with either the LPHN-1 siRNAs or the null vector (NT) did not significantly change mRNA expression relative to the WT control (Fig. 10A). Similarly, the LPHN-3 siRNA-associated oligonucleotides significantly $(\mathrm{p}<0.01)$ decreased its mRNA expression about $65 \%$ relative to the WT cells. There were no significant changes in mRNA expression of the LPHN-1 transcript in either the LPHN-1 KD or the NT cells (Fig. 10B). 1 increased cytosolic $\mathrm{Ca}^{2+}$ in cells transfected with the NT control, however, relative to the NT control, TCAP-1 did not increase $\mathrm{Ca}^{2+}$ in either the LPHN-1 and -3 siRNA-transfected cells, which showed a significant decrease $(\mathrm{p}<0.01$ and $\mathrm{p}<0.001$, respectively $)$ in intracellular $\mathrm{Ca}^{2+}$ 701 concentrations (Fig. 10D,E). However, because both LPHN-1 and -3 siRNA oligonucleotides unexpectedly reduced intracellular $\mathrm{Ca}^{2+}$ concentrations by similar amounts, we repeated this study 
by ablating the LPHN-1 and -3 receptors using CRISPR methods. The E5U7 target reduced LPHN-

1 expression by about $90 \%(\mathrm{p}<0.01)$ whereas, the E5D3 target reduced mRNA levels by about 95\% $(\mathrm{p}<0.05)$ relative to the WT cells (Fig. 11A). A significant decrease $(\mathrm{p}<0.05)$ in LPHN-1

706

707

708

709

710

711

712

713

714

715

716

717

718

719

720

721

722

723

724

725

726

mRNA levels were present in both sets of transgenic cells (Fig. 11B). Importantly, cell morphology

was normal in the transgenic cells (Fig.11C). CRISPR-based KOs of the LPHN-3 gene were unsuccessful after numerous attempts (data not shown; see discussion), hence studies were performed with the LPHN-1 KOs only. Similar to that achieved using the siRNA knock-down cells, both CRISPR-associated KO transgenic cells (E5U and E5D) reduced intracellular $\mathrm{Ca}^{2+}$ levels by about $60 \%(\mathrm{p}<0.001)($ Fig.11 D,E). Taken together, both the siRNA- and CRISPRassociated methods to reduce mRNA expression indicate that the TCAP-1 associated intracellular $\mathrm{Ca}^{2+}$ flux was mediated primarily by its interactions on LPHN-1 and -3 .

Figure 10: siRNA knockdown of LPHN-1 and -3 in C2C12 cells. A. Cells transfected with the LPHN-1-targetting siRNAs showed a significant reduction $(\mathrm{p}<0.01)$ in LPHN-1 mRNA expression. B. Cells transfected with the LPHN-3 targetting mRNA significantly $(p<0.01)$ reduced LPHN-3 mRNA expression. C. Cells treated with either siRNAs showed normal morphology. D. Changes in $\mathrm{Ca}^{2+}$ accumulation in cells transfected with either LPHN-1 or -3 siRNA oligonucleotides. E. Quantification of the data shown in 'D' at 200 seconds.

Figure 11: .CRISPR-based knockouts of the LPHN-1 and -3 genes in $\mathrm{C2C12}$ cells. The two clones (E5U7) (A) and (E5D3) (B) significantly reduced LPHN-1 expression relative to NT and WT cells. C. The morphology of the $\mathrm{C} 2 \mathrm{C} 12$ cells were normal in both transfected cell lines. D. Changes in cytosolic $\mathrm{Ca}^{2+}$ accumulation in the various cell types. E. Quantification of the data shown in 'D' after 200 seconds. F, G, H,I. Changes in NADH production as determined by the resasurin assay . J. Quantification of the data shown in F-I, K. Reduction in PGA-1 $\alpha$ mRNA 
727

728

729

730

731

732

733

734

735

736

737

738

739

740

741

742

743

744

745

746

747

748

expression by PCR in E5U7 and E5D3 clones. * $\mathrm{p}<0.05 ;{ }^{*} \mathrm{p}<0.01 ;{ }^{* *} \mathrm{p}<0.001 ;{ }^{* * *} \mathrm{p}<0.0001$. Mean \pm SEM indicated $\mathrm{n}=7-8$.

To corroborate these findings with the previous observations that TCAP-1 could regulate energy metabolism in skeletal muscle cells, the action of TCAP-1 on NADH production via a resazurin assay was performed on the CRISPR LPHN KO cells (Fig 11F-I). From 30-150m, the TCAP-1treated WT $\mathrm{C} 2 \mathrm{C} 12$ cells showed a significant increase ( $<0.01 ; \mathrm{p}<0.05$, respectively) in fluorescence compared to the vehicle (Fig. 11F). LPHN-1 E5U7 (Fig. 11G) and E5D3 (Fig.11H). KOs did not show an increase after TCAP-1 treatment, whereas the NT control cells showed a significant $(\mathrm{p}<0.01$ increase after $120 \mathrm{~m}$ (Fig. 11I). FCCP treatment, indicating cell viability induced significant increases ( $<<0.001 ; \mathrm{p}<0.0001)$ across all cell types (Fig. $11 \mathrm{~F}, \mathrm{G}, \mathrm{H}, \mathrm{I})$.

Given that the in vivo studies showed that TCAP-1 can modulate MHCI and that TCAP-1 may also affect other hormones and signalling factors, it was unclear if the purported fibre changes observed in TA muscle was a direct result of TCAP-1. Therefore, because PGC- $1 \alpha$ is a transcription factor that up-regulates MHCI expression [46], the TCAP-1 actions on PGC-1 $\alpha$ was measured by qRT-PCR. Following the TCAP-1 treatment (100nM), neither the E5U7 nor the E5D3 cells showed any significant increases, whereas, both the WT cells and NT controls showed about a $50 \%$ increase $(\mathrm{p}<0.05)$ in PGC-1 $\alpha$ expression (Fig. 11K). This indicated that TCAP-1 has the potential to directly influence MCH fibre expression at the transcriptional level. 


\section{Discussion}

750

751

752

753

754

755

756

757

758

759

760

761

762

763

764

765

766

767

768

769

770

771

This study describes a novel mechanism underlying skeletal muscle physiology. This investigation is the first to show a functional relationship between teneurins and latrophilins (LPHN) with respect to skeletal muscle function in mammals using rodent models. We have previously established that there is a functional peptide on the distal tip of the teneurin extracellular region which we have termed 'teneurin C-terminal associated peptide' (TCAP) and is highly active in the CNS. Now, our data indicates that TCAP-1 affects skeletal muscle strength and fatigue, in vivo, via a glucose-associated and, likely, an aerobic mitochondrial-based mechanism. This mechanism is consistent with our previous findings in neurons and the CNS. Moreover, TCAP-1 interacts with the putative teneurin receptors, LPHN-1 and -3 to activate the PLC-IP3-DAG pathway to regulate intracellular $\mathrm{Ca}^{2+}$ flux that ultimately regulates glucose importation and mitochondrial activity. The hypotheses developed from the in vivo studies were subsequently tested in vitro utilizing the rat skeletal cell line, $\mathrm{C} 2 \mathrm{C} 12$, to establish a cellular model upon which to base the in vivo actions of TCAP-1 with respect to skeletal muscle dynamics.

A critical aspect of this study was the utilization of TCAP-1 as a peptide analogue of the distal Cterminal region of teneurins. The genomic structure of the TCAP region of teneurins indicated that it possessed a potentially cleavable peptide $[22,24]$. A synthetic version of TCAP-1 was developed by replacing the $\mathrm{N}$-terminal glutamine with pyroglutamyl acid and amidating the $\mathrm{C}$-terminal residue [24]. The resultant synthetic peptide was highly efficacious at regulating neural function, behaviour and reproductive physiology in rodents [24,31,33,36-38] indicating that TCAP-1, itself, possessed independent biological functions. Thus, rat/mouse TCAP-1 was utilized in this study based on our previous work with this peptide. As indicated in Fig.1, the primary structure of rat and mouse TCAP-1 is identical, and consequently, the same peptide was utilized for all in vivo 
772 and in vitro experiments. However, it is important to point out that, although there are four

773 paralogous forms of teneurins and TCAP in vertebrates, albiet, with significant primary structure

774 conservation among them, our study has utilized only TCAP-1. TCAP-1 was utilized, therefore,

775 as a proxy for all TCAPs present in the organism or tissue, to determine the potential to regulate

776 skeletal muscle function. Based on our previous studies of this peptide and its level of primary

777 structure conservation, evidence indicates that our supposition is valid.

778

779

780

781

782

783

784

785

786

787

788

789

790

791

792

793

794

Elucidation of the teneurin/TCAP-LPHN network is complex. To date, there are 4 teneurins found in vertebrates, each of which possesses a TCAP at its extracellular tip [4,17,18,23,24,26]. Moreover, the 3 latrophilin paralogues (LPHN1-3) have been identified in the vertebrate genome $[29,47,48]$. A clear stoichiometry among teneurins and the LPHNs has been only partially resolved. Both ligand and receptor proteins possess multiple domains that interact with a variety of peripheral ligands in the extracellular matrix, the membrane and intracellularly as well $[10,13,14,21,22]$. TCAP, as an amphiphilic peptide, that may be cleaved [14,22], or expressed separately $[33,34]$ is a 'wild-card' in this perplexity of molecular interactions. Although TCAP is clearly bioactive with respect to cytoskeletal reorganization [32,33,37,38], glucose regulation $[3,39]$, signal transduction [24,38,39,49], metabolism [24,32,34,39] and stress-associated behaviour [36, 50-54], these studies have focused at the neurological level. Despite this emphasis, few studies [55] regarding the role of teneurins/TCAP and LPHN on skeletal muscle physiology have been reported.

Our goal in examining the role of TCAP-1 and LPHN-1 and -3 was not intended to establish a specific molecular interaction, per se, but rather to show that the teneurin/TCAP-LPHN system plays an important role in skeletal muscle metabolism. Consequently, our investigation that paralogues of teneurins, TCAPs and LPHNs were present both in hind-limb skeletal muscle 
preparations and in $\mathrm{C} 2 \mathrm{C} 12$ cells provided the basis of this molecular system with respect to skeletal muscle physiology. Because TCAP-1 co-localization to cell membranes was associated with the dystroglycan (DG) complex [38], we used DG antibodies to delineate the sarcolemma. In this study, the interaction of the teneurin-3 and LPHN-1 in the TA muscle occurred at specific nodes in the sarcolemma rather than being spread throughout all regions of DG labelling (see Fig. 3B). Our data indicates that teneurin-3 is the dominant teneurin in skeletal muscle tissue. However, the antisera available for the teneurins limited us to visualize histochemically only teneurin-3-like epitopes, although PCR expression indicated that the teneurin-3 transcript was expressed. All 4 TCAPs were expressed by PCR although TCAP-3 showed low expression. In contrast, expression of these transcripts in $\mathrm{C} 2 \mathrm{C} 12$ cells indicated high expression of teneurin-3 along with all 4 TCAPs (see Fig. 6A,B). This is the first time we have observed high TCAP expression without the corresponding teneurin expression using PCR (Lovejoy, unpublished observations), although we have only focused on neurons previously. We acknowledge that it can be difficult to reconcile the expression patterns of teneurins using the antibodies available at the time, however, it is important that both elements are present. These data may indicate a fundamental difference among teneurin and TCAP expression in skeletal cells relative to neurons.

Our data indicated that TCAP-1, like in neurons [39], regulates glucose-mediated aerobic-based energy metabolism in skeletal muscle. Several observations support this hypothesis. First, in vivo, ir-LHPN primarily labeled small and intermediate muscle fibres in the rat TCA muscle (see Fig. 3C,D), that are typically associated with aerobic action. Second, with respect to MHC proteins, TCAP-1 showed the greatest increase in MCHI expression in both short-term and long-term TCAP-1 treatment of rats. Muscle kinetics are dependent, in part, on the relative proportion of muscle fibers types. Although the TA muscle consists of 95\% type-II muscle (fast-twitch 
818 glycolytic muscle fiber type), TCAP-1 imparts traits of type-I fibers (slow-twitch and oxidative)

819 which possess greater MHC expression. Importantly, both short-term $(\mathrm{p}<0.01)$ and long-term

820 TCAP-1 $(\mathrm{p}<0.01)$ administration (Fig.3 E,F) increased in the MCHI fibre expression, although in

821 short-term TCAP-1- treated animals, MHCII expression was specifically decreased in MHCIIa,

$822(\mathrm{p}<0.05)$; MHCIIx $(\mathrm{p}<0.01)$ and MHCIIb $(\mathrm{p}<0.05)$ mRNA expression, where only MHCIIB

823 showed a decrease $(\mathrm{p}<0.01)$ in the long-term treated rats. These expressional changes of MHC

824 transcription were corroborated by the expression of PGC-1 $\alpha$, a critical transcriptional co-factor

825 that regulates the mitochondrial actions of myosin chain transcription. Using the $\mathrm{C} 2 \mathrm{C} 12$ cells as a

826 model, TCAP-1 increased the transcription of PGC-1 $\alpha$ and was inhibited $(\mathrm{p}<0.05)$ by CRISPR-

827 mediated KOs of the LPHN-1 gene. Thus the TCAP-1-mediated $\mathrm{Ca}^{2+}$ surge may activate CaMKIV

828 and $\mathrm{CaN}$ transcriptional regulators to promote the transcription of PGC-1 $\alpha$. Overall, this indicates

829 that TCAP-1 is increasing slow-twitch gene expression, consistent with the in vivo contractile

830 kinetics observed in Fig 5. Third, rats treated with TCAP-1 enhanced baseline contractile kinetics

831 under basal and fatigue conditions using both short- and long-term TCAP-1 administration. Fourth,

832 a single dose of TCAP-1 increased uptake of ${ }^{18} \mathrm{~F}-2$-deoxyglucose in rat hind-limb regions as

833 determined by fPET analysis. Fifth, because $\mathrm{Ca}^{2+}$ and ATP are required for proper muscle

834 contraction initiation and relaxation, TCAP-1 significantly increased GLUT4 expression (Fig.8A),

835 increased ${ }^{3} \mathrm{H}-2$-deoxyglucose uptake (Fig. 8D), ATP (Fig. 8E) and NADH (Fig. 8F) concentrations

836 and increased the protein expression of SDH in the TCA cycle (Fig. 8G,H) using the C2C12

837 myoblasts and myotubules. Taken together, these studies support the hypothesis that TCAP-1

838 regulates glucose uptake and metabolism in skeletal muscle cells in a similar manner previously

839 described in neurons [39]. 
840 Glucose is the main energy nutrient for skeletal muscle function, thus, up-regulation of glucose metabolism could impact skeletal muscle activity. Therefore, the influence of TCAP-1 on these contractile kinetic parameters indicates that TCAP-1 modulates $\mathrm{Ca}^{2+}$ levels to enhance SRsarcomere coupling. During fatigue, cytosolic $\mathrm{Ca}^{2+}$ levels accumulate due to inefficient SRsarcomere coupling, thereby reducing muscle function as was observed in contractile kinetic parameters such as peak twitch force and 1/2RT. TCAP-1 treatment significantly increased both parameters, indicating a clear role in $\mathrm{Ca}^{2+}$ modulation. Moreover, these results also suggest that TCAP-1 increases ATP production rate to meet the energetic demands of the muscle during fatigue. After the contraction, $\mathrm{Ca}^{2+}$ is cleared from the cytosol and re-uptaken into the SR via the associated $\mathrm{Ca}^{2+}$-ATPase (SERCA) pumps. SERCA pumps are high energy-consuming channels that account for $20-50 \%$ of the energy turnover in a single contraction cycle $[43,56]$. Prolonged stimulation results in the rapid depletion of ATP, thus reducing SERCA activity, ultimately leading

852 to the accumulation of cytosolic $\mathrm{Ca}^{2+}$. However, because TCAP-1 increases glucose uptake into 853 the muscle, it provides additional substrates for energy metabolism which could maintain SERCA 854 activity during fatigue. This is corroborated by the finding that TCAP-1 had significantly faster 1/2RT during fatigue compared to vehicle treatment and by the increase in the type-1 muscle fiber associated gene transcription that occurred in both short-term and long-term actions of TCAP-1.

857 From these studies, it is clear that TCAP-1 targets the mitochondria as it has potent actions upon $858 \mathrm{Ca}^{2+}$ modulation and glucose signaling. As TCAP-1 increases $\mathrm{Ca}^{2+}$ uptake into the mitochondria, 859 likely from shuttling $\mathrm{Ca}^{2+}$ from the $\mathrm{SR}$, this stimulates enzymes in the TCA cycle, specifically 860 glycerol phosphate dehydrogenase, pyruvate dehydrogenase phosphatase, isocitrate 861 dehydrogenase and oxoglutarate dehydrogenase [57,58]. This activates mitochondrial respiration 862 via the ETC and leads to increased energetic output, as seen by increases in ATP, NADH and 
863 SDH. Thus, this may explain enhanced metabolism and function results under TCAP-1 treatment.

864 Previous studies in neurons have established that the IP3-DAG pathway is activated in response

865 to TCAP-1. In this study, we showed that a similar situation occurs in C2C12 cells and, likely, in

866 skeletal muscle. TCAP-1 treatment of $\mathrm{C} 2 \mathrm{C} 12$ cells increase intracellular $\mathrm{Ca}^{2+}$ flux that can be

867 blocked using IP3 receptor (2-APB) and phospholipase C (U73122) inhibitors. Moreover, this

868 increase in intracellular $\mathrm{Ca}^{2+}$ is likely responsible for the depolarization of the mitochondrial

869 membranes. This work supports a previous report that SR-associated $\mathrm{Ca}^{2+}$ release was directed

870 toward the mitochondria in skeletal muscle [59].

871 These studies are consistent with previous observations in immortalized mouse neurons [39] and

872 in zebrafish [34]. Although these previous studies indicate a relationship with TCAP-1 and LPHN

873 action on $\mathrm{Ca}^{2+}$ flux involving the IP3-DAG pathway $[39,60]$ other studies indicate that the LPHN-

874 mediated AMP-PKA pathway may also be activated by teneurins and TCAP $[61,62]$. For example,

875 TCAP-1 and -3 can increase cAMP levels in immortalized mouse neurons [24,37,49]. Further,

876 studies of vertebrate teneurins have also implicated activation of the PKA-cAMP cascade [31].

877 However, our goal in this study was to establish a mechanism by which TCAP-1 can regulate

878 energy metabolism in $\mathrm{C} 2 \mathrm{C} 12$ cells, and for this reason we have focused on a $\mathrm{Ca}^{2+}$-associated

879 mechanism, as it aligns with previous studies. However, we acknowledge that given the

880 complexity of teneurin-LPHN actions, other signal transduction systems such as ERK-MEK [38]

881 are also likely required for the full set of teneurin- and TCAP-mediated LPHN actions on cells.

882 Ancient-evolving peptide-protein systems will likely impinge on more than one intracellular signal

883 cascade events because they evolved before many of the later intracellular signaling transducing

884 pathways [31]. 
885 The mitochondria are ultimately responsible for supplying aerobic-based energy requirements to

886

887

888

889

890

891

892

893

894

895

896

897

898

899

900

901

902

903

904

905

906

907

eukaryotic cells. We have previously shown the relationship of TCAP-1 mediated energy

production and the mitochondria in the mouse neurons [39] and in zebrafish metabolism [34],

however this was the first study to establish the link between the teneurin/TCAP-LPHN system

and mitochondria in skeletal muscle cells. Although we have not studied mitochondria respiration

directly in this study, previously we showed that TCAP-3-treated zebrafish [34] increased both

basal and respiratory reserve capacity. Although total mitochondrial respiration is linked to proton

leak and ATP-linked respiration [63], no TCAP-3-associated actions on the latter could be

detected, but proton leak was increased in these studies.

The role of the teneurins, TCAP and LPHNs, together, has previously not been examined in skeletal muscle. Therefore, we utilized both siRNA- and CRISPR-based methods to determine if the reduced activity of the LPHN-1 and -3 receptors would attenuate TCAP-1-mediated intracellular actions. Both CRISPR-based KOs of LPHN-1 significantly reduced the TCAP-1 associated increase in intracellular $\mathrm{Ca}^{2+}$. We were unsuccessful to create a LPHN-3 KO however. The length of the LPHN-3 gene in mice is about 10 times that of the LPHN-1 gene due to much longer intronic sequences. Thus, this extended sequence may have played a role in the lack of viability of the CRISPR- associated LPHN-3 oligonucleotides. Moreover, TCAP-1-mediated intracellular $\mathrm{Ca}^{2+}$ was established using pharmacological antagonists of the PLC-IP3-IP3R pathway of the SR. This rise in intracellular $\mathrm{Ca}^{2+}$ led to increased cellular glucose, concomitant with increases in ATP and $\mathrm{NADH}$ production. Indeed, the TCAP-1-mediated increase in intracellular $\mathrm{Ca}^{2+}$ corroborated with mitochondrial membrane hyperpolarization and increased succinate dehydrogenase activity indicating that TCAP-1 also acted to increase mitochondrial activity. However, the siRNA oligonucleotides did inhibit the actions of both receptors as 
908

909

910

911

912

913

914

915

916

917

918

indicated by the significant reduction in the TCAP-1-mediated cytosolic $\mathrm{Ca}^{2+}$ response. siRNA KDs of the LPHN-1 and -3 has been successfully used in the past using the mouse pancreatic $\beta$ cell line, MIN6 [64] where the authors showed that LPHN-3 KDs reduced insulin secretion by reducing cAMP levels via a Gi-mediated pathway. Although we have not examined the direct role of TCAP-1 on pancreatic insulin release, this study is consistent with our supposition that TCAP, itself, is associated with glucose regulation in vivo [3,39]. In our current study, however, our experiments showed that ablation of $\mathrm{LPHN}-1$ or -3 reduced TCAP-1-mediated $\mathrm{Ca}^{2+}$ concentrations toward baseline levels. These results surprised us. We expected that the $\mathrm{KO}$ or $\mathrm{KD}$ or either receptor would render only a partial suppression of the $\mathrm{Ca}^{2+}$ response. Because this was not the case, one possibility is that there is an interaction among the LPHN isoforms specifically, or their combined actions with the teneurins.

Teneurin and LPHN interaction is complex where the stoichiometry among the 4 teneurin and 3 LPHN paralogues has not been ascertained. Although studies using vertebrate models establish clear evidence of teneurin-LPHN interaction [14,22,28,31], the specific correspondence of any teneurin with any LPHN as cognitive pairs has yet to be established. The teneurins are multifunctional transmembrane proteins that have TCAP at their distal extracellular tip. Even less is understood regarding the promiscuity of the LPHNs with respect to TCAP interactions. Previously, Silva and his associates [31] showed that the teneurin-2 region possessing the TCAP unit was required for full binding to the LPHN-1 (Lasso), and Husic and her colleagues [32] showed that the transgenic expression of teneurin-1 TCAP co-precipitated with the transgenic over-expressed hormone binding domain (HBD) of LHPN-1 and, moreover, modulated the cell adhesion characteristics of HEK293 cells overexpressed with the LPHN-1 mRNA. In this current study, we established that both LPHN-1 and teneurin-3 transcripts were present and are co- 
931 localized in the sarcolemma (Fig.3). These data corroborate with the PCR expression data 932 indicating that these mRNA transcripts show the highest expression, but are not meant to suggest 933 that this is indicative of cognitive ligand and receptor pairs, per se.

934 There is evidence that LPHN paralogues interact with each other. In our LPHN-1 and -3 935 attenuation studies, the reduction of one receptor inhibited the TCAP-1 mediated Ca ${ }^{2+}$ actions of 936 the other receptor. It is possible that there is a minor $\mathrm{Ca}^{2+}$ response mediated by the non-target 937 LPHN, but too low to detect with our assay conditions, although this seems unlikely. Homo-and 938 heterophilic oligomerization is a characteristic of the GPCRs, but this has not been well-studied in 939 Adhesion GPCR family members $[65,66]$. In LPHN-1, the C-terminal fragment and N-terminal 940 fragment is cleaved in vivo and re-associates with the $\alpha$-latrotoxin $(\alpha \mathrm{LTX})$ mutant ligand LTX $^{\mathrm{N} 4 \mathrm{C}}$ 941 [67], although this phenomenon has not been studied in detail in other LPHN paralogues despite 942 the high degree of conservation among these domains. Further, studies using the 'stachel' peptide 943 have provided additional insight into potential LPHN paralogue interactions with each other $944[64,68,69]$. The stachel peptide represents the N-terminus of the C-terminal fragment following 945 cleavage of the conserved GPCR-autoproteolysis (GAIN) region [70]. The recombinant expressed 946 stachel peptide induces diverse G-protein associations across LPHN paralogues, whereas $\alpha$ LTX 947 favours G11 signalling via LPHN-1 [60,71,72]. We and others have previously shown that the 948 TCAP amino acid sequence resembles that of Secretin GPCR family ligands and $\alpha$ LTX [26], thus 949 we posit that TCAP may represent the endogenous ligand that $\alpha$ LTX co-evolved with to become 950 a toxin.

951 One of the questions we did not address in this study was the trigger that stimulates TCAP to 952 regulate skeletal muscle physiology. Our hypothesis, at this time, is that TCAP is liberated locally 953 in the sarcolemma either by a direct cleavage of the teneurin $[14,22,23]$ or by independent mRNA 
transcription, translation and release from skeletal muscle or other local tissues $[33,34]$. We have

955 shown in the past that TCAP-1 can increase teneurin transcription in immortalized neurons [24],

956 but we have yet to establish this in vivo. Although TCAP is highly expressed in the brain, our

957 studies showing its presence in as a circulating hormone in serum has been equivocal (Lovejoy, 958 unpublished observations). As this is a critical aspect of TCAP action, this is a goal for upcoming 959 studies.

960

961

962

963

964

965

966

967

968

969

970

971

972

973

974

975

976

In summary, our data in this study indicate that TCAP-1 regulates energy metabolism in skeletal muscle via an insulin-independent mechanism, and by doing so, modulates contractile kinetics, via $\mathrm{Ca}^{2+}$ dynamics and ATP production. Together, these data describe a previously unknown mechanism to regulate skeletal muscle dynamics. These data provide the foundation for a proposed mechanism of TCAP-1 action in skeletal muscle. TCAP-1 interacts with LPHN-1 and -3 to stimulate the activation of G-protein-coupled PLC leading to the increased conversion of PIP3 into IP3 and DAG. Increased IP3 levels stimulates the IP3R on the SR, opening $\mathrm{Ca}^{2+}$ channels to increase cytosolic $\mathrm{Ca}^{2+}$ levels. Cytosolic $\mathrm{Ca}^{2+}$ is imported into the mitochondria likely via the $\mathrm{Ca}^{2+}$ uniporter (MCU) which stimulates the TCA cycle and electron transport chain (ETC). Enhanced ETC activity results in increased proton extrusion from the mitochondrial matrix and hyperpolarization of mitochondrial membrane potential. This ultimately results in increased ATP and NADH production, as well as increased SDH-ATP levels. $\mathrm{Ca}^{2+}$ is subsequently pumped out of the mitochondria likely via $\mathrm{Na}^{+} / \mathrm{Ca}^{2+}$ exchangers (NCX), thus restoring homeostatic levels of $\mathrm{Ca}^{2+}$. Moreover, we showed that the TCAP-1 increased cellular energy availability by increased glucose importation into cells likely due to increased GLUT4 expression. The TCAP-1 mediated mechanism is likely due to its interactions with LPHNs -1 and -3 . 


\section{Acknowledgments}

978 We thank the Canadian Natural Sciences and Engineering Research Council (NSERC) for

979 Discovery Grants to Profs. D.A. Lovejoy, M. Locke and L. Buck and for NSERC Post-Graduate

980 Scholarships to Dr. Andrea Reid, Yani Chen, Mei Xu and Mia Husic and an Ontario Graduate

981 Scholarship to Thomas Dodsworth. We also thank Protagenic Therapeutics Inc. for operational

982 funding to Prof. D.A. Lovejoy

\section{Author Contributions:}

Dr. Andrea Reid performed most of the experiments in this study, and wrote the initial draft of this 


\section{References}

1. Ni T, Yue J, Sun G, Zou Y, Wen J, Huang J. Ancient gene transfer from algae to animals: mechanisms and evolutionary significance. BMC Mol Biol 2012; 12: 83. Microbiol. 2012; 2: 1-11.

3. Lovejoy DA, Hogg DW. Information processing in affective disorders: Did an ancient peptide 2000039: 1-8. protozoan gene transfer in early metazoans and protists: Evolution of the teneurin C-terminal associated peptides. Gen Comp Endocrinol 2013; 188: 144-150.

1011 predates animal origins. Science 2003; 301: 361-363. choanoflagellate Monosiga brevicollis and the origin of metazoans. Nature 2008; 451: 783-788.

1015 Change and continuity. Mol Cell Endocrinol. 2011; 331: 170-178.

1016 8. Tucker RP. Horizontal gene transfer in choanoflagellates. J Exp Zool B Mol Dev Evol 2013; 1017 320: 1-9.

1018 9. Zhang D, de Souza RF, Anantharaman V, Iyer LM, Aravind L. Polymorphic toxin systems: comprehensive characterization of trafficking modes, mechanism of action, immunity and ecology using comparative genomics. Biol Direct. 2012; 7:18. 
1021 10. Baumgartner S, Martin D, Hagios C, Chiquet-Ehrismann R. Ten-m, a Drosophilia gene related 1022 to tenascin is a new pair-rule gene. EMBO J. 1994; 13: 3728-3740.

1023 11. Hong W, Mosca TJ, Luo L. Teneurins instruct synaptic partner matching in an olfactory map. 1024 Nature 2012; 484: 201-207.

1025 12. Kenzelmann D, Chiquet-Ehrismann R, Leachman NT, Tucker RP. Teneurin-1 is expressed in 1026 interconnected regions of the developing brain and is processed in vivo. BMC Dev Biol. 2008; 8: 102730.

1028 13. Levine A, Bashan-Ahrend A, Budai-Hadrian O, Gartenber D, Menasherow S, Wides R. Odd 1029 Oz: a novel Drosophila pair-rule gene. Cell 1994; 77: 587-598.

1030 14. Li J, Shalev-Benami M, Sando R, Jiang X, Kibrom A, Wang J. et al. Structural basis for 1031 teneurin function in circuit-wiring: a toxin motif at the synapse. Cell 2018; 173: 735-748.

1032 15. Mosca TJ, Hong W, Dani VS, Favaloro V, Luo L. Trans-synaptic Teneurin signalling in 1033 neuromuscular synapse organization and target choice. Nature 2012; 484: 237-241.

1034 16. Rubin BP, Tucker RP, Martin D, Chiquet-Ehrismann, R. Teneurins: a novel family of neuronal 1035 cell surface proteins invertebrates, homologous to the Drosophila pair-rule gene product Ten-m. 1036 Dev Biol 1999; 216: 195-209.

1037 17. Tucker RP, Chiquet-Ehrismann R. Teneurins: a conserved family of transmembrane proteins 1038 involved in intercellular signalling during development. Dev Biol 2006; 290: 237-245.

1039 18. Young TR, Leamey CA. Teneurins: important regulators of neural circuitry. Int J Biochem 1040 Cell Biol 2009; 41: 990-993.

1041 19. Minet AD, Chiquet-Ehrismann R. Phylogenetic analysis of teneurin genes and comparison to 1042 the rearrangement hotspot elements of E. coli. Gene 2000; 257: 87-97. 
1043

1044

1045

1046

1047

1048

1049

1050

1051

1052

1053

1054

1055

1056

1057

1058

1059

1060

1061

1062

1063

1064

1065

20. Minet AD, Rubin BP, Tucker RP, Baumgartner S. Chiquet-Ehrismann R. Teneurin-1, a vertebrate homologue of the Drosophila pair-rule gene ten-m, is a neuronal protein with a novel type of heparin-binding domain. J Cell Sci 1999; 112: 2019-2032.

21. Oohashi T, Zhou XH, Feng K, Richter B, Mörgelin M, Perez MT, et al. Mouse ten-m/Odz is

a new family of dimeric type II transmembrane proteins expressed in many tissues. Cell Biol 1999; 145: 563-577.

22. Jackson VA, Meijer DH, Carrasquero M, van Bezouwen LS, Lowe ED, Kleanthous C, et al.

Structures of Teneurin adhesion receptors reveal an ancient fold for cell-cell interaction. Nat

Commun 2018; 9:1079.

23. Lovejoy DA, Al Chawaf A, Cadinouche A. Teneurin C-terminal associated peptides: An enigmatic family of neuropeptides with structural similarity to the corticotrophin releasing factor and calcitonin family of peptides. Gen Comp Endocrinol 2006; 148: 299-305.

24. Wang L, Rotzinger S, Barsyte-Lovejoy D, Qian X, Elias CF, Bittencourt JC et al. Teneurin proteins possess a carboxy terminal corticotropin-releasing factor-like sequence that modulates emotionality and neuronal growth. Mol Brain Res 2005; 133: 253-265.

25. Aravind L, Anantharaman V, Zhang D, de Sousa RF, Iyer LM. Gene flow and biological conflict systems in the evolution of eukaryotes. Front Cell Infect Microbiol 2012; 2: 89.

26. Michalec OM, Chang B, Lovejoy N, Lovejoy DA. Corticotropin-releasing factor (CRF) and its relationship to an ancient peptide family. Front Endocrinol 2020; 11: 529.

27. Sekar R, Chow BKC. Role of the secretin peptide family and their receptors in the hypothalamic control of energy homeostasis. Horm Metab Res 2013; 45:945-954.

28. Araç D, Li J. Teneurins and latrophilins: two giants meet at the synapse. Curr Opin Struct Biol 2019; 54: 141-151. 
1066

1067

1068

1069

1070

1071

1072

1073

1074

1075

1076

1077

1078

1079

1080

1081

1082

1083

1084

1085

1086

1087

1088

29. Fredricksson R, Lagerstrom L, Lundin LG, Schioth H. The G protein coupled receptors in the human genome form five main families. Phylogenetic analysis, paralogon groups and fingerprints. Mol. Pharmacol. 2003; 63: 1256-1272.

30. Fredriksson R, Schiöth H, The repertoire of G-protein coupled receptors in fully sequenced genomes. Mol Pharmacol 2005; 67: 1414-1425.

31. Silva JP, Lelianova VG, Ermolyuk YS, Vysokov N, Hitchen PG, Berninghausen O et al. Latrophilin 1 and its endogenous ligand Lasso/teneurin-2 form a high-affinity trans-synaptic receptor pair with signaling capabilities. Proc Natl Acad Sci USA 2011; 108: 12113-12118.

32. Husic M, Barsyte-Lovejoy D, Lovejoy DA. Teneurin C-terminal associated peptide (TCAP)1 and latrophilin interaction in HEK293 cells: Evidence for modulation for intercellular adhesion. Front. Endocrinol. 2019; 10: 22.

33. Chand D, Casatti CA, DeLannoy L, Song L, Kollara A, Barsyte-Lovejoy D, et al. C-terminal processing of the teneurin proteins: Independent actions of a teneurin C-terminal associated peptide in hippocampal cells. Mol Cell Neurosci. 2013; 52: 38-50.

34. Reid RM, Reid AL, Lovejoy DA, Biga PR. Teneurin C-terminal associated peptide (TCAP)-3 increases metabolic activity in zebrafish. Front Mar Sci. 2021; 7: 591160.

35. Tan L, Xu K, Vaccarino F, Lovejoy DA, Rotzinger S. Repeated intracerebral teneurin Cterminal associated peptide (TCAP)-1 injections produce enduring changes in behavioral responses to corticotropin-releasing factor (CRF) in rat models of anxiety. Behav Brain Res 2008; $188,195-200$.

36. Tan LA, Al Chawaf A, Vaccarino FJ, Boutros JC, Lovejoy DA. Teneurin C-terminal associated peptide (TCAP)-1 increases dendritic spine density in hippocampal neurons and decreases anxiety-like behaviors in rats. Physiol Behav 2011; 104: 199-204. 
37. Al Chawaf A, St. Amant K, Belsham DD, Lovejoy DA. Regulation of neurite outgrowth in immortalized hypothalamic cells and hippocampal primary cultures by teneurin C-terminal associate peptide-1 (TCAP-1). Neuroscience 2007; 144: 1241-1254.

38. Chand D, Song L, De Lannoy L, Barsyte-Lovejoy D, Ackloo S, Boutros PC et al. C-terminal region of teneurin-1 co-localizes with dystroglycan and modulates cytoskeletal organization through an ERK-dependent stathmin- and filamin A-mediated mechanism in hippocampal cells. Neuroscience 2012; 219: 255-270.

39. Hogg DW, Chen Y, D’Aquila AL, Xu M, Husic M, Tan LA et al. A novel role of the corticotropin-releasing hormone $(\mathrm{CRH})$ regulating peptide, teneurin $\mathrm{C}$-terminal associated peptide (TCAP)-1 on glucose uptake into the brain. J Neuroendocrinol 2018; 30: e12579.

40. Richter EA, Hargraves M. GLUT4 and skeletal muscle glucose uptake. Physiol Rev 2013; 93: 993-1017.

41. Santos JM, Ribeiro SB, Gaya AR, Appell HJ, Duarte JA. Skeletal muscle pathways of contraction-enhanced glucose uptake. Int J Sports Med 2008; 29: 785-794.

42. Sayer AA, Dennison EM, Syddall HE, Gilbody HJ, Philips DIW, Cooper C. Type 2 diabetes, muscle strength, and impaired physical function: the tip of the iceberg? Diabetes Care 2005; 28: $2541-2542$.

43. Holwerda AM, Locke M. Hsp25 and Hsp72 content in rat skeletal muscle following controlled shortening and lengthening contractions. Appl Physiol Nutr Met 2014; 39: 1380-1387.

44. Maher F. Immunocolocalization of GLUT1 and GLUT3 glucose transporters in primary culture neurons and glial. J Neurosci Res 1995; 42: 459-469.

45. Uemura E, Greenlee HW. Insulin regulates neuronal glucose uptake by promoting translocation of glucose transporter GLUT3. Exp Neurol 2006; 198: 48-53. 
1112 46. Liang H, Ward WF. PGC-1 $\alpha$ : a key regulator of energy metabolism. Adv Physiol Educ 2006; $1113 \quad 30: 154-151$.

1114 47. Davletov BA, Shamotienko OG, Lelianova VG, Grishin V, Ushkaryov YA. Isolation and 1115 biochemical characterization of a calcium-independent alpha-latrotoxin-binding protein. J Biol 1116 Chem 1996; 1271: 23239-23245.

1117 48. Silva J-P, Ushkaryov YA. The latrophilins, “split-personality” receptors. Adv Exp Med Biol 1118 2010; 706: 59-75.

1119 49. Qian X, Barsyte-Lovejoy D, Chewpoy RB, Wang L, Gautam N, Wang N et al. Characterization 1120 of teneurin C-terminal associated peptide (TCAP)-3 from rainbow trout hypothalamus. Gen Comp 1121 Endocrinol 2004; 137: 205-216.

1122 50. Al Chawaf A, Xu K, Tan L, Vaccarino F, Lovejoy DA, Rotzinger S. Corticotropin-releasing 1123 factor behaviours are modulated by intravenous administration of teneurin C-terminal associated 1124 peptides. Peptides 2007; 28: 1406-1415.

1125 51. Erb S, McPhee M, Brown ZJ, Kupferschmidt DA, Song L, Lovejoy DA. Repeated intravenous 1126 administrations of teneurin-C terminal associated peptide (TCAP)-1 attenuates reinstatement of 1127 cocaine seeking by corticotropin-releasing factor (CRF) in rats. Beh Brain Res 2014; 269: 1-5.

1128 52. Kupferschmidt D, Lovejoy DA, Rotzinger S, Erb S. Teneurin C-terminal associated peptide 1129 (TCAP)-1 blocks the effects of corticotropin-releasing factor (CRF) on the reinstatement of 1130 cocaine seeking and expression of cocaine-induced behavioral sensitization. Br J Pharmacol 2011; 1131 163: 574-583.

1132 53. Rotzinger, S, Lovejoy DA, Tan L. Behavioral effects of neuropeptide ligands in rodent models 1133 of depression and anxiety Peptides 2010; 31: 736-756. 
1134 54. Tan LA, Chand D, De Almeida R, Xu M, Colacci M, De Lannoy et al. Modulation of 1135 neuroplastic changes and corticotropin-releasing factor associated behaviour by a phylogenetically 1136 ancient and conserved peptide family. Gen Comp Endocrinol 2012; 176: 309-313.

1137 55. Ishii K, Suzuki N, Mabuchi Y, Ito N, Kikura N, Fukada S-I et al. Muscle satellite cell protein 1138 teneurin-4 regulates differentiation during muscle regeneration. Stem Cells 2015; 33: 3017-3027.

1139 56. Calderón JC, Bolaños P, Caputo C. The excitation-contraction coupling mechanism in 1140 skeletal muscle Biophys Rev 2014; 6:133-160.

1141 57. Denton RM. Regulation of mitochondrial dehydrogenases by calcium ions. Biochim Biophys 1142 Acta 2009; 1787: 1309-1306.

1143 58. Wan B, La Noue KF, Cheung JY, Scaduto RC. Regulation of citric acid cycle by calcium. J 1144 Biol Chem 1989; 264:13430-13439.

1145 59. Dias-Vegas AR, Cardova A, Valladares D, Llanos P, Hildago C, Gharardi G et al. 1146 Mitochondrial calcium increase induced by RyR1 and $\mathrm{IP}_{3} \mathrm{R}$ channel activation after membrane 1147 polarizations regulates skeletal muscle metabolism. Front Physiol 2018; 9: 791

1148 60. Rahman MA, Ashton AC, Meunier F, Davletov BA, Dolly JO, Ushkaryov YA. Norepinephrine 1149 exocytosis stimulated by alpha-latrotoxin requires both external and stored calcium, and is 1150 mediated by latrophilin, G proteins and phospholipase C. Phil Trans R Soc London B 1999; 354: $1151 \quad 379-386$.

1152 61. J Lang, Y Ushkaryov, A Grasso, C B Wollheim. Ca2+-independent insulin exocytosis induced 1153 by alpha-latrotoxin requires latrophilin, a G protein-coupled receptor. EMBO J 1998; 17:648-57.

1154 62. Sando R, Südhof TC. Latrophilin GPCR signaling mediates synapse formation. Elife. $1155 \quad 2021 ; 10: \mathrm{e} 65717$. 
63. Rolfe DF, Brand MD. The physiological significance of mitochondrial proton leak in animal

1157 cells and tissues Biosci Rep 1997; 17: 9-16.

1158 64. Röthe J, Thor R, Winkler J, Knierim AB, Binder C, Huth S, et al. Involvement of the adhesion

1159 GPCRs latrophilin in the regulation of insulin release. Cell Rep 2019; 26: 1537-1584.

1160 65. Meza-Aguilar DG, Boucard AA. Latrophilins updated. Biomol Concepts 2014; 5: 457-478.

1161 66. Milligan G. Ward RJ, Marsango S. 2019 GPCR homo-oligomerization. Curr. Opin. Cell

1162 Biol. 57:40-47

1163 67. Volynski KA, Silva J-P, Lelianova VG, Atiqur Rahman M, Hopkins C, Ushkaryov YA.

1164 Latrophilin fragments behave as independent proteins that associate and signal on binding to

1165 LTX(N4C) EMBO J 2004: 23; 4423-4433.

116668 Müller A, Winkler J, Fiedler F, Sastraihardja T, Binder C, Schnabel R et al. Oriented cell

1167 division I the C. elegans embryo is coordinated by G-protein signaling dependent on the Adhesion

1168 GPCR LAT-1. PLOS Genetics 2015; 11: e1005624.

1169 69. Nazarko O, Kibrom A, Winkler J, Leon K, Stoveken H, Salzman G, et al. A comprehensive

1170 mutagenic screen of the Adhesion GPCR latrophin/ADGRL1. iScience 2015; 3; 264-278.

1171 70. Liebscher I, Schön J, Peterson SC, Fischer L, Auerback N, Demberg LM et al. A tethered

1172 agonist within the ectodomain activates the adhesion G protein-coupled receptors GPR126 and

1173 GPR133. Cell Rep 2014; 9: 2018-2026.

1174 71. Davletov BA, Meunier FA, Ashton AC, Matsushita H, Hirst WD, Lelianova VG, et al. Vesicle

1175 exocytosis stimulated by alpha-latrotoxin is mediated by latrophilin and requires both external and 1176 stored Ca2+. EMBO J 1998;17: 3909-3920.

1177 72. Lelianova VG, Davletov BA, Sterling A, Atiqur Rahman M, Grishin EV Totty NF et al. $\alpha-$ 1178 latrotoxin receptor, latrophilin, is a novel member of the secretin family of G protein-coupled 
bioRxiv preprint doi: https://doi.org/10.1101/2021.10.25.465698; this version posted October 25, 2021. The copyright holder for this preprint (which was not certified by peer review) is the author/funder, who has granted bioRxiv a license to display the preprint in perpetuity. It is made available under aCC-BY 4.0 International license.

1179 receptors. J. Biol. Chem. 1997; 272:21504-21521. 
Figure 1

A

RAT TCAP-1

QQLLGTGRVQGYDGYFVLSVEQYLELSDSANNIHFMRQSEI-NH2

MOUSE TCAP-1

QQLLGTGRVQGYDGYFVLSVEQYLELSDSANN I HFMRQSEI-NH2

RAT TCAP-2

QQLLSTGRVQGYËGYYVLPVEQYPELADSSSNIQFLRQNEMT-NH2

MOUSE TCAP-2

QQLLSTGRVQGYEGYYVLPVEQYPELADSSSNIQFLRQNEM-NH2

RAT TCAP-3

- QLLSAGKVQGYDGYYVLSVEQYPELADSANNIQFLRQSEI-NH2

MOUSE TCAP- 3

- QLLSAGKVQGYDGYYVLSVEQYPELADSANNIQFLRQSEI-NH2

RAT TCAP-4

QQVLNTTGRVQGYDGFFVTSVEQYPELSDSANNI HFMRQSEM-NH2

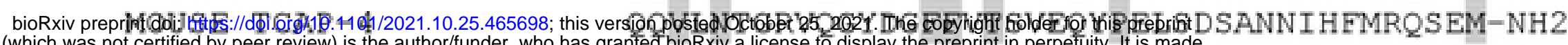
(which was not certified by peer review) is the author/funder, who has granted bioRxiv a license to display the preprint in perpetuity. It is made

B

SYN. MOUSE TCAP-1

PEQLLGTGRVQGYDGYFVLSVEQYLELSDSANNIHFMRQSEI-NH2 SC.MOUSE TCAP-1 PETHSSLELRVSLIGEQQFIGYENQSDQNYGLLAYFDRVGMS-NH2

Figure 1 
B

\section{LPHN-3 gene}

$\mathrm{C}$

Exon count: 23 Target 1 Target 3

focate atand

\begin{tabular}{|l|l|l|l|}
\hline \multicolumn{2}{|c|}{ LPHN-1 } & \multicolumn{2}{c|}{ LPHN-3 } \\
\hline Target 1 & 5'-ACATTGTCAAATATGACCTG-3' & Target 4 & 5'-GAGCGCTCAACGGCTCATCG-3' \\
\hline Target 2 & 5'-TGGAACCTACAAATACCTGG-3' & Target 5 & 5'-CACGATGCTTTTAGCACCTG-3' \\
\hline Target 3 & 5'-CGTGGACTATGCCTTCAACA-3' & Target 6 & 5'-TCGAGAGCGCCAACTACGGG-3' \\
\hline
\end{tabular}


A
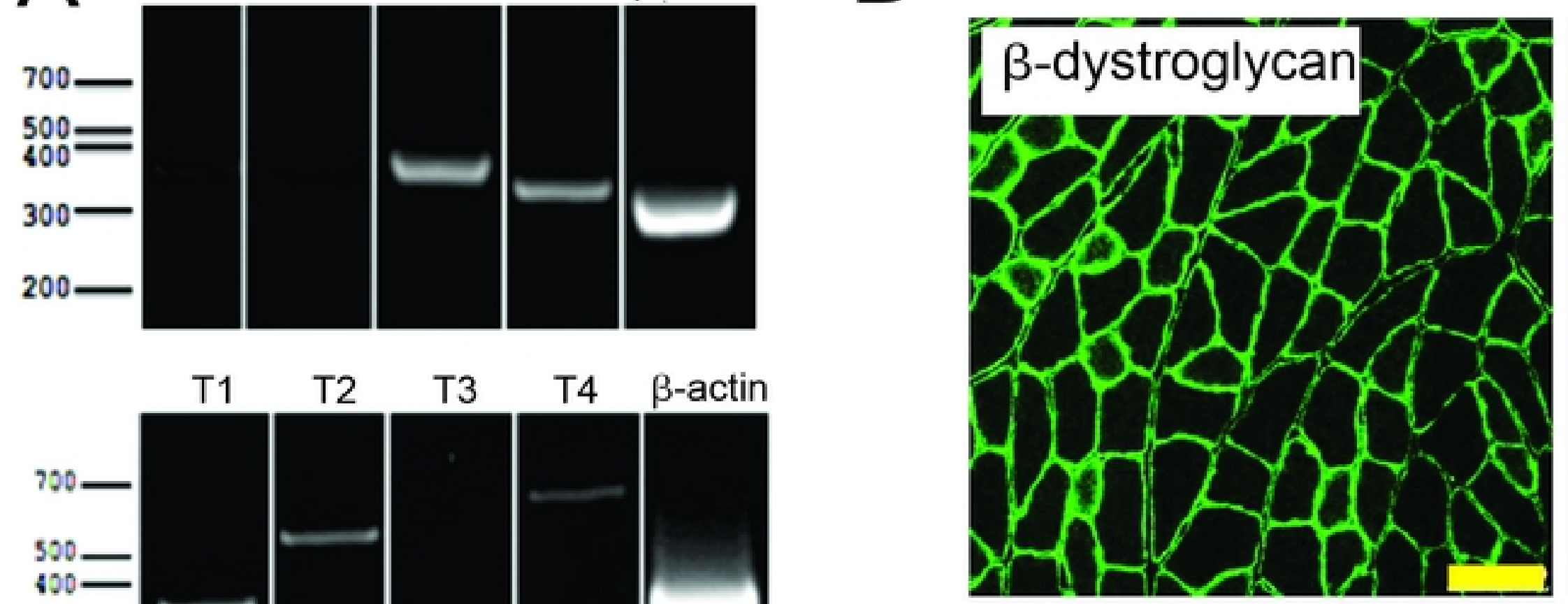

Teneurin-3
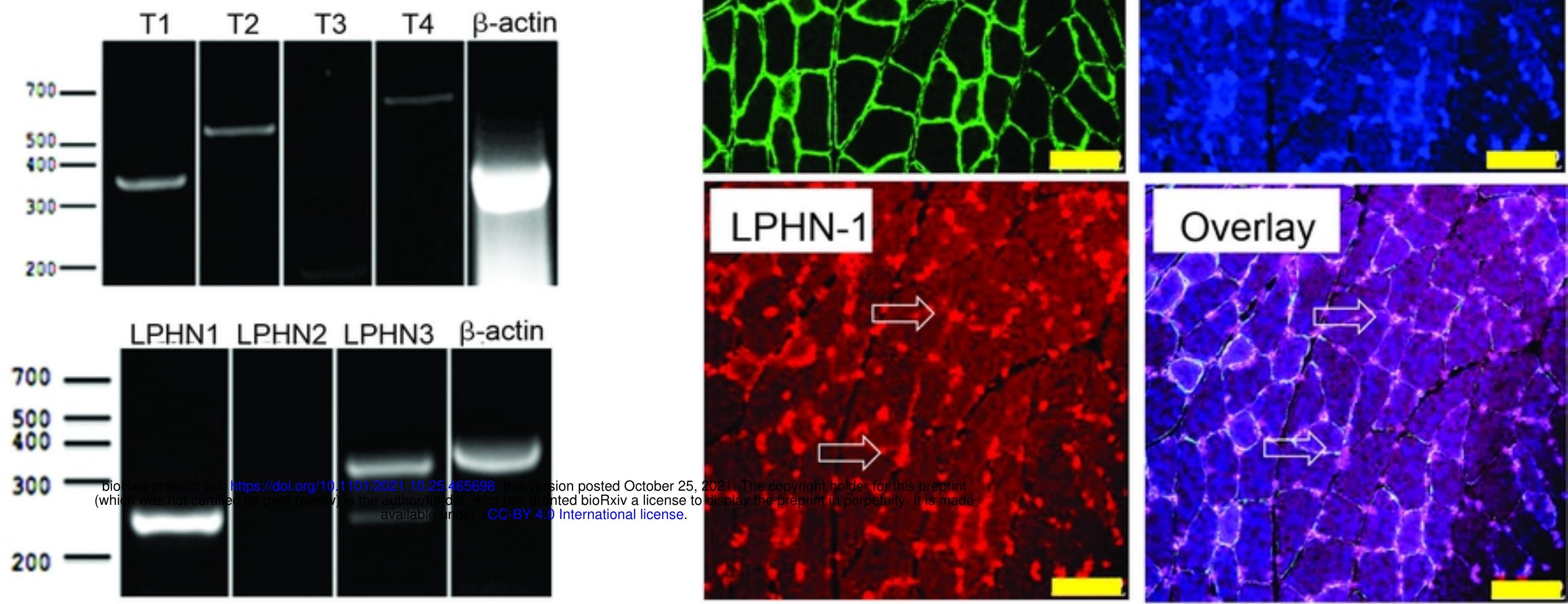

C
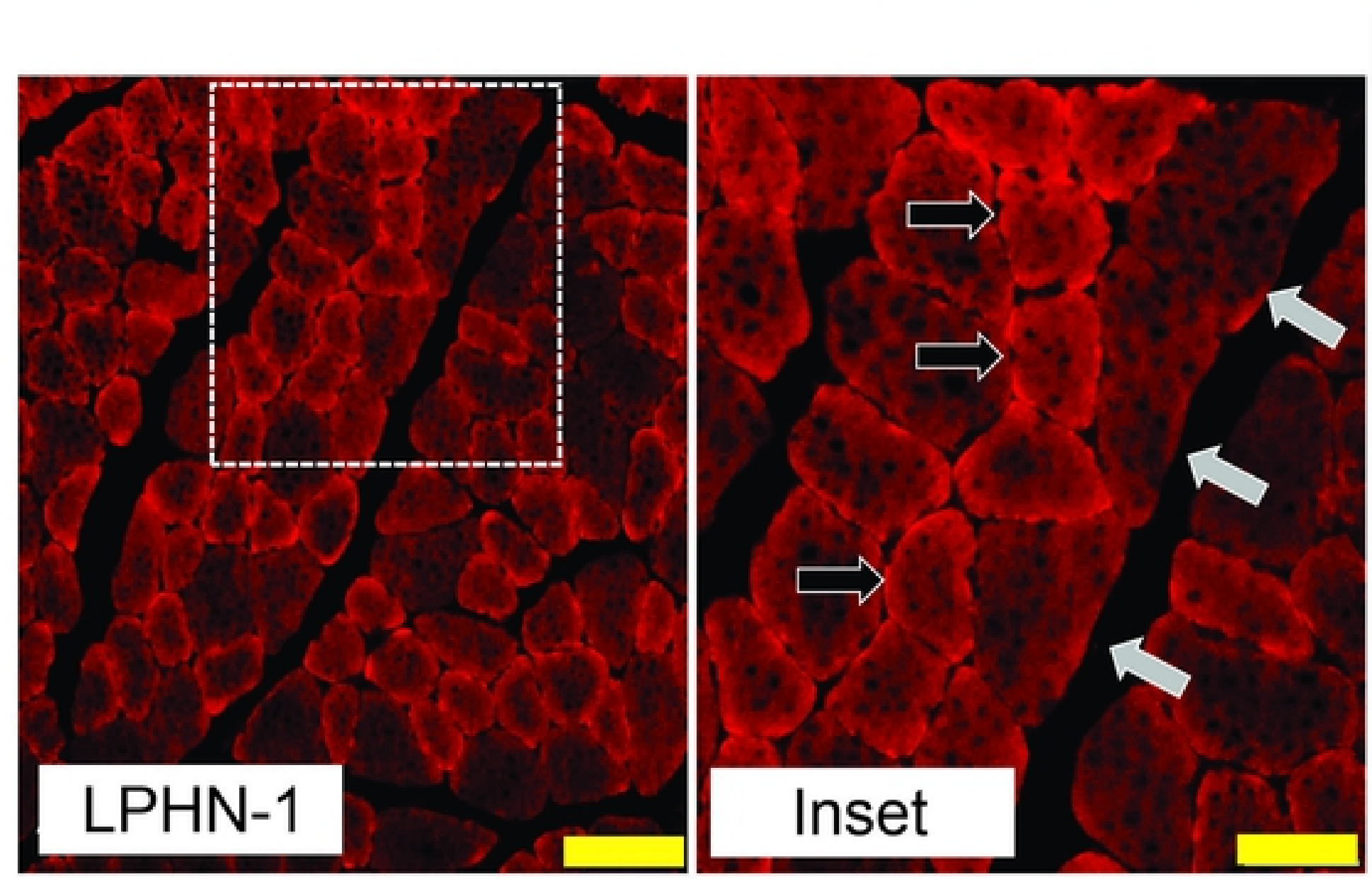

D

Small/Moderate Cells

Large Cells

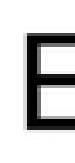

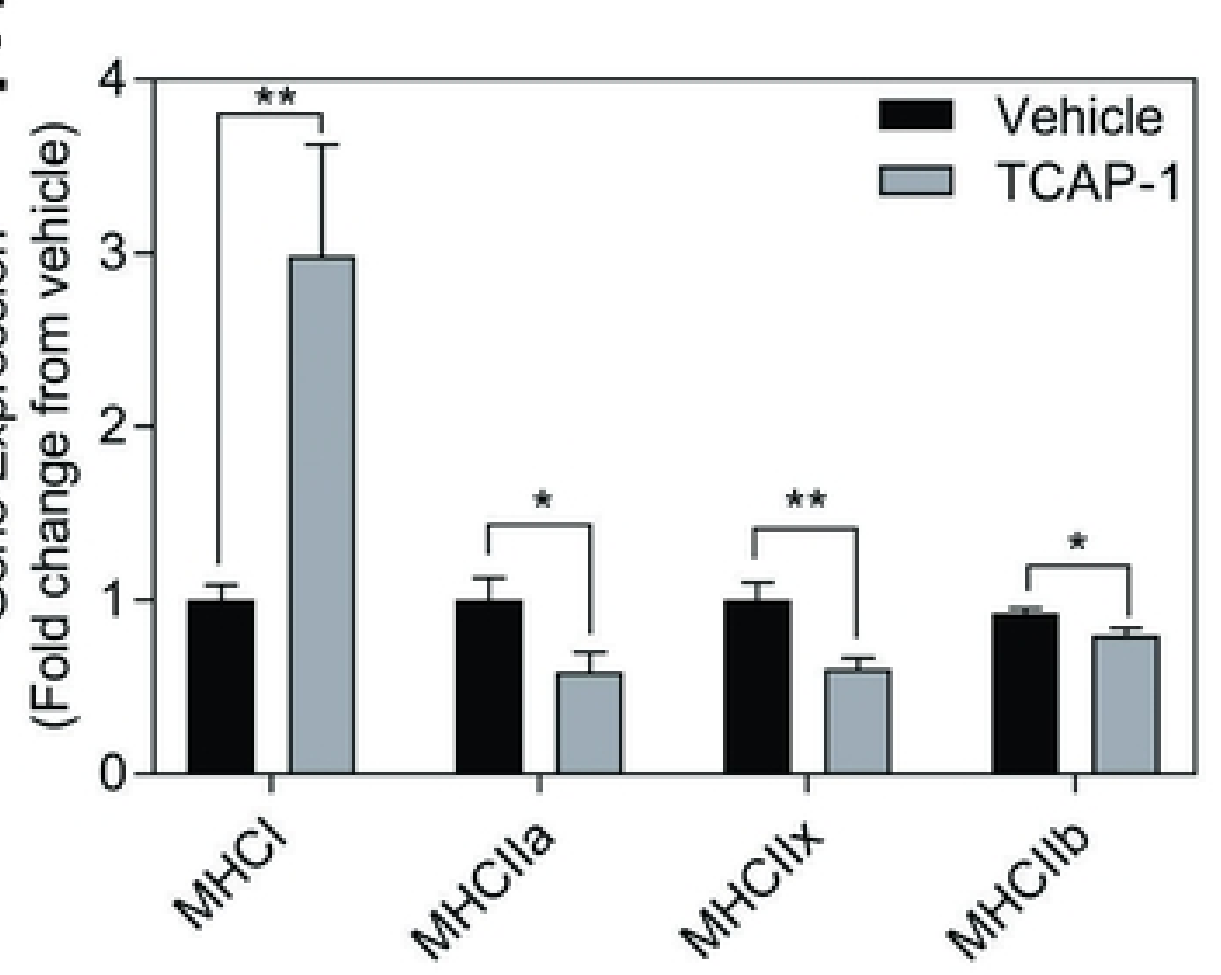

\section{$\mathrm{F}$}

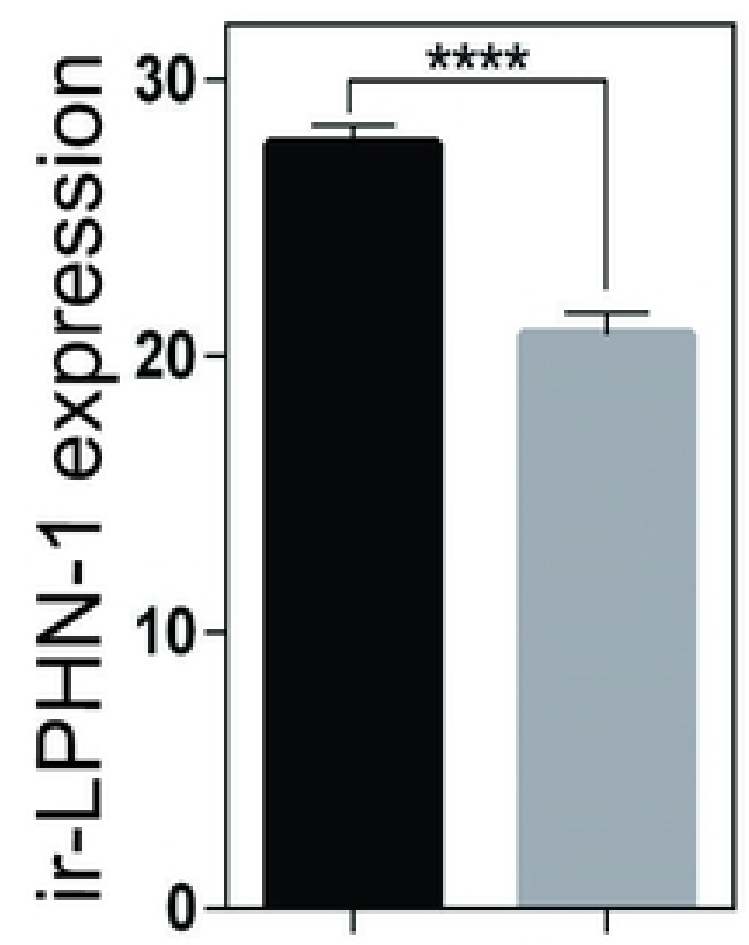

Figure 3

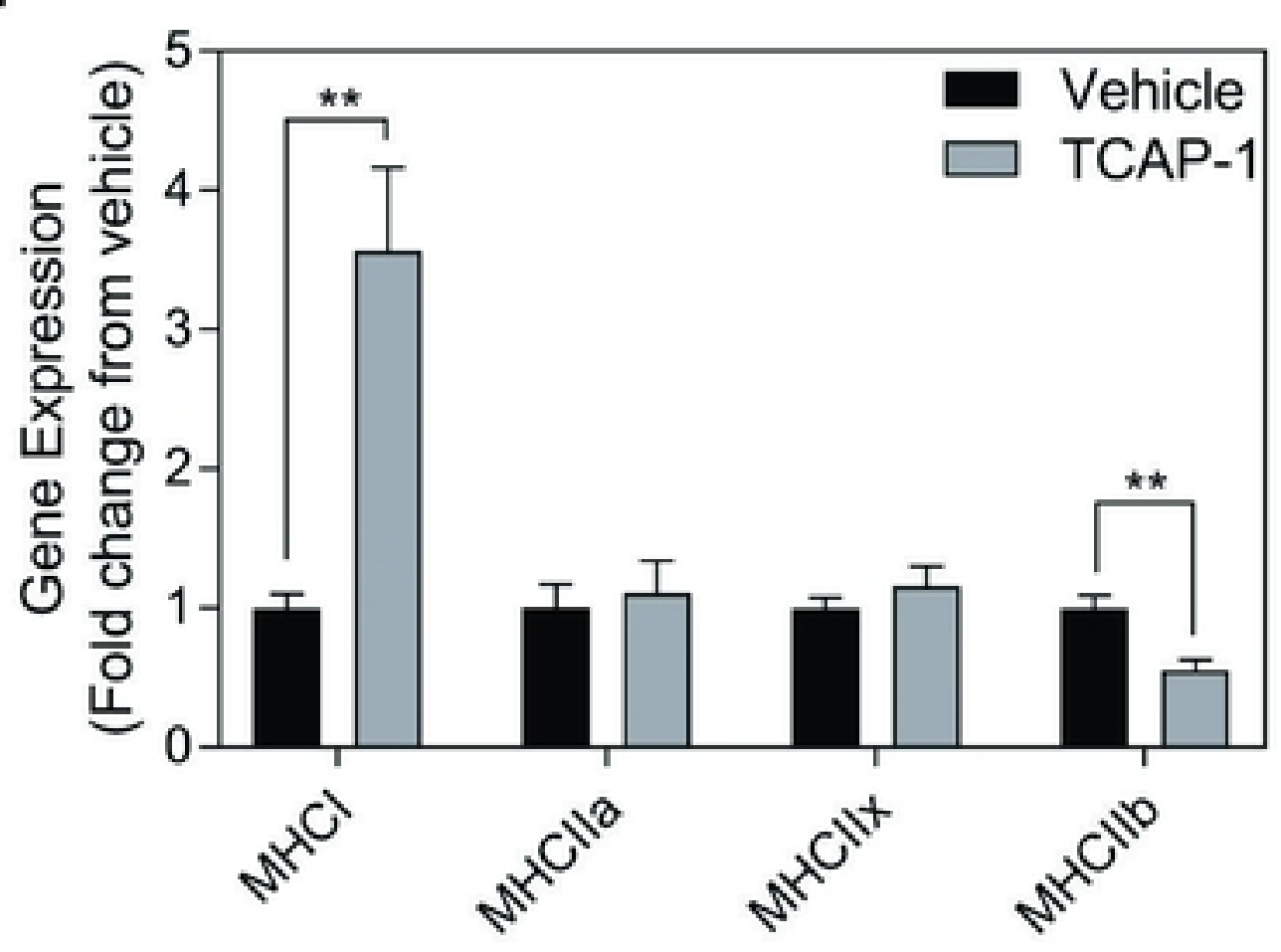



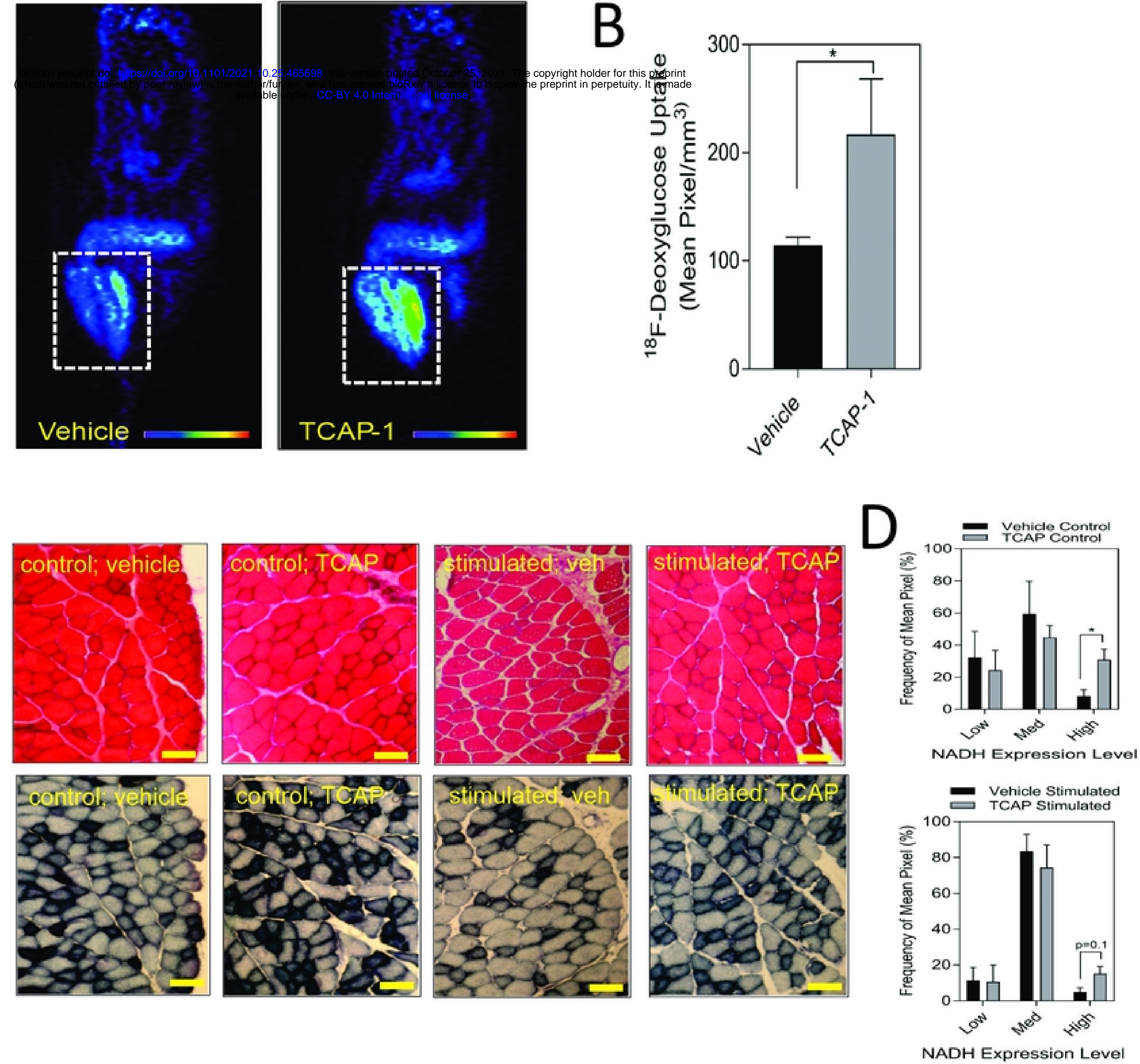

Figure 4 
$A$

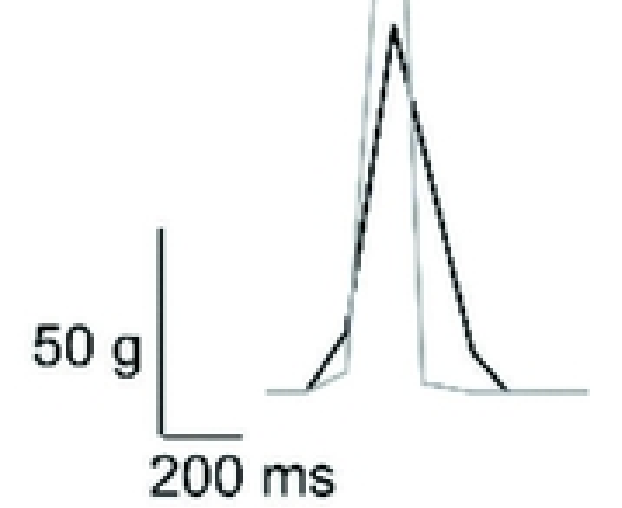

B

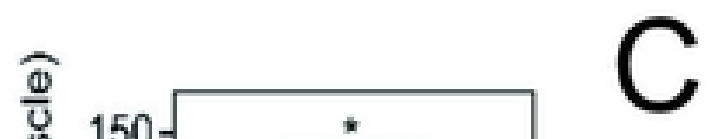

$E$
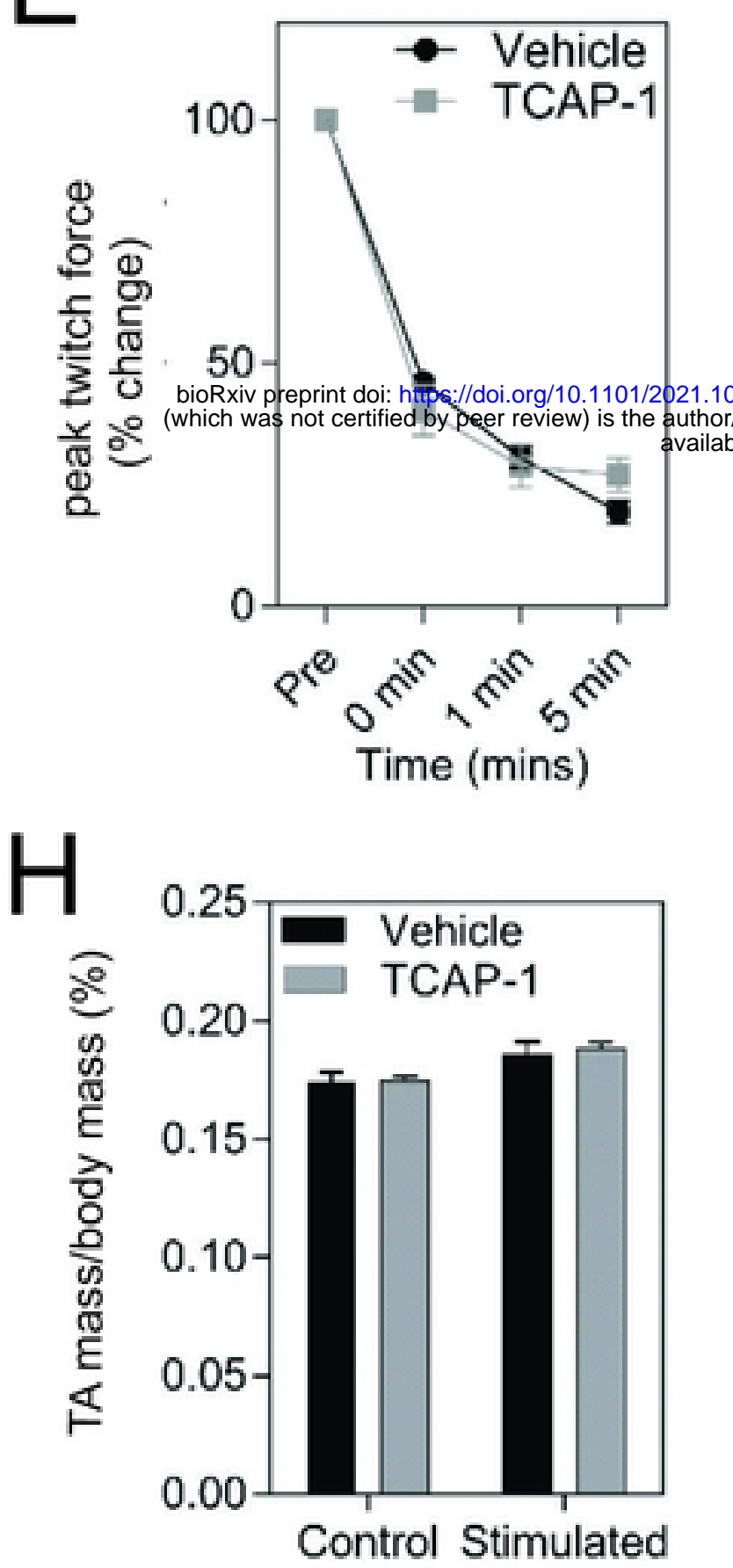

k

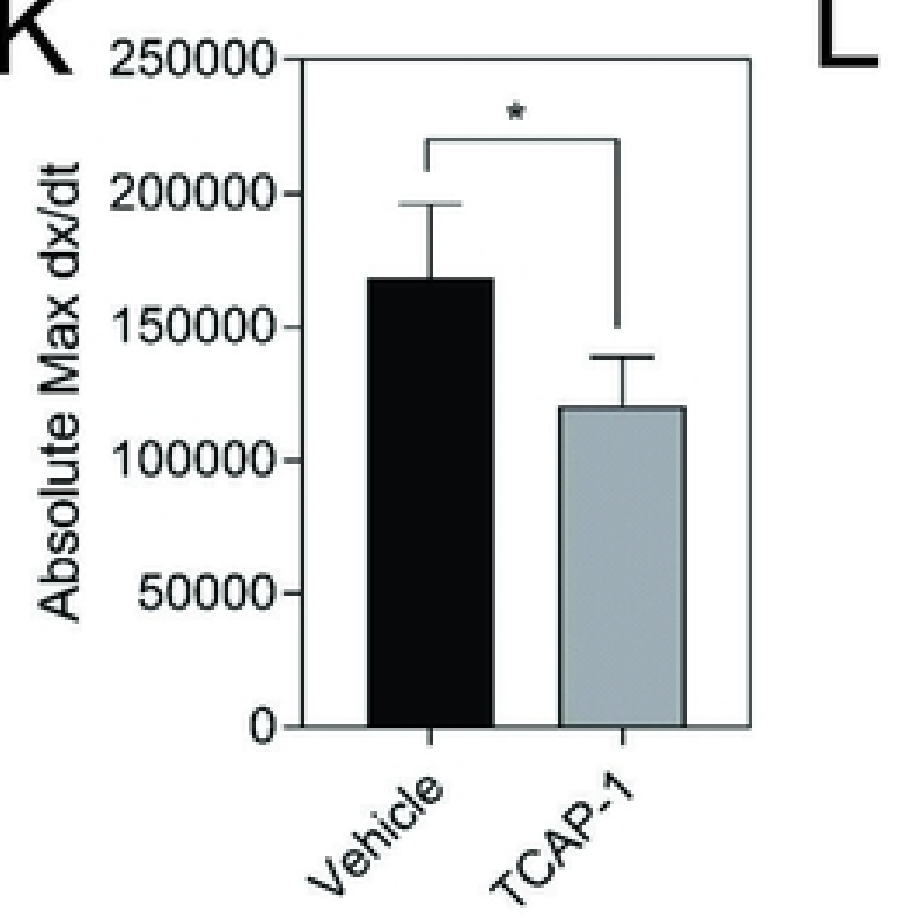

F
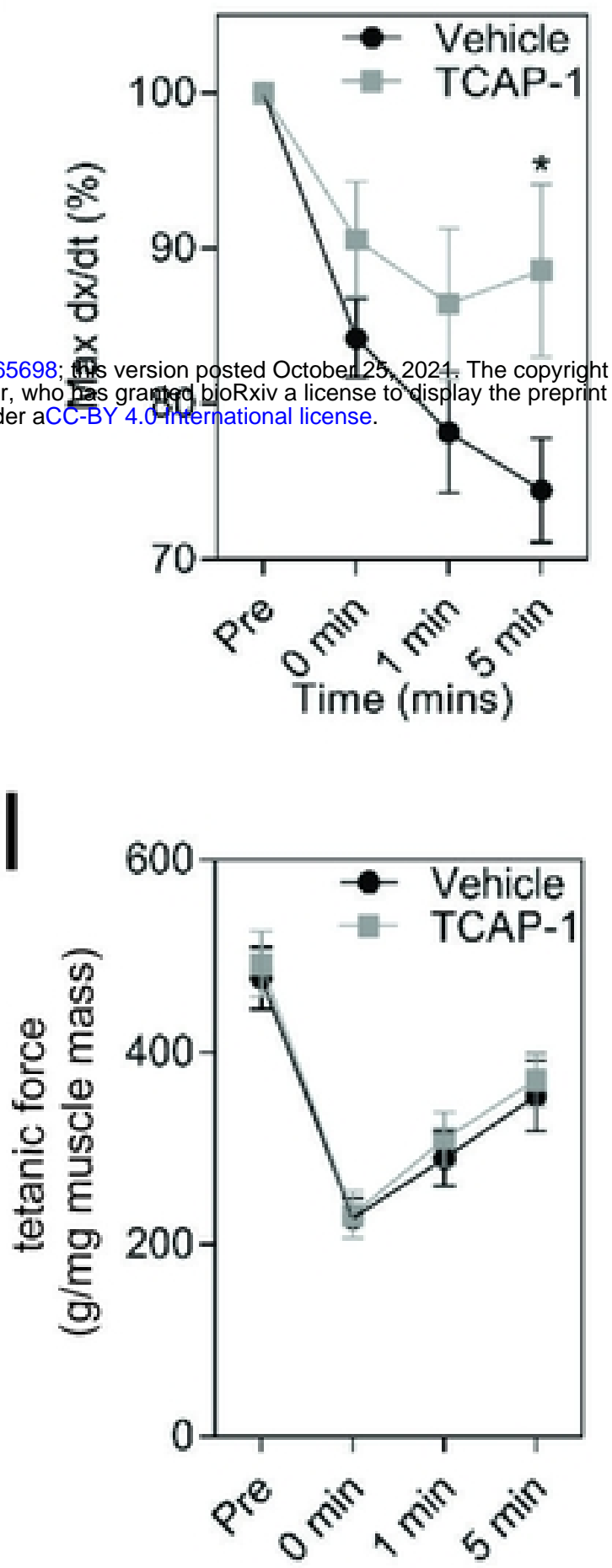

Time (mins)
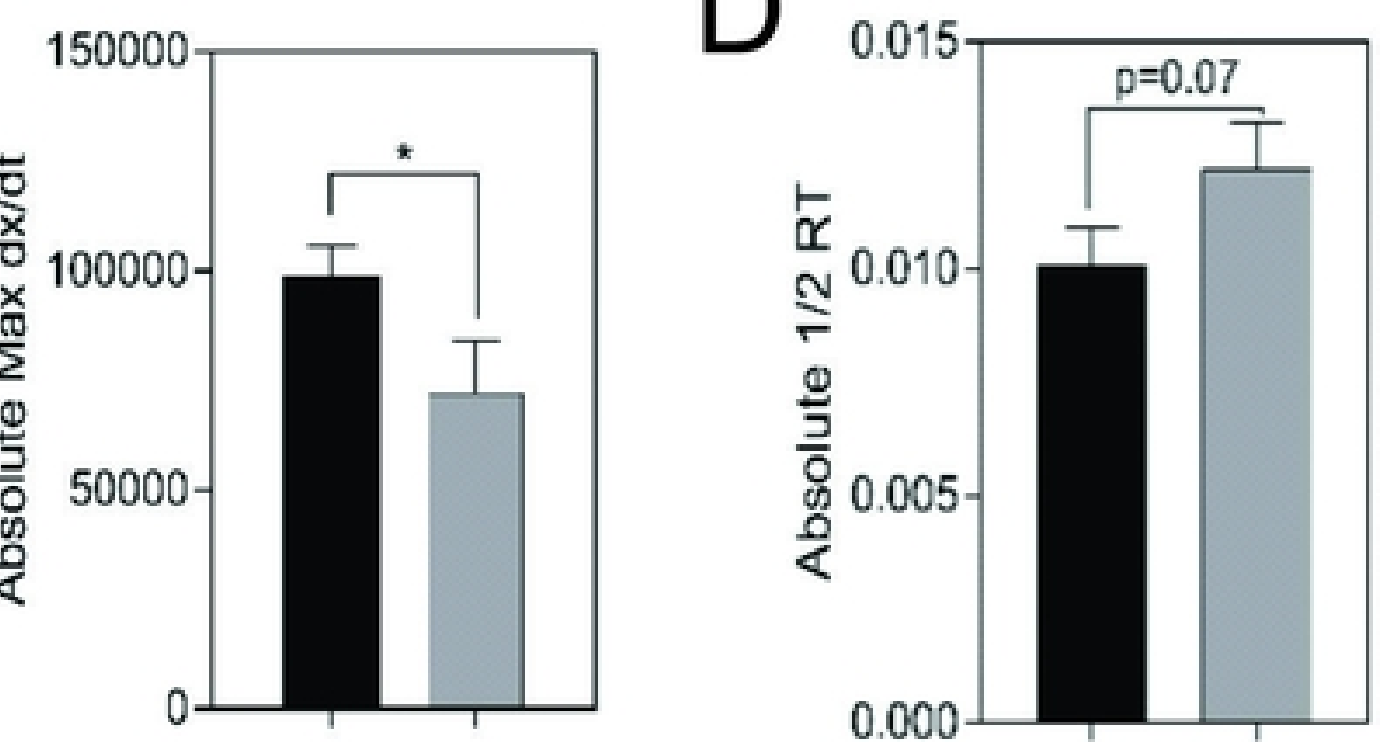

G
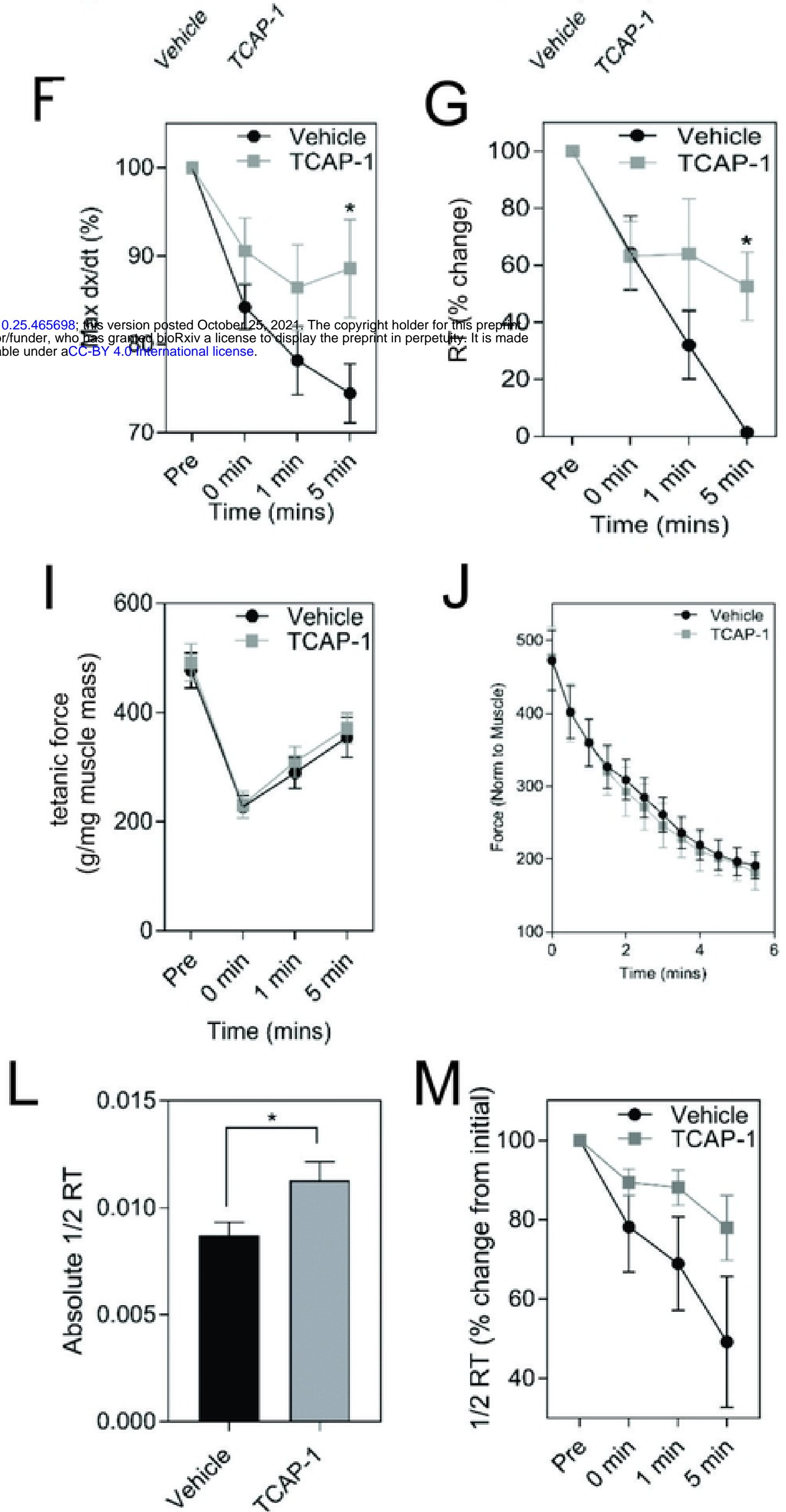

M
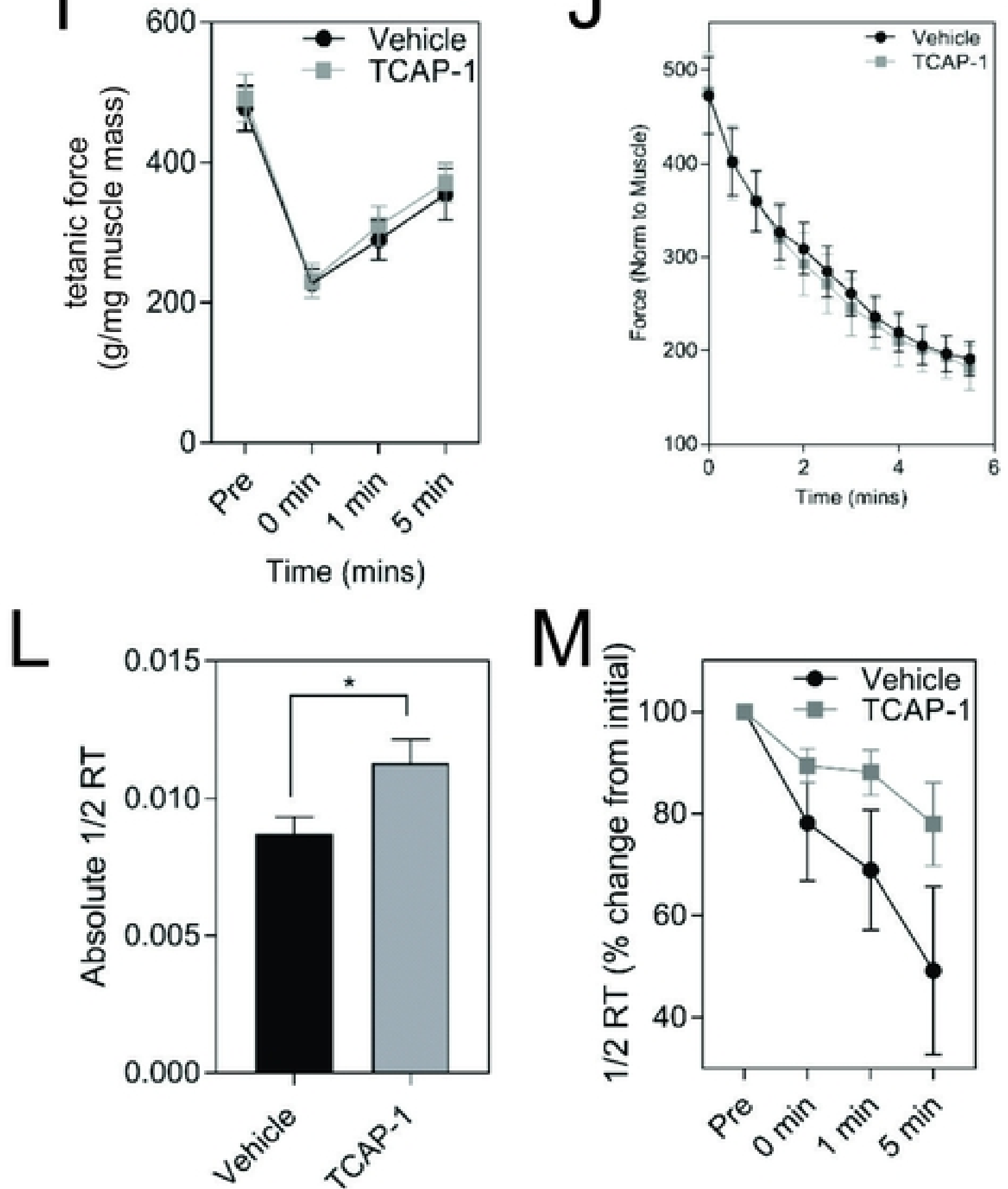

Figure 5 
A

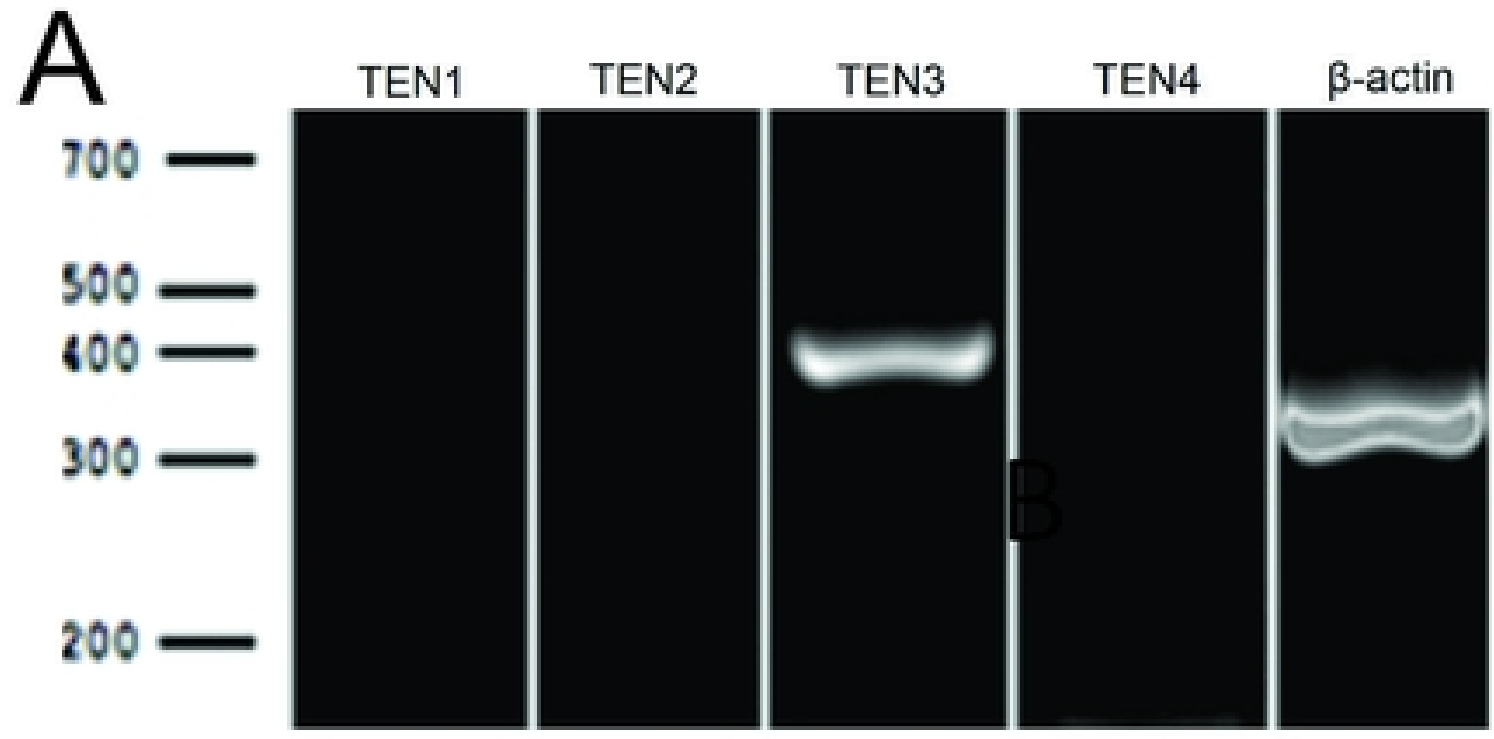

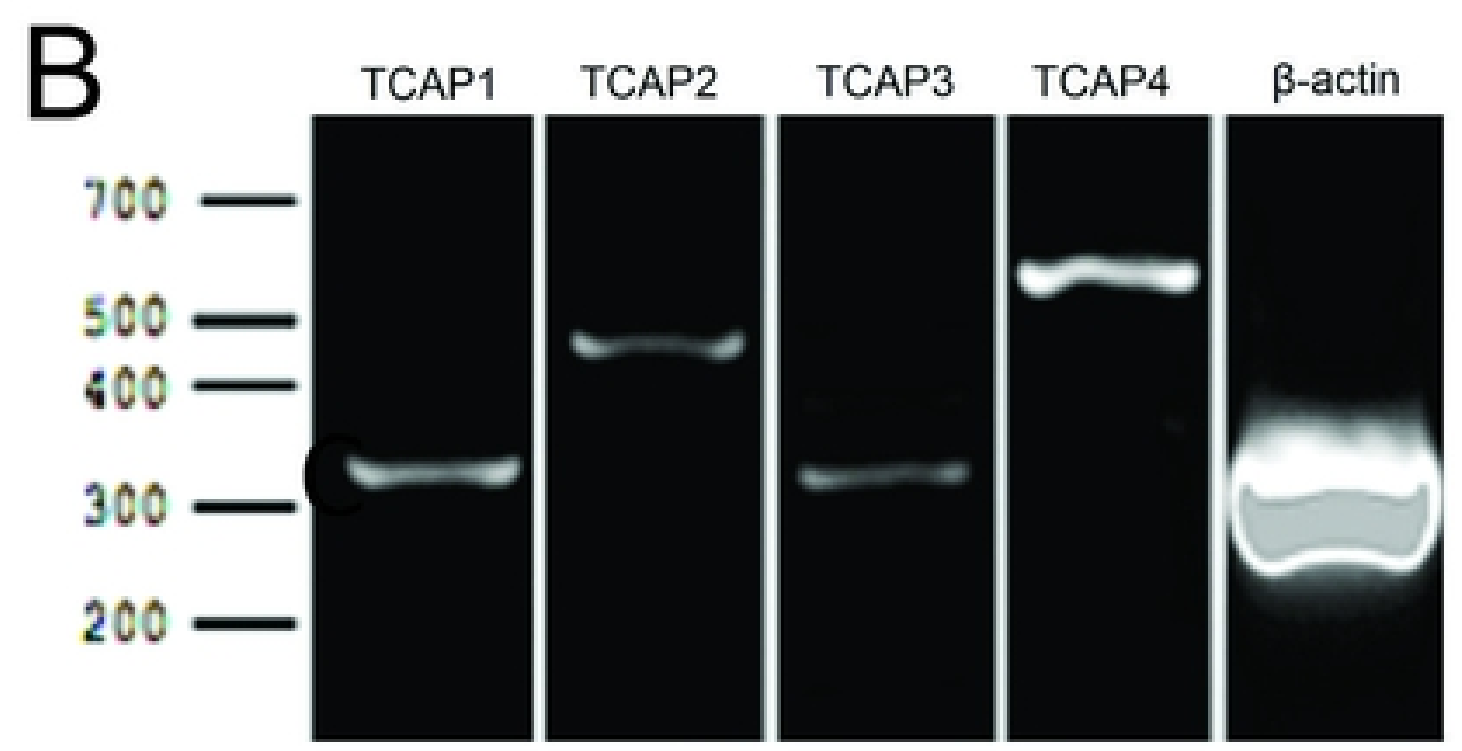

C

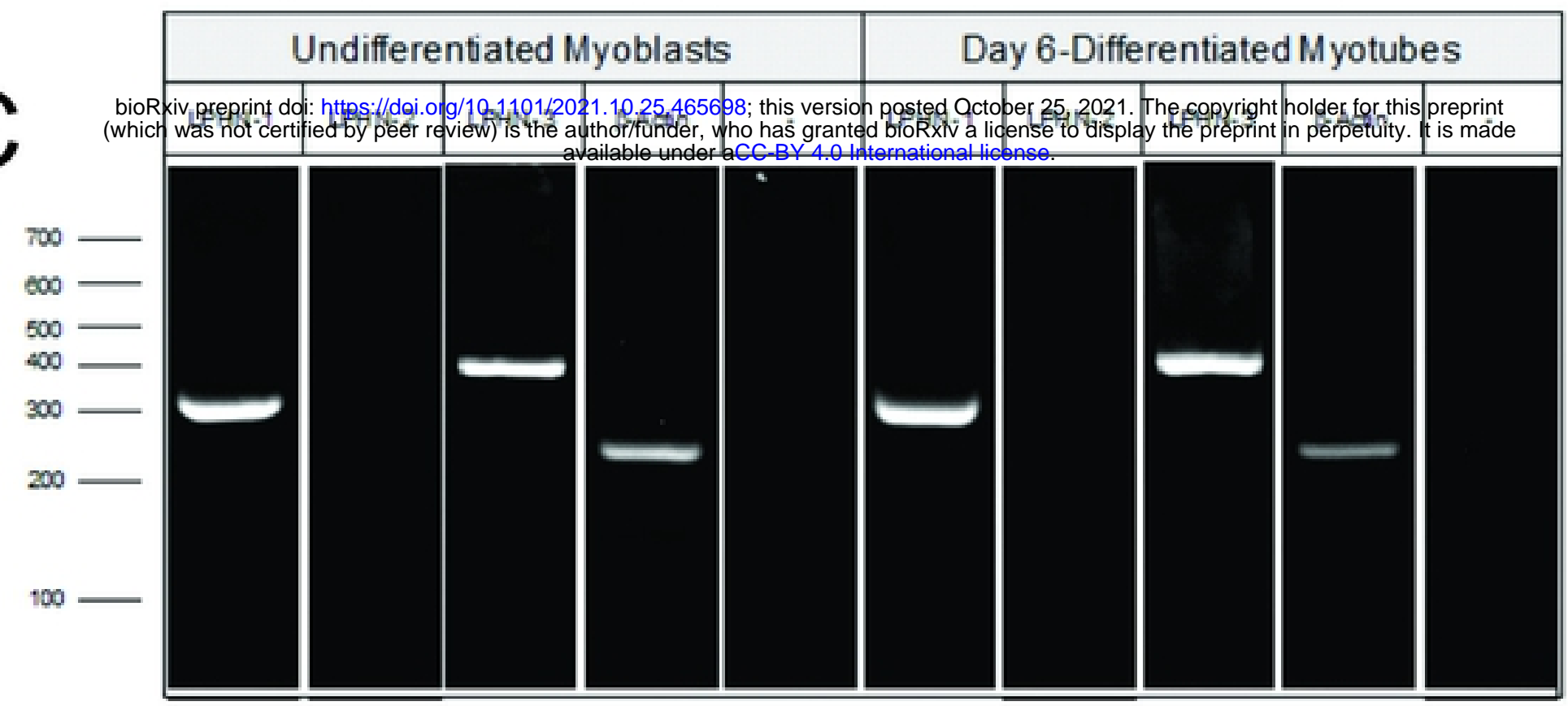

vehicle

E

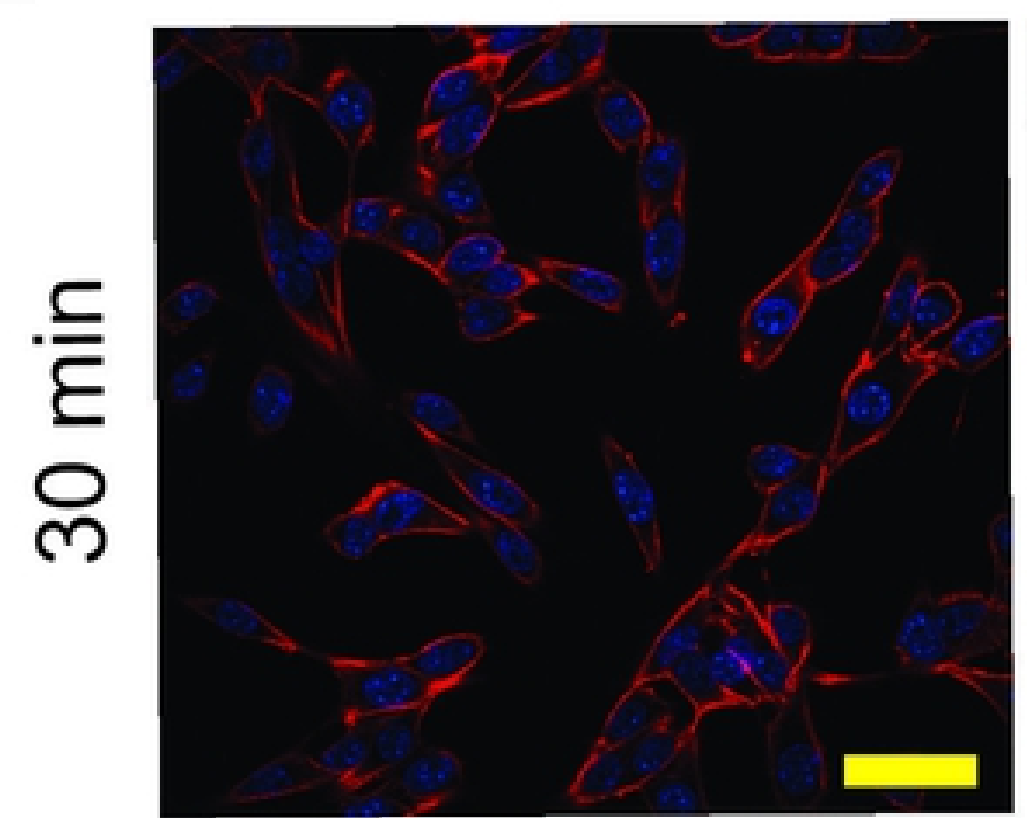

ণ্ঠ

N
TCAP-1

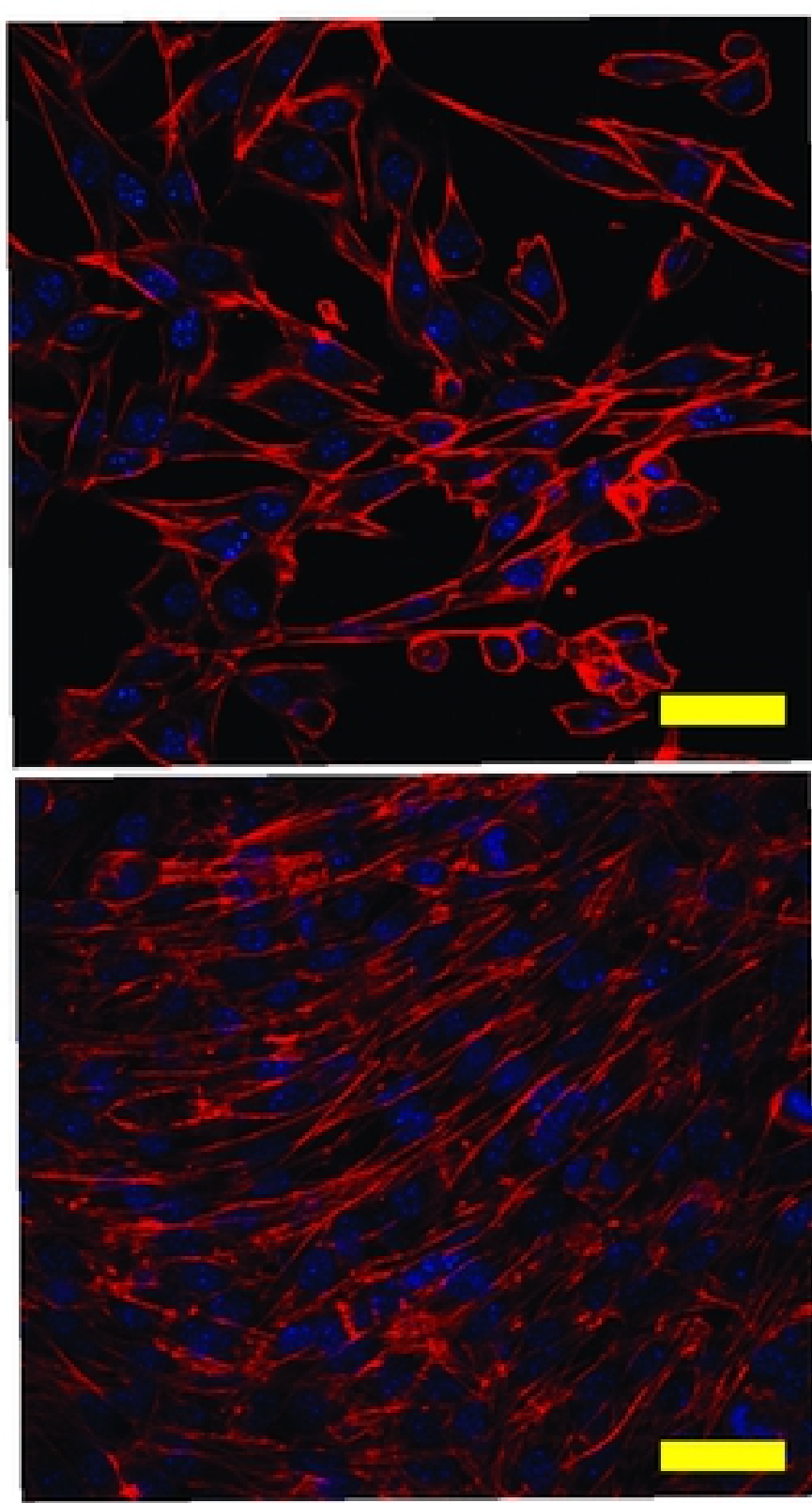

D

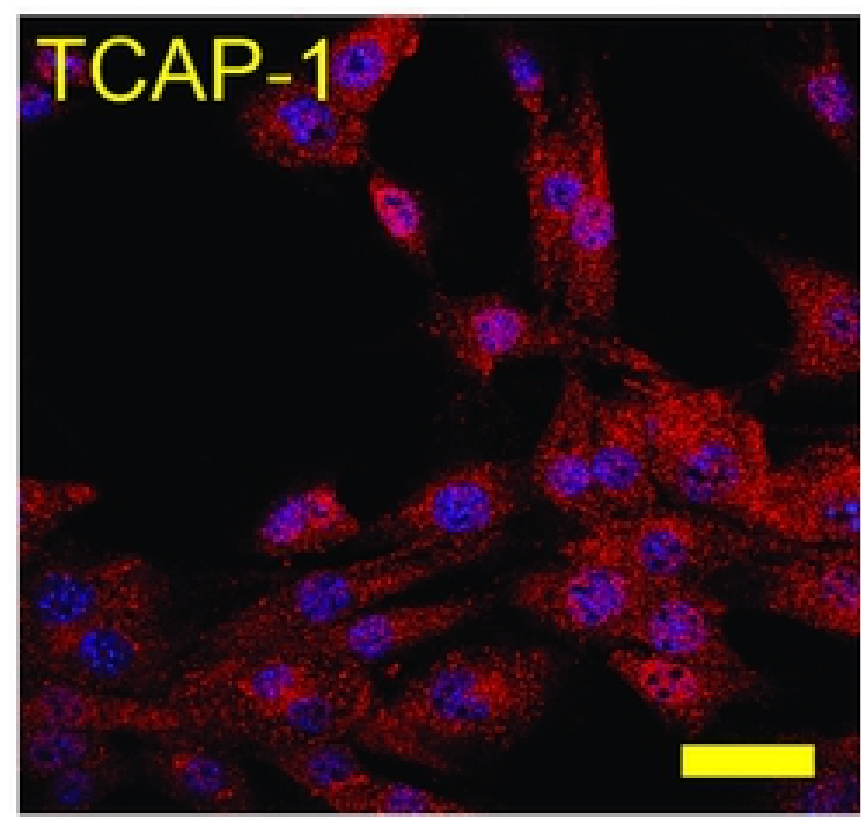

DAPI/FITC-TCAP-1 $\square$
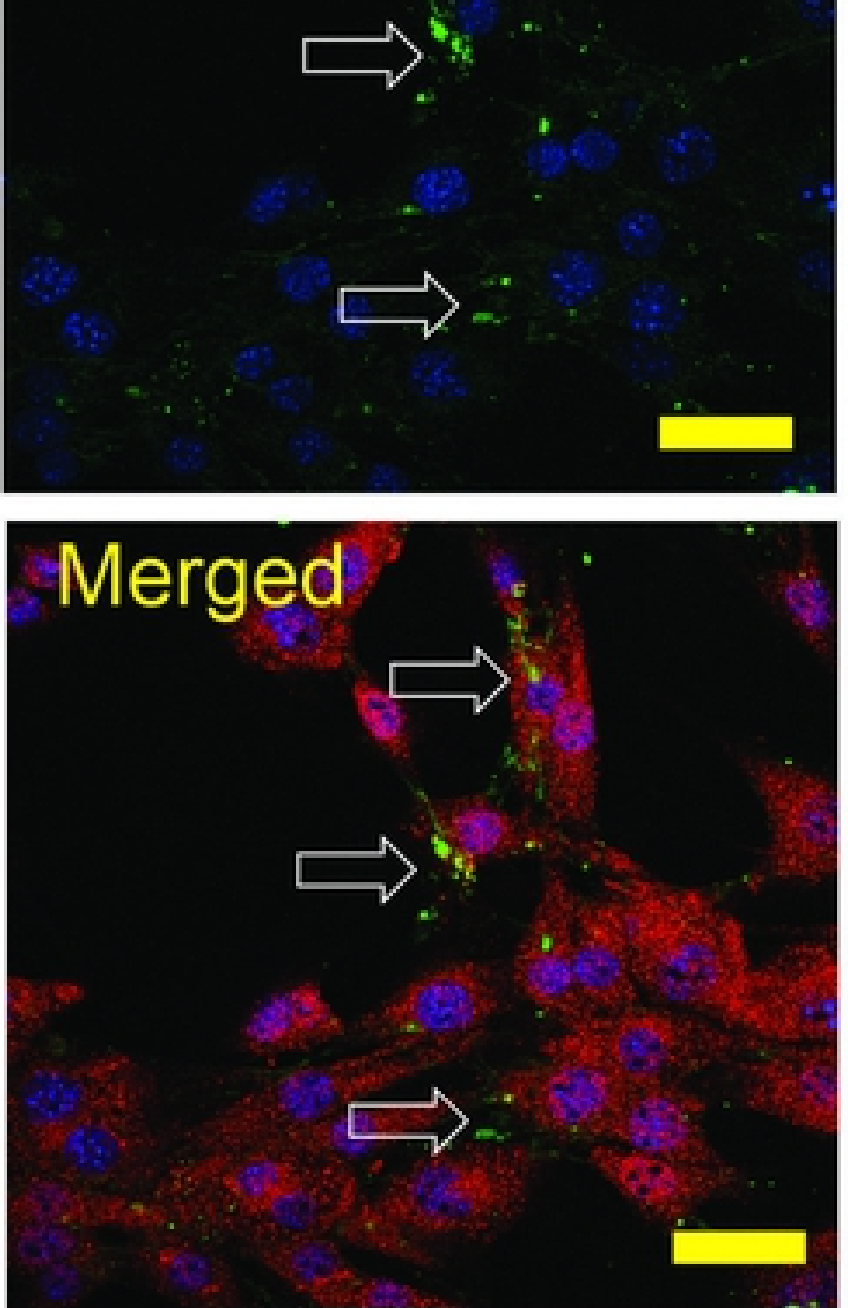

Figure 6 
A
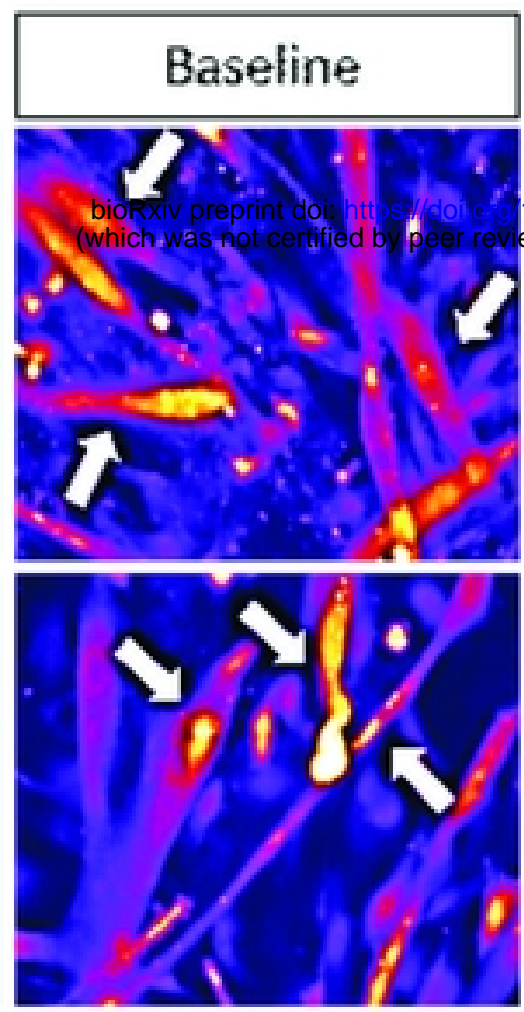

4

$\frac{E}{\frac{5}{5}}$

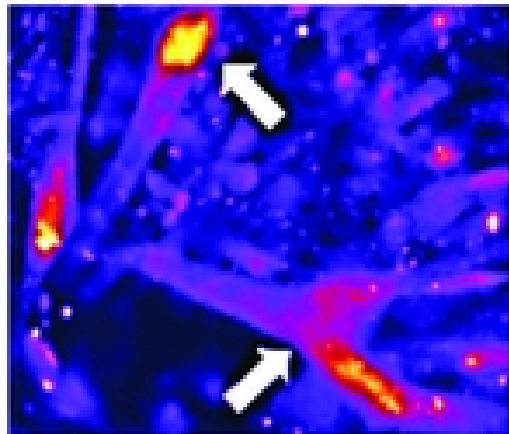

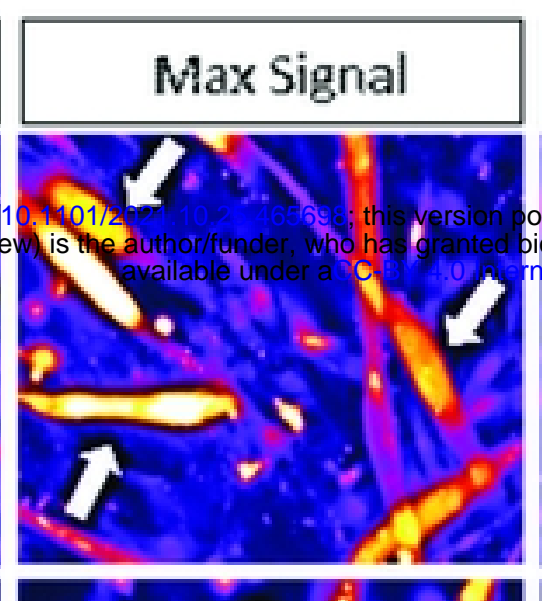

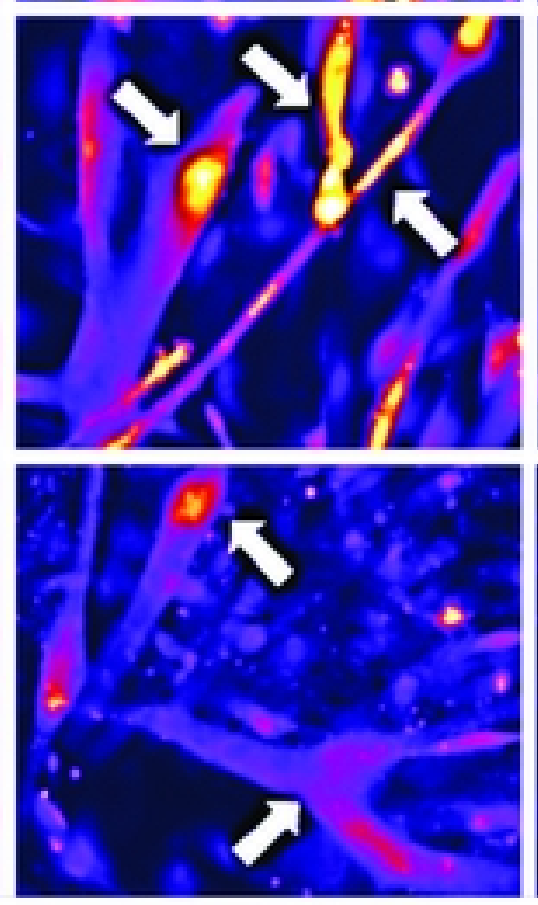

F

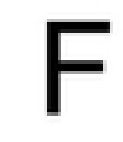

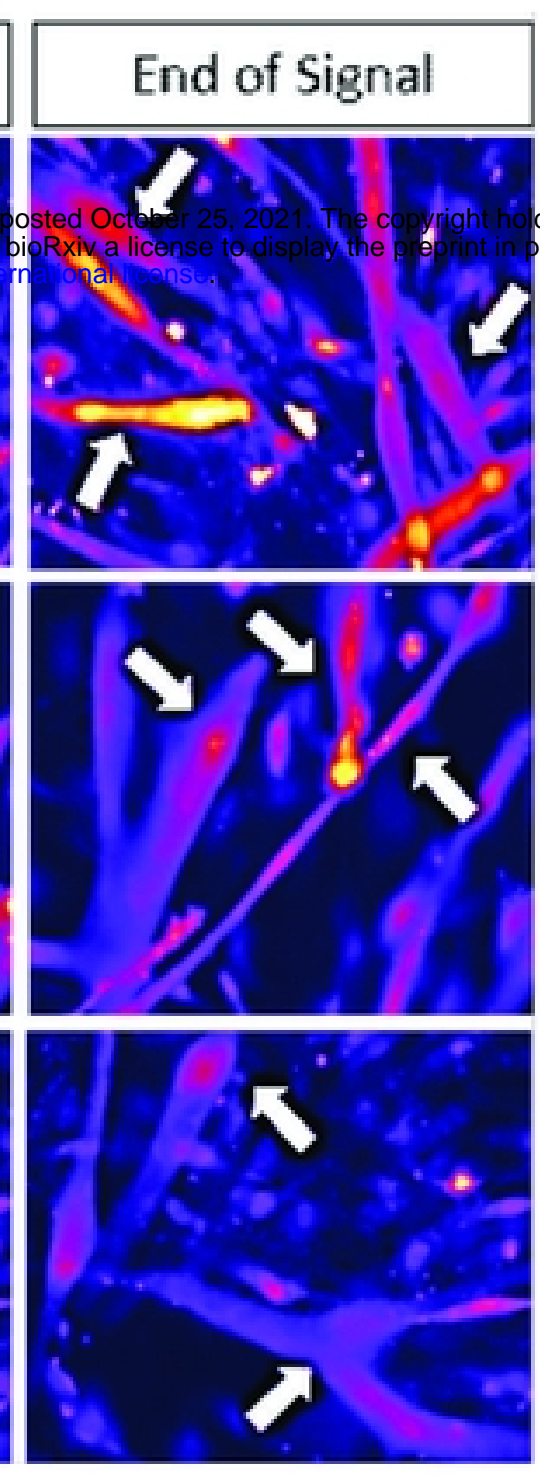

E

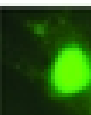

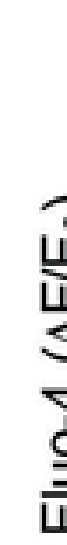

눙

B
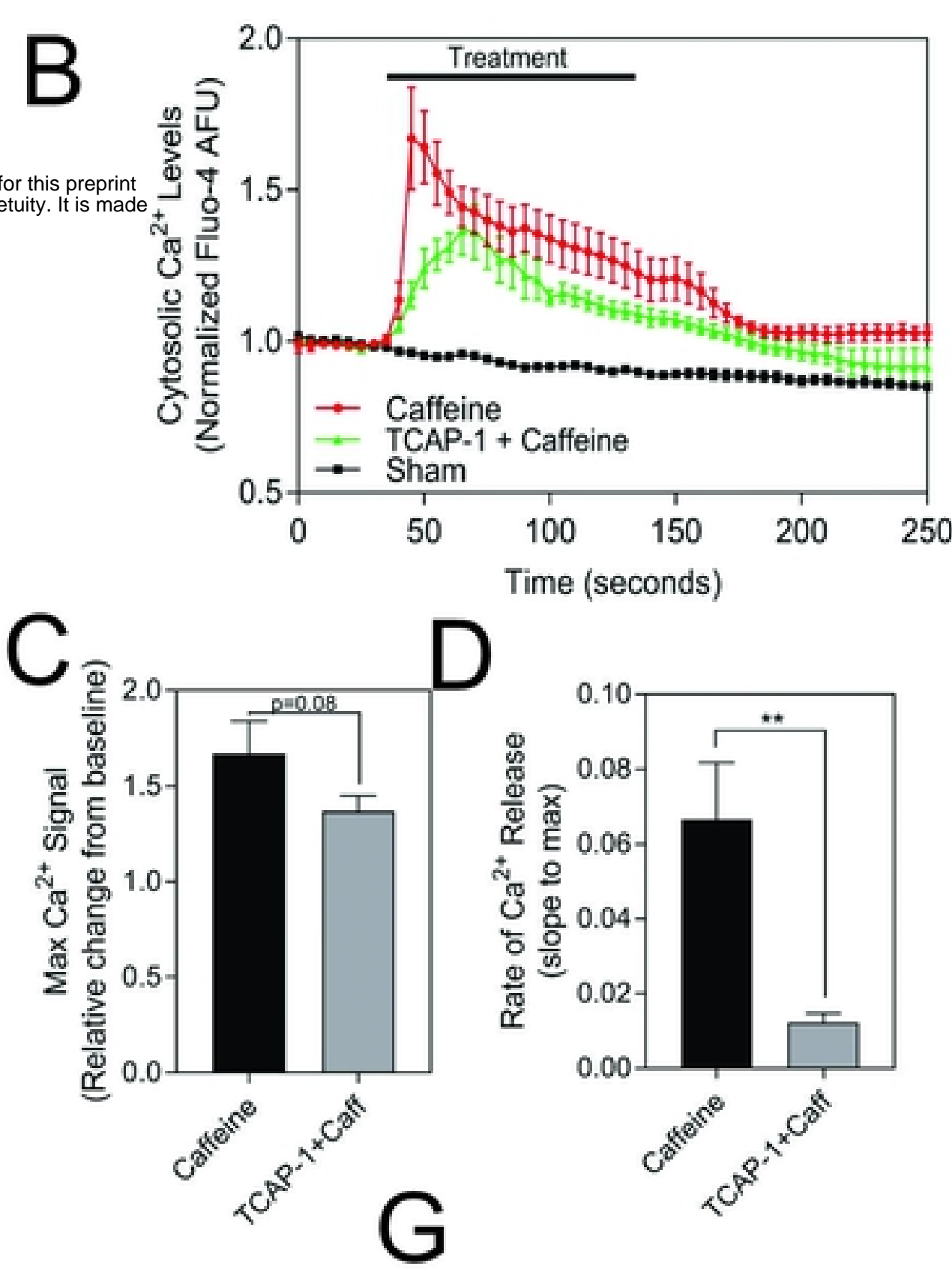

D
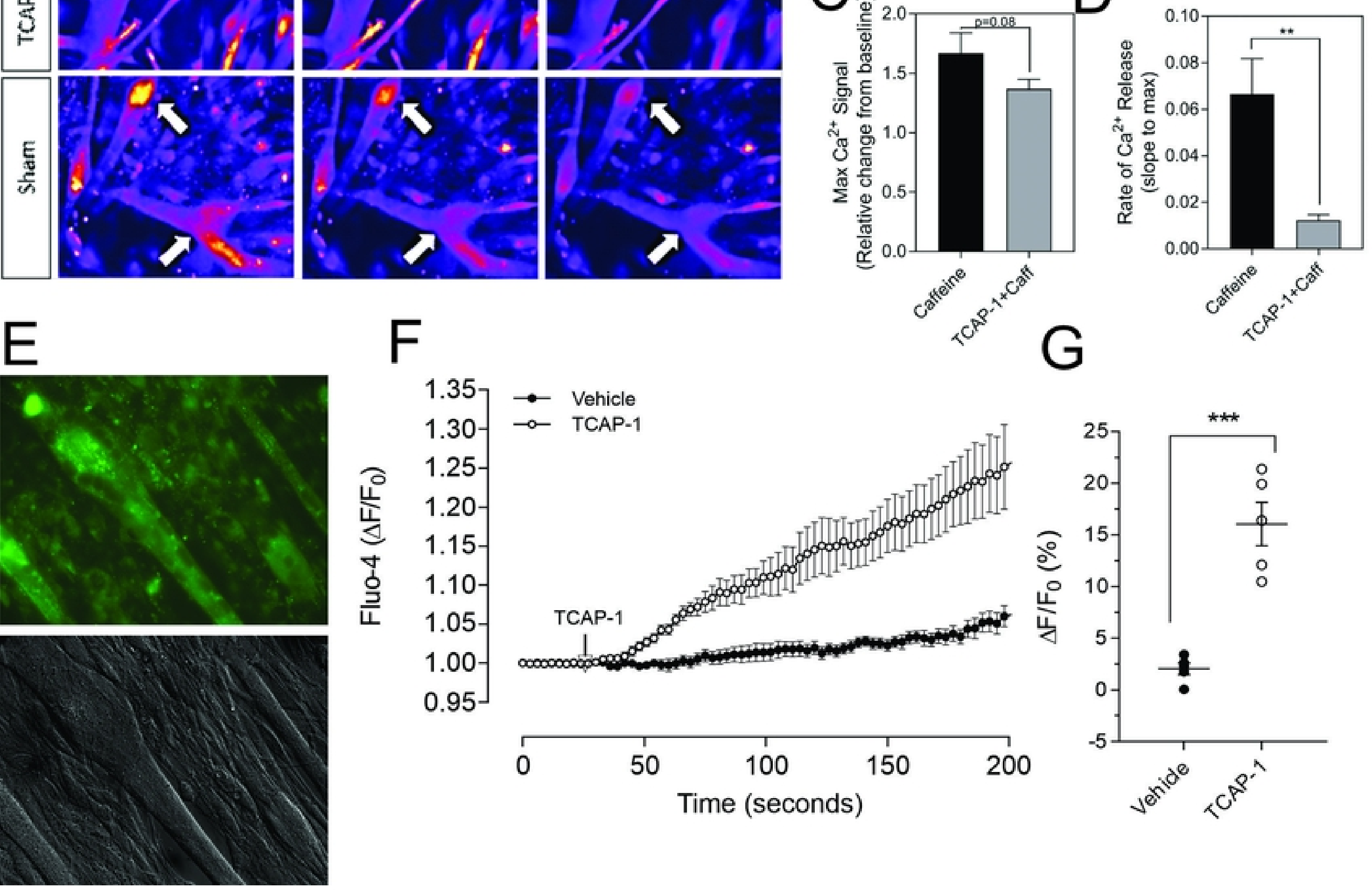

0.95

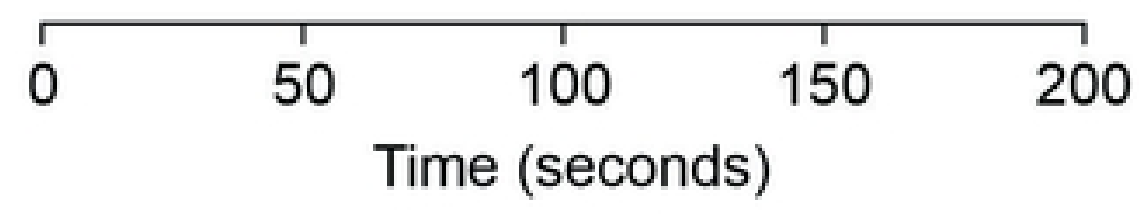

Figure 7 


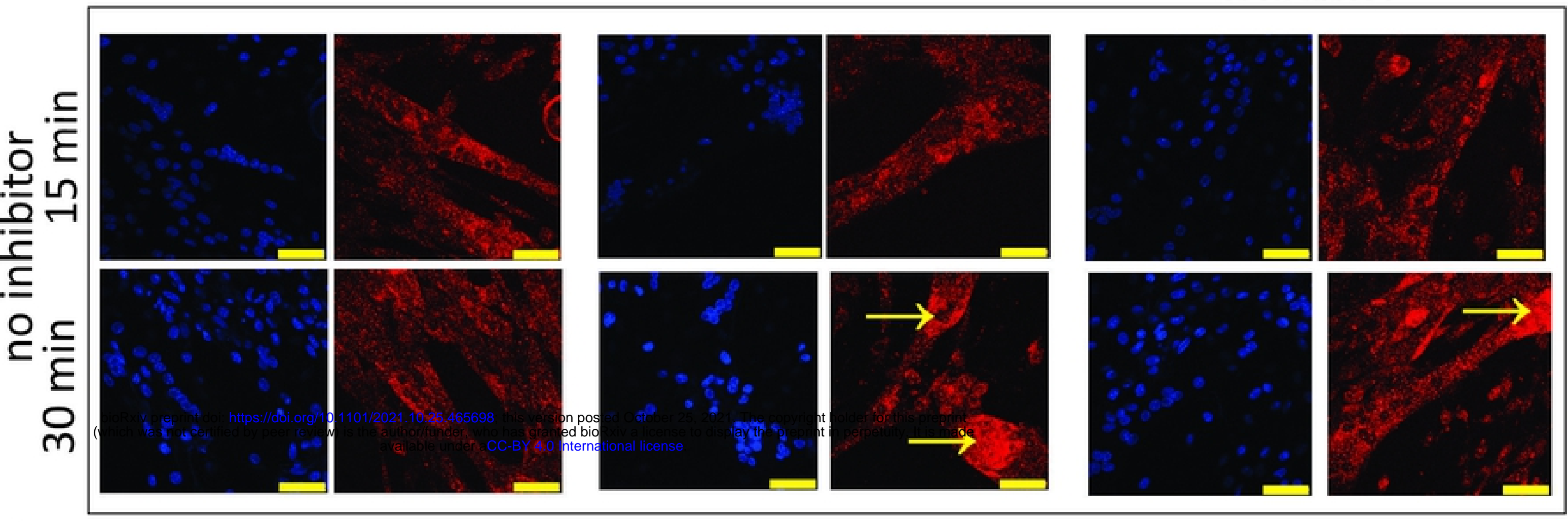

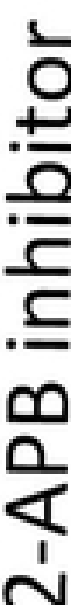

B
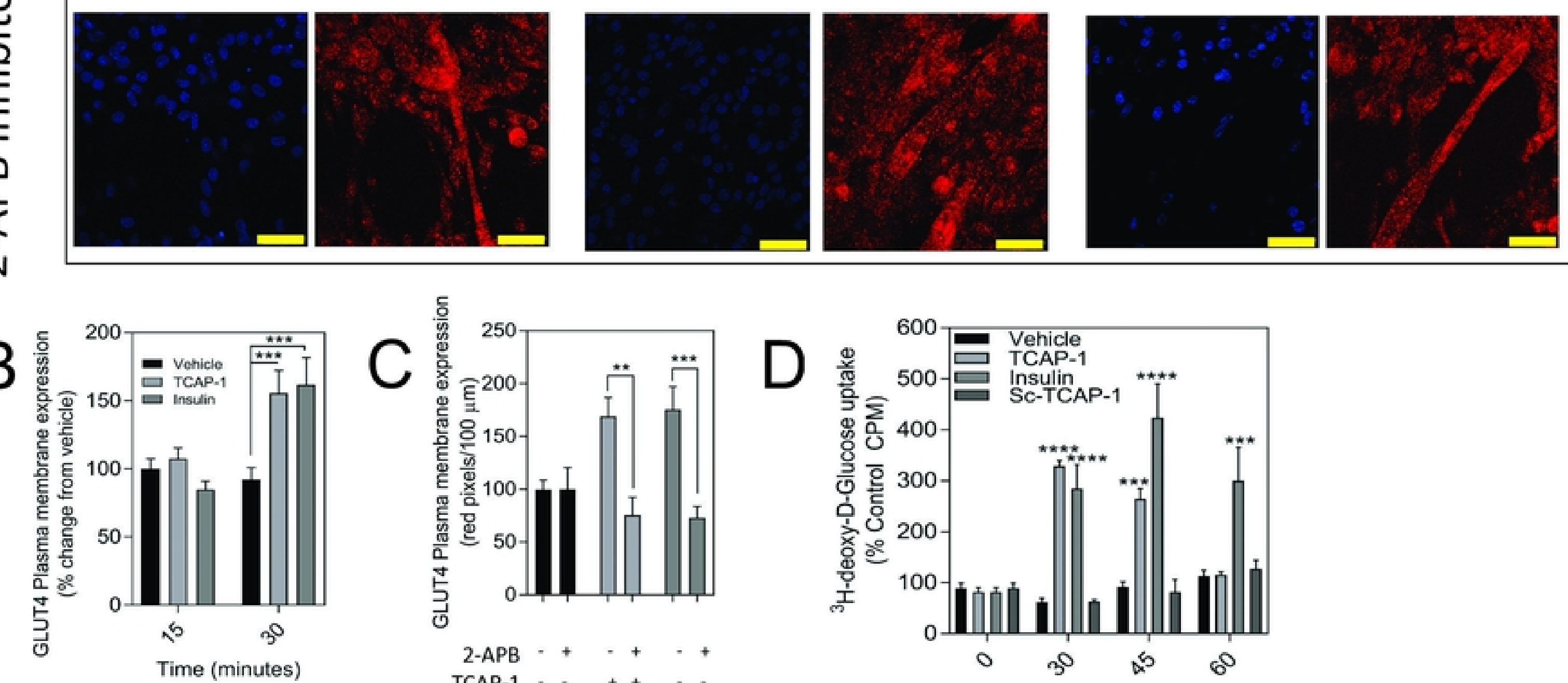
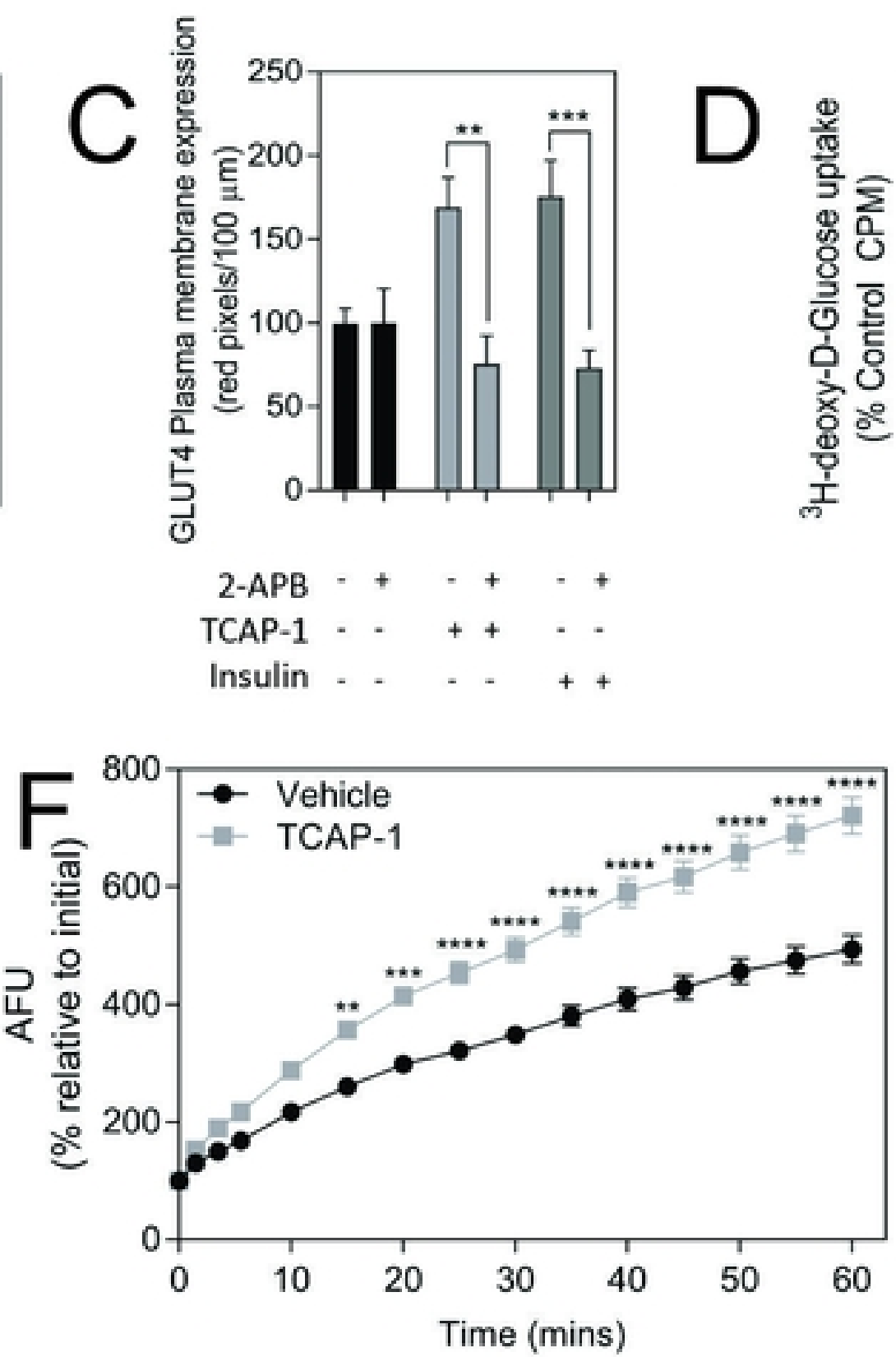

G

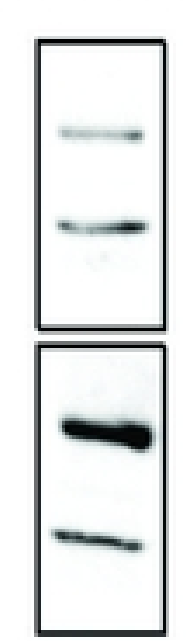

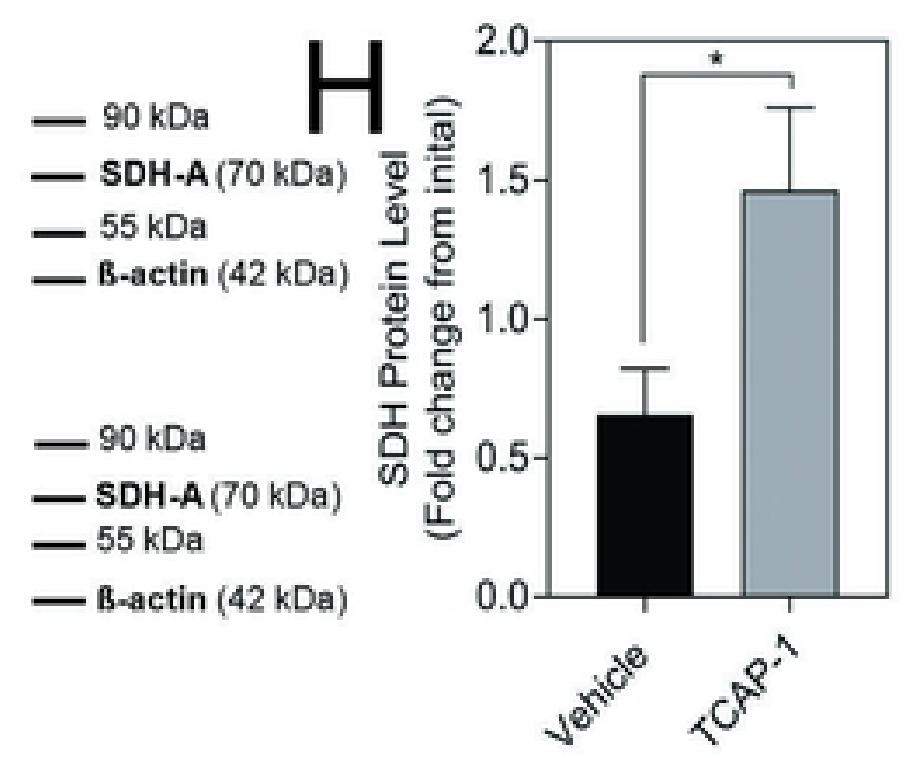

Figure 8 
A

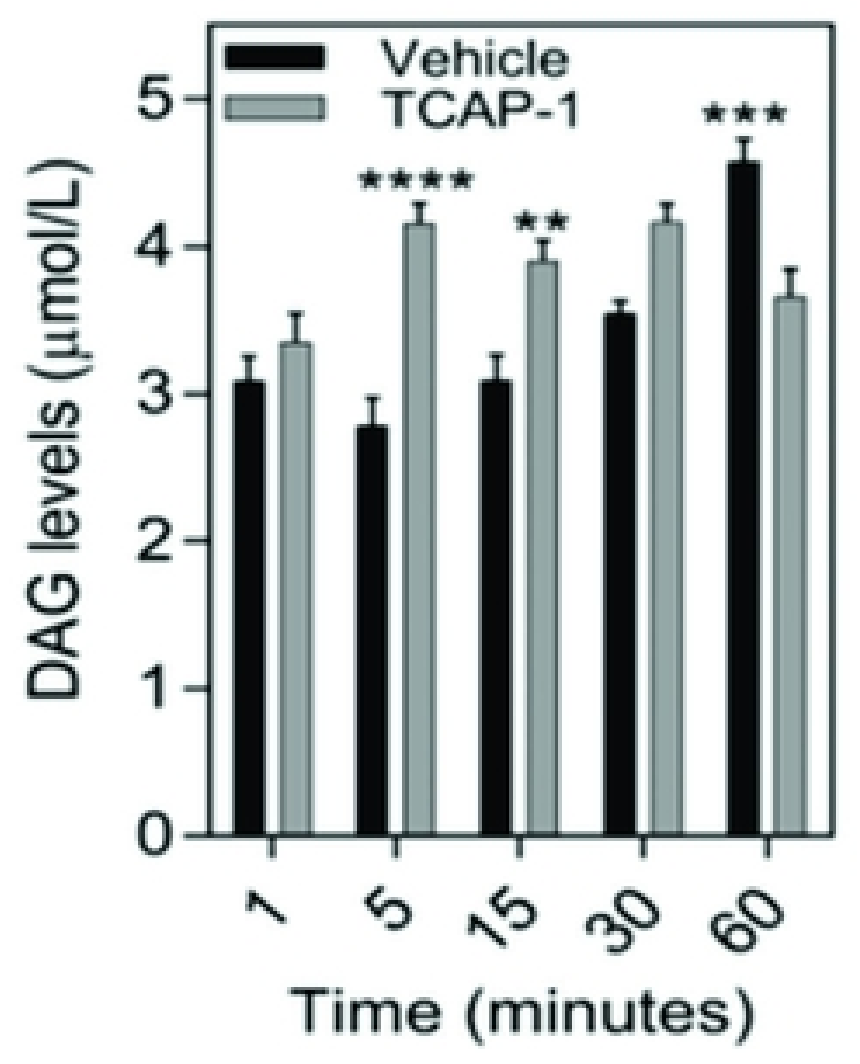

C

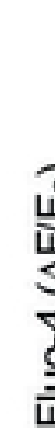

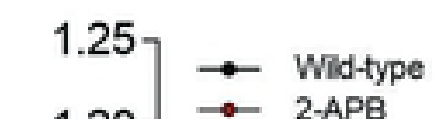

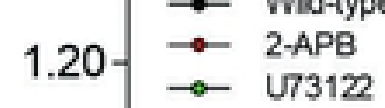

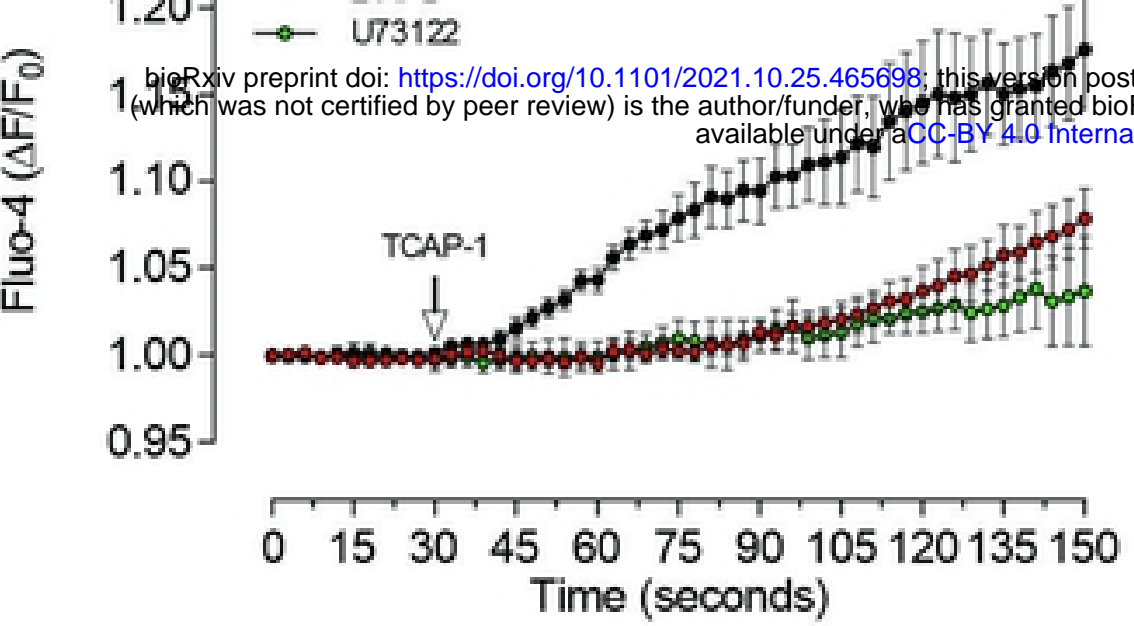

E

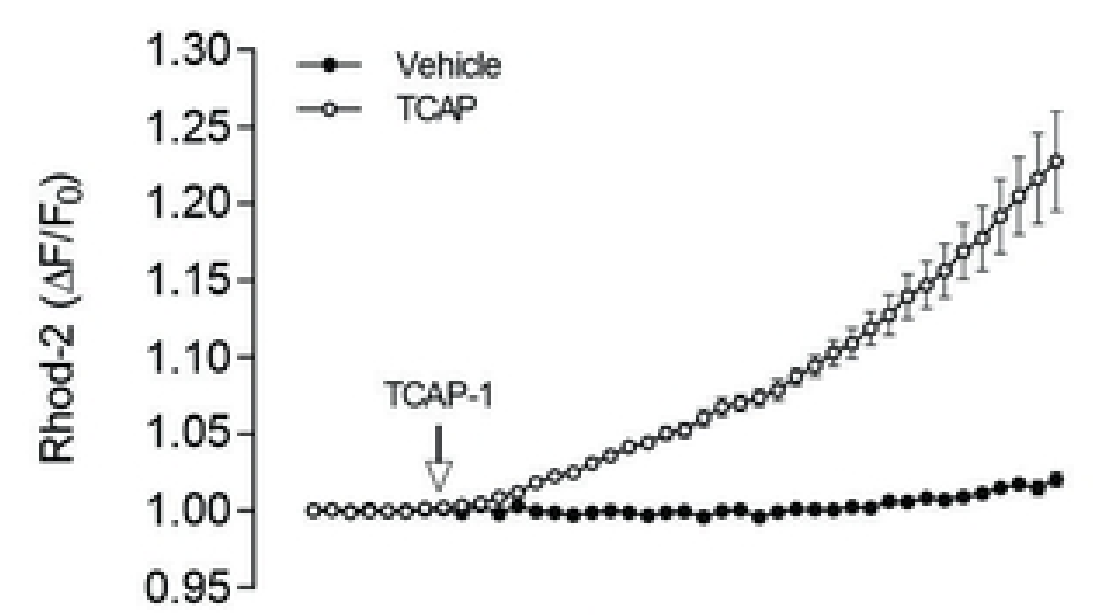

$\begin{array}{lllllllllll}0 & 25 & 50 & 75 & 100 & 125 & 150 & 175 & 200 & 225\end{array}$

Time (seconds)

$\epsilon$

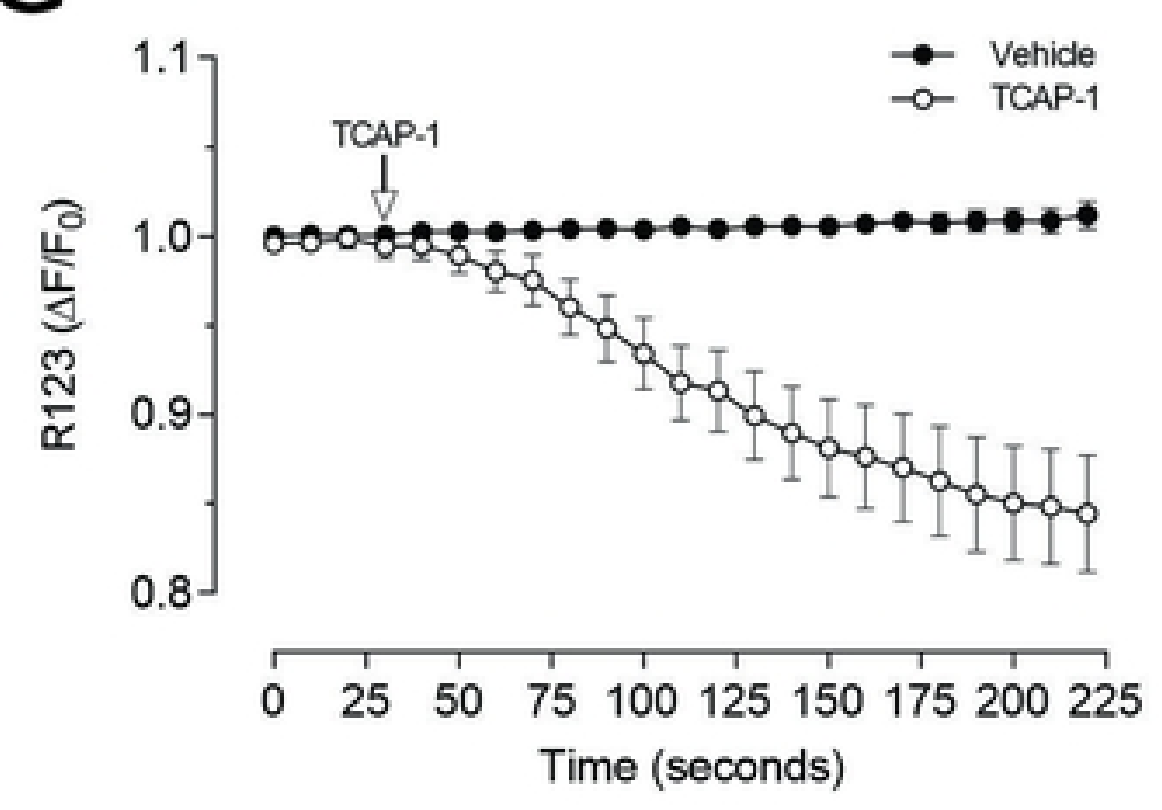

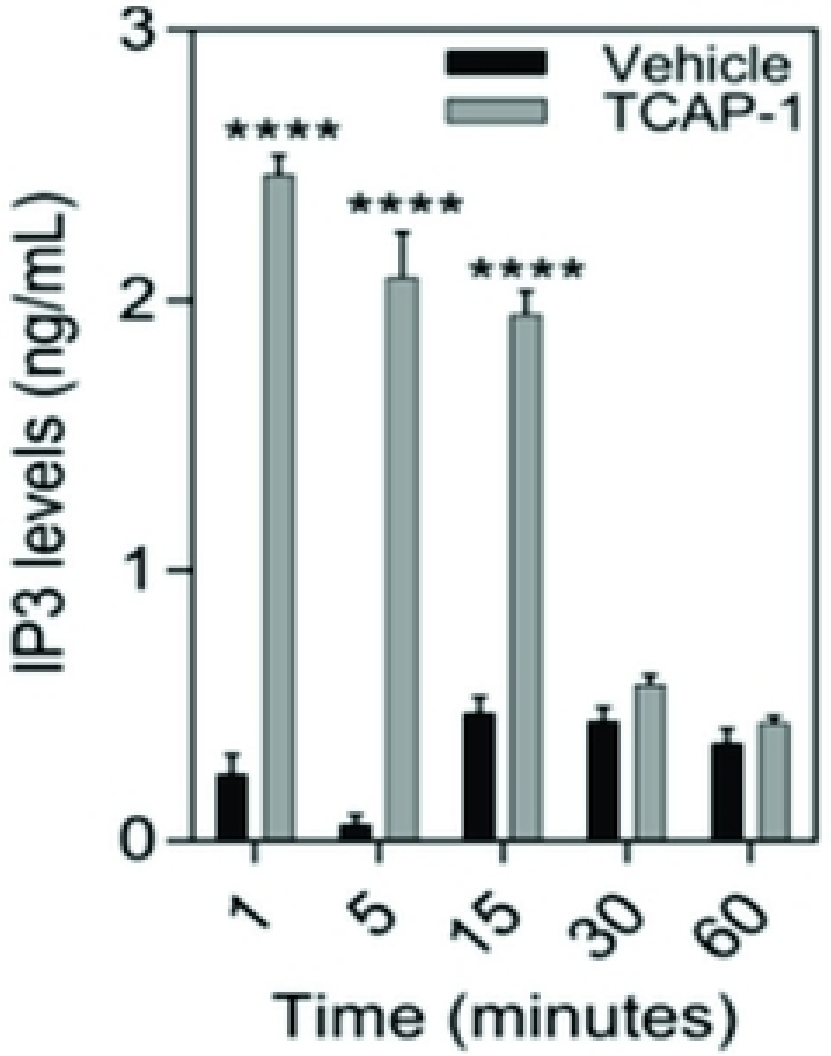

D

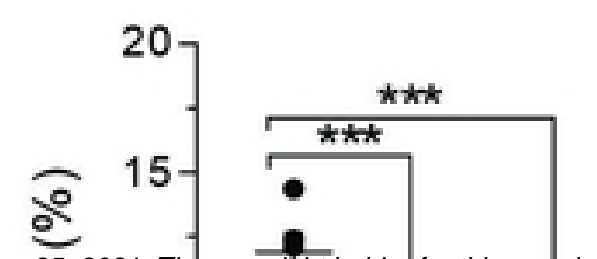

25,2021. The copyright holder for this preprint

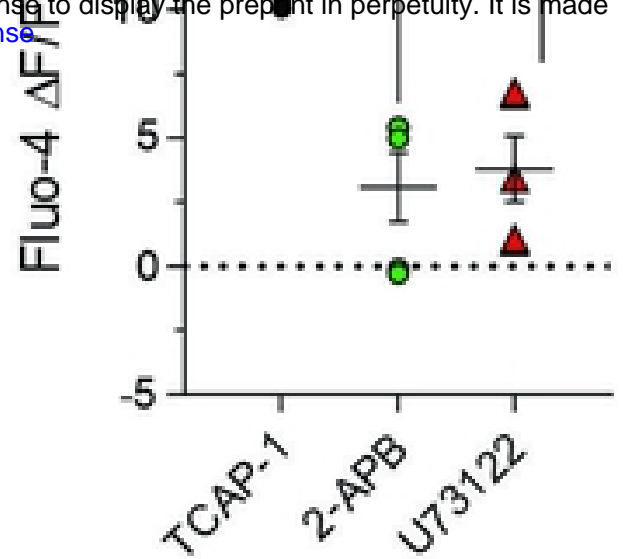

5
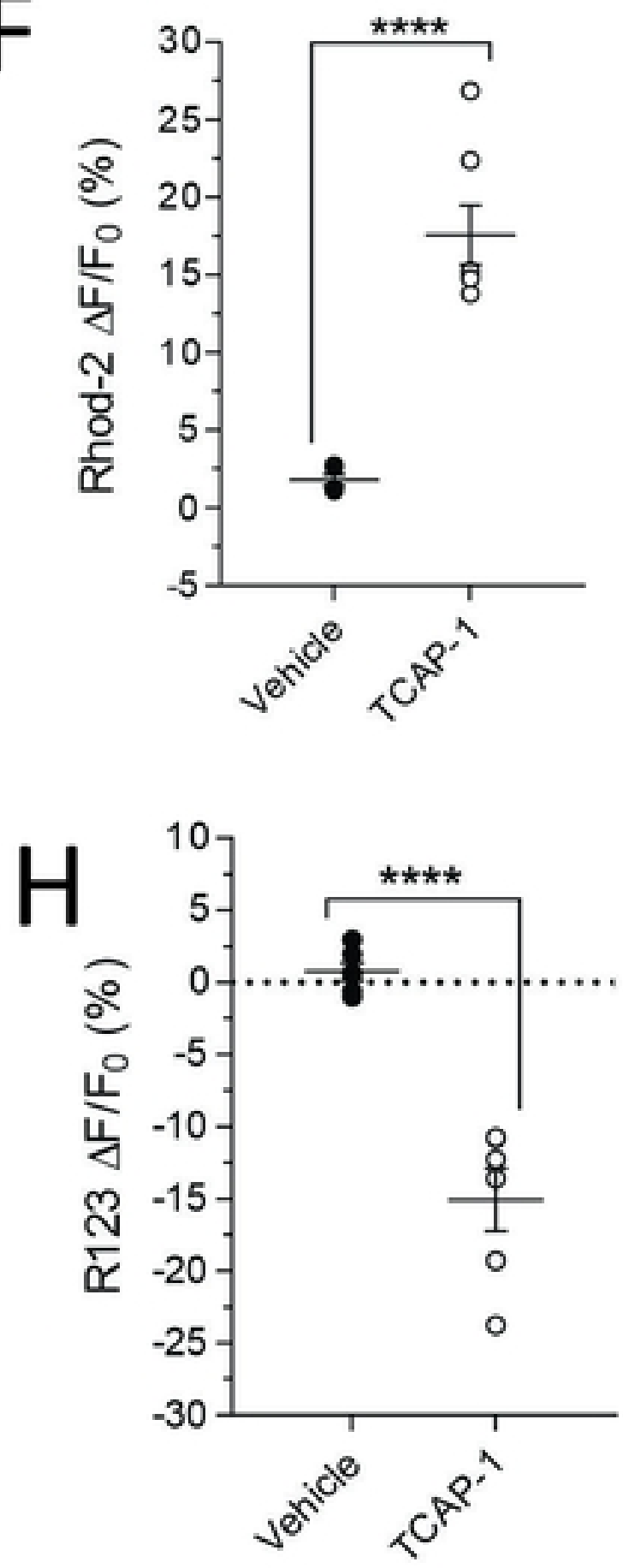

Figure 9 

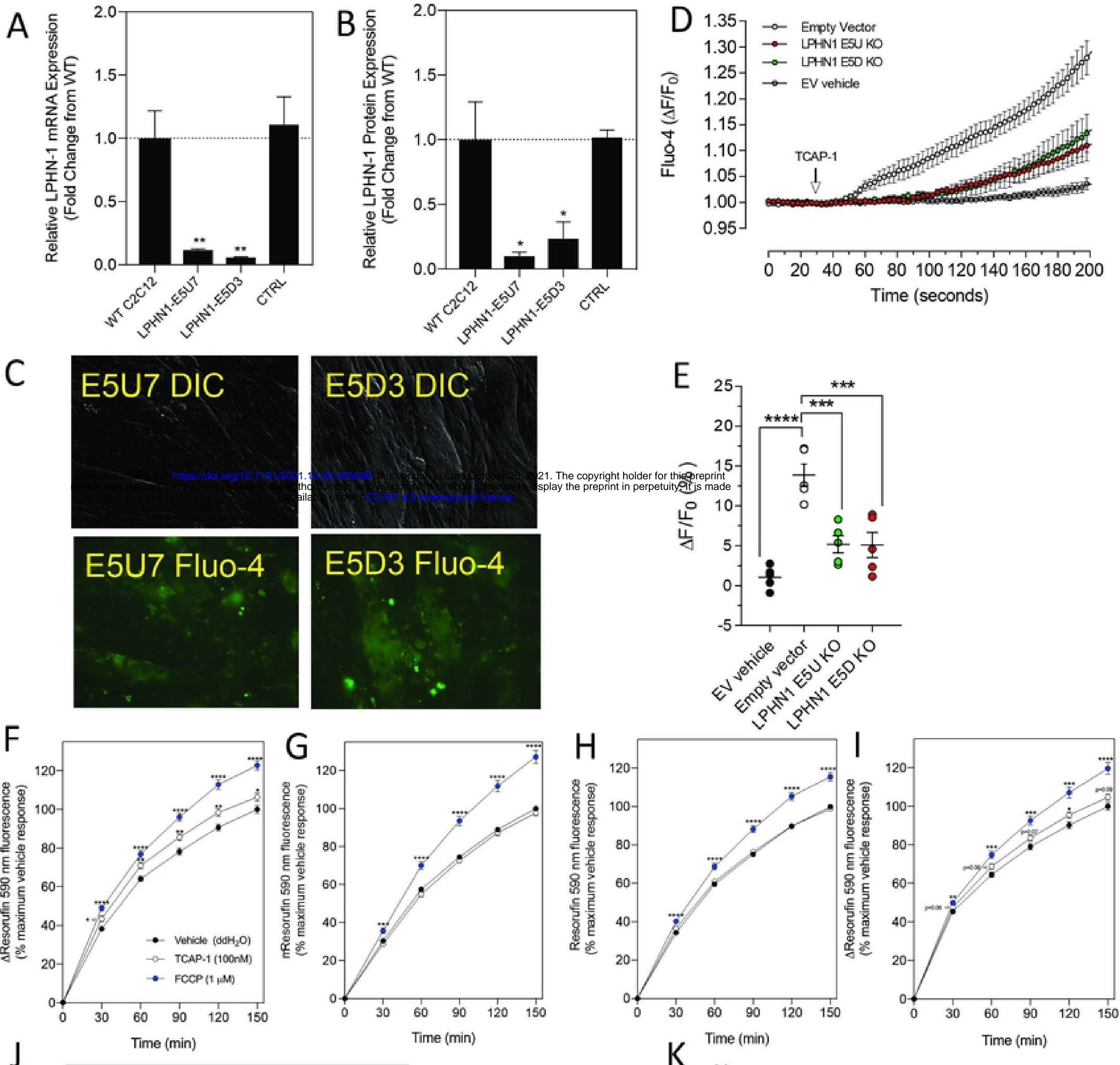

J
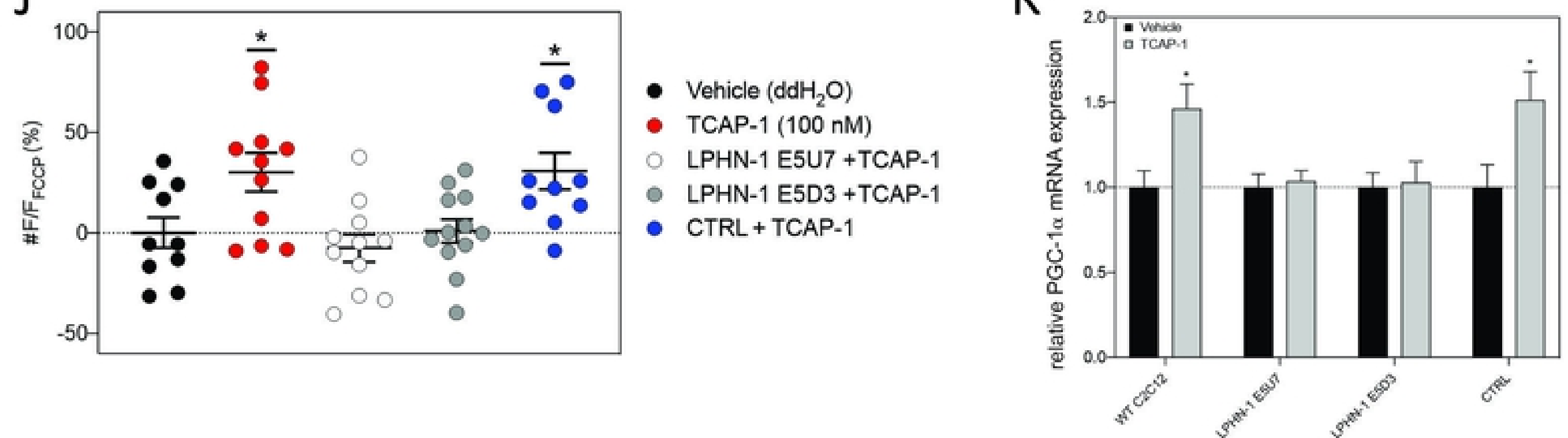

Figure 11 